\title{
Concept and Operation of Robotic Nondestructive Testing Systems for Space Exploration Objectives
}

Drew M. Goodman

Follow this and additional works at: https://researchrepository.wvu.edu/etd

\section{Recommended Citation}

Goodman, Drew M., "Concept and Operation of Robotic Nondestructive Testing Systems for Space Exploration Objectives" (2016). Graduate Theses, Dissertations, and Problem Reports. 5694.

https://researchrepository.wvu.edu/etd/5694

This Thesis is protected by copyright and/or related rights. It has been brought to you by the The Research Repository @ WVU with permission from the rights-holder(s). You are free to use this Thesis in any way that is permitted by the copyright and related rights legislation that applies to your use. For other uses you must obtain permission from the rights-holder(s) directly, unless additional rights are indicated by a Creative Commons license in the record and/ or on the work itself. This Thesis has been accepted for inclusion in WVU Graduate Theses, Dissertations, and Problem Reports collection by an authorized administrator of The Research Repository @ WVU. For more information, please contact researchrepository@mail.wvu.edu. 


\title{
Concept and Operation of Robotic Nondestructive Testing Systems for Space Exploration Objectives
}

\author{
Drew M. Goodman
}

Thesis submitted to the Benjamin M. Statler College of Engineering and Mineral Resources at West Virginia University

In partial fulfillment of the requirements for the degree of

\author{
Master of Science in \\ Mechanical Engineering \\ Thomas Evans, Ph.D., Chair \\ Aaron Noble, Ph.D. \\ Edward Sabolsky, Ph.D. \\ Department of Mechanical and Aerospace Engineering \\ Morgantown, West Virginia \\ 2016
}

Keywords: Nondestructive Testing, Schmidt Rebound Hammer, Impact Hammer, Ultrasonic Pulse Velocity, Asteroid Characterization, Data Analysis Copyright 2016 Drew M. Goodman 


\begin{abstract}
Concept and Operation of Robotic Nondestructive Testing Systems for Space Exploration

Objectives

Drew M. Goodman
\end{abstract}

Interaction with asteroid bodies is an important component of the upcoming NASA Asteroid Redirect Mission (ARM) and further space exploration. To provide in-situ material identification for exploration objectives, two robotic nondestructive testing (NDT) systems titled the Impact Sensor (IS) and Robotic UPV were proposed. The IS device is based on the impact hammer NDT approach. While an impact hammer relies solely on a rebound value, analysis was conducted to determine if impact force-time histories could provide similar information. The IS prototypes consisted of impact mechanisms, as well as; a force torque sensor (FTS) and 7 degree of freedom (7-DOF) robotic manipulator-two components slated for robotic exploration missions. The first IS prototype, titled the IS-1; was designed to retrieve impact centric metrics. Two prototype iterations - the IS- 1 and IS-2 - were designed, tested, and evaluated in this work. Due to parameters inherent to the selected FTS and impact mechanism, IS-1 test results did not display material correlations. However, analysis of IS-1 results provided the guidelines for a second prototype. The IS prototypes were tested on analog materials to gather force-time metrics and create material correlations. The robotic integration of the UPV system (robotic UPV system) involved creating suitable attachments to integrate UPV transducers with 7-DOF robotic manipulators. The robotic UPV design consisted of Proceq's Pundit PL-200 UPV system with FTS and robotic manipulators. The testing focused on evaluating operational parameters and system integration using precise robotic placement. Specifically, robotic UPV testing analyzed effects from transducer force, transducer alignment, transducer type, transducer angular offset, and specimen length. Each robotic UPV test was conducted with concrete specimen varying from 1-6m length. For both NDT systems the proof-of-concept was confirmed. From IS-2 test results, correlations between material and force-time history metrics were observed. In addition, correlations were observed between robotic UPV magnitude and the transducer force, transducer type, transducer angular offset, and beam length variables. From IS-2 and robotic UPV test results, operational parameters were suggested for both systems. With continued advancements, both robotic NDT systems show promising capability to meet space exploration objectives. 


\section{Acknowledgements}

First, I would like to thank my advisor Dr. Thomas Evans and the members of the West Virginia Robotic Technology Center (WVRTC). Because of the investment and tremendous effort of Dr. Evans and the WVRTC team, this research and has developed to the maturity presented. In addition, Dr. Evans' proficient leadership and support of the Robotic In-situ Surface Exploration System (RISES) project has always inspired me. Because of Dr. Evans' care, support, and commitment for his team, the RISES project continually presented professional research. In addition, the team at West Virginia Robotic Center has been a continuous support to my work and the entire RISES project. Specifically from the WVRTC team, I would like to thank Michael Campbell, Dr. Chad Panther, and Patrick Lewis for providing me with support, guidance, and time. Dr. Evans and the team at WVRTC possess a wealth of knowledge, dedication, and experience that allows them to carry NASA's pioneering spirit to new heights. Their investment in my knowledge and professional development has taught me how to break walls of adversity and create the forefront of innovation.

The brilliance and passion that Dr. Noble brought to the RISES team impacted my motivation, organization, and understanding needed to complete this research. In addition the students under Dr. Noble, Kara Savage and Thomas "Wes" Edge, have been a true benefit to my work by providing samples, baseline testing, and sample validation. Also from the WVRTC Campus and RISES team, Dr. Brijes Mishra and his graduate student Grant Speer provided me with expertise in sample fabrication and rock mechanics.

I would sincerely like to thank Dr. Edward Sabolsky for foundational support by joining my defense committee. As an undergraduate professor, Dr. Sabolsky aided my understanding of basic mechanics of materials and material testing concepts. As an undergraduate teaching assistant, the guidance he provided his graduate students allowed me to operate and understand material dynamics and strength testing machines. As a member of the WVRTC campus team, Dr. Sabolsky's attention to detail and expertise in materials research has provided new avenues for WVRTC sensor development and testing. 
This work was supported by an Early Stage Innovations grant from NASA's Space Technology Research Grants Program. Thus, I would like to thank NASA's Space Technology Research Grants Program. Without the Early Stage Innovations (ESI) Grant provided by NASA's Space Technology Research Grants Program, the RISES project would not exist. Furthermore the reporting, presenting, and collaboration with NAS A ESI personnel provided me with inspiration and expertise needed for the RISES project.

Lastly, I would like to thank my family and my patient fiancée, Brianna Kowalsky. I am thankful for all the times they waited for to me finish excessively describing this research to all strangers that would listen. I am thankful for the many moments where they allowed me verbally process my thoughts, and encouraged me to keep pursuing my goals. In closing, I am truly thankful to have my fiancée and family's continual love and support. 


\section{Table of Contents}

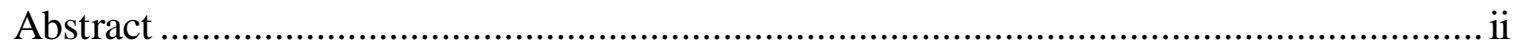

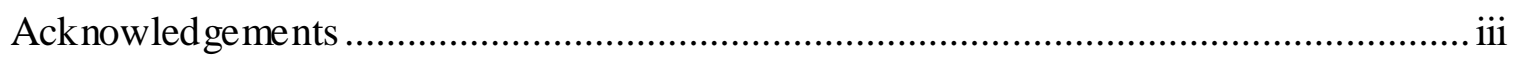

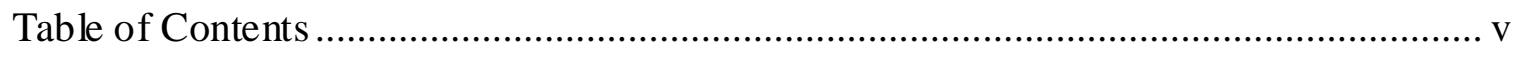

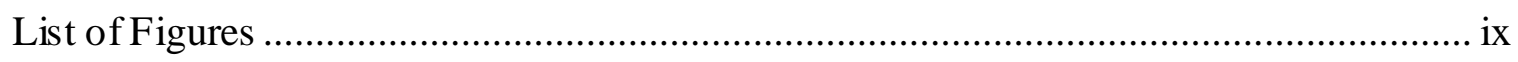

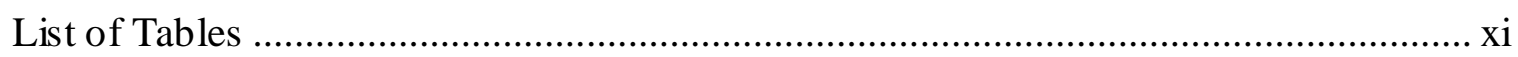

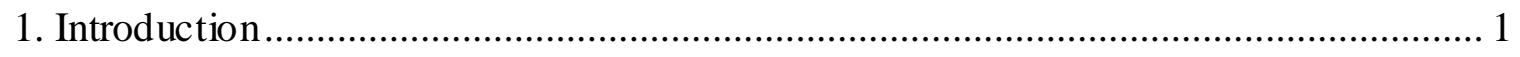

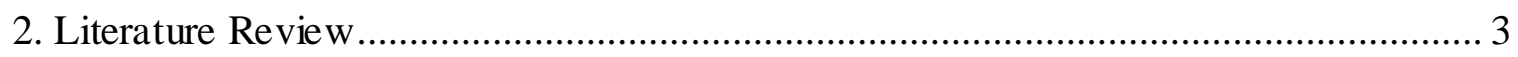

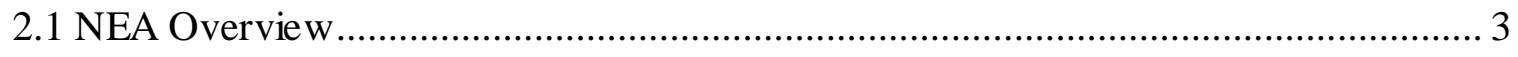

2.2 Rock Nondestructive Testing Methods Overview .................................................... 4

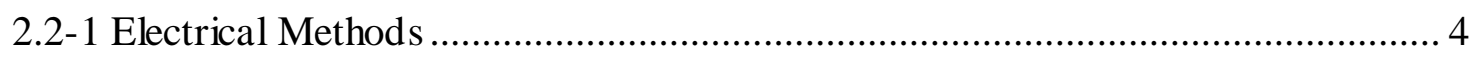

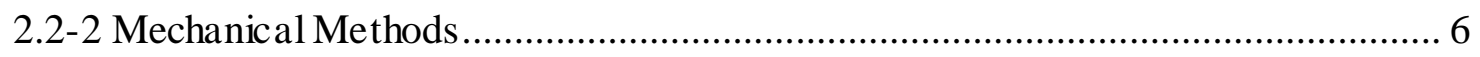

2.3 Details of the selected supporting baseline NDT methods ...................................... 13

2.3-1 Schmidt hammer theory and standard s............................................................ 13

2.3-2 UPV Direct Trans mission Theory and Standards .............................................. 16

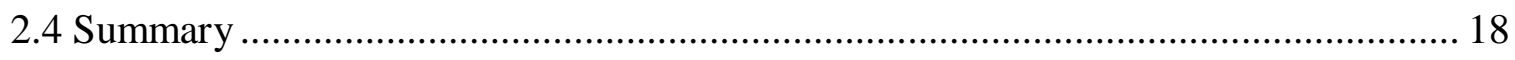

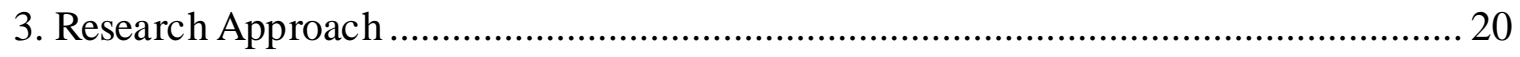

3.1 Proposed Innovations and Project Organization ....................................................... 20

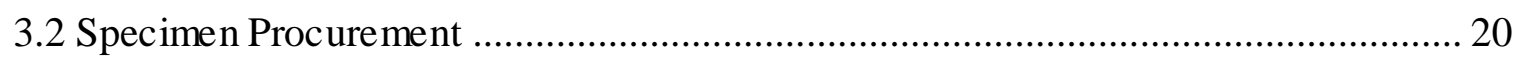

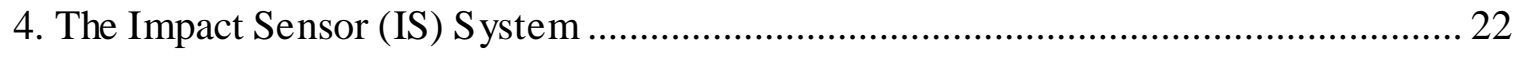




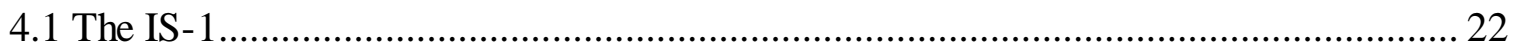

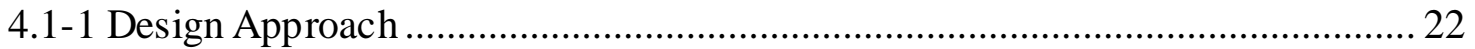

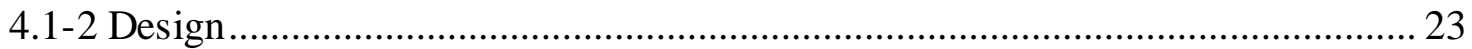

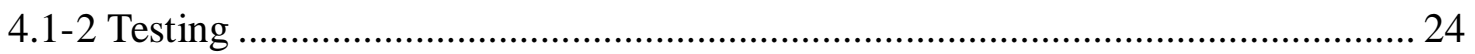

4.1-3 Data Collection, Extraction, and Analysis Methods ...................................... 26

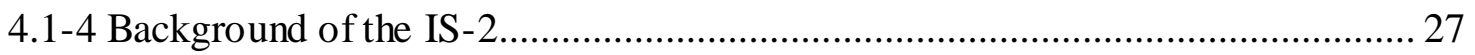

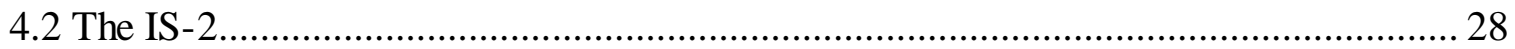

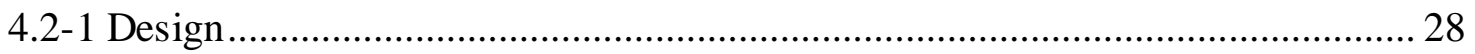

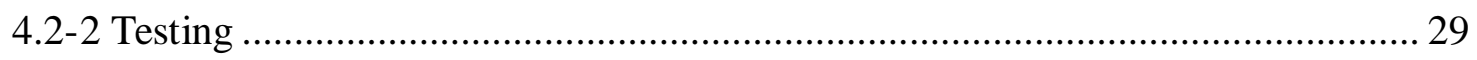

4.2-3 Data Collection, Extraction, and Analysis Methods ........................................ 31

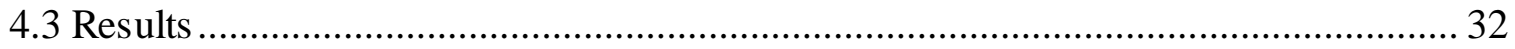

4.3-1 Proof of Concept Test ............................................................................. 32

4.3-2 Impact Location and Thickness Test ......................................................... 33

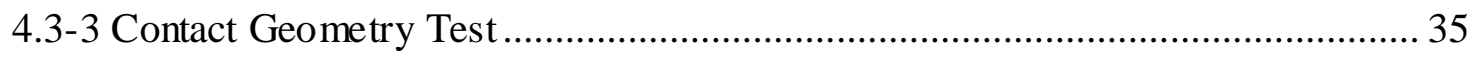

4.3-4 Refined Strength Range Test .................................................................. 36

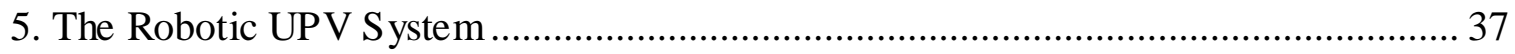

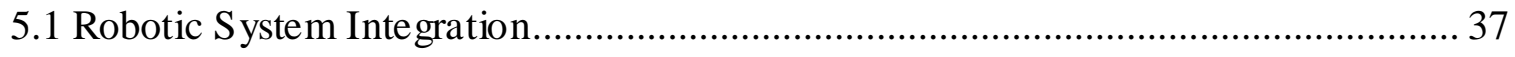

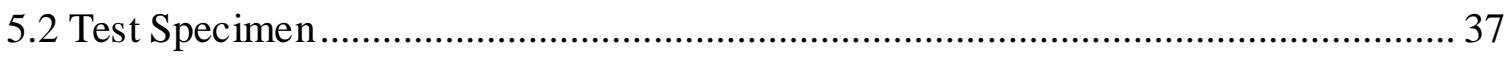

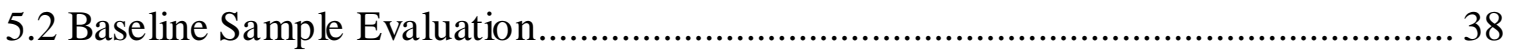

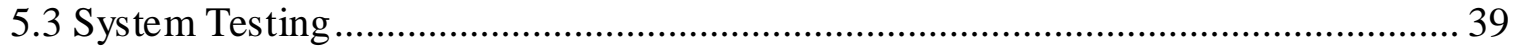


5.3 Robotic UPV System Data Extraction and Analysis Methods ............................... 42

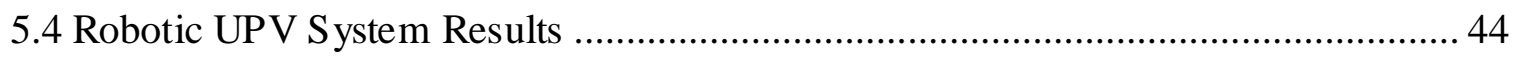

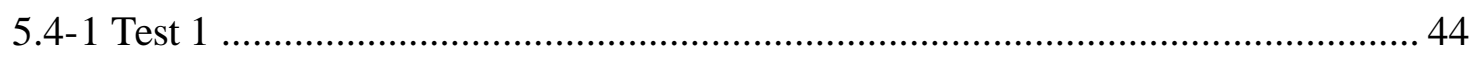

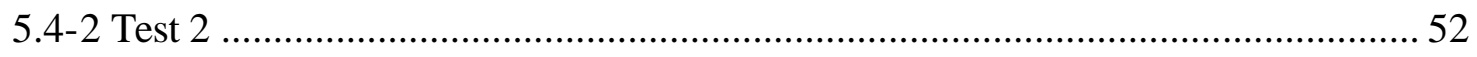

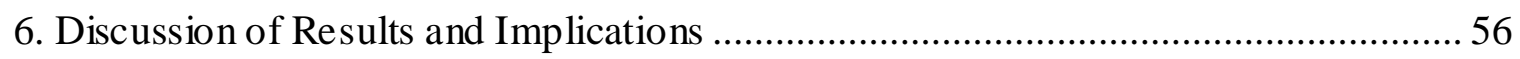

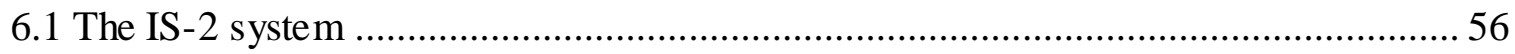

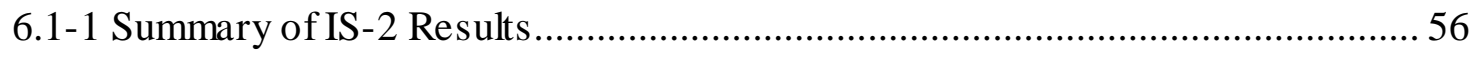

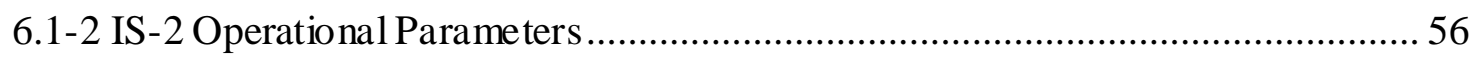

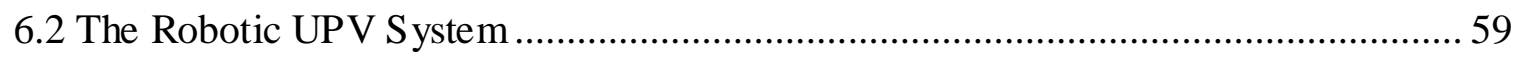

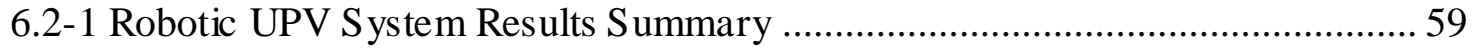

6.2-2 Robotic UPV System Suggested Operational Parameters ................................ 60

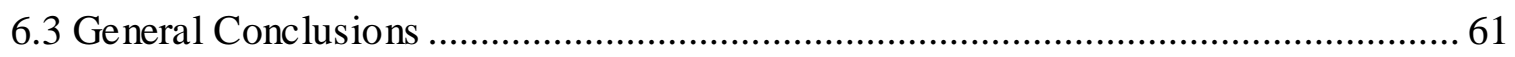

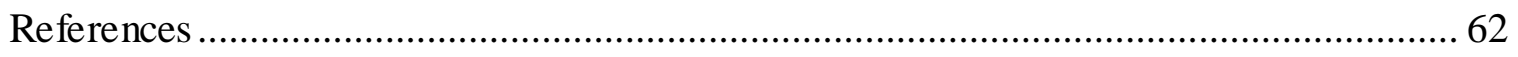

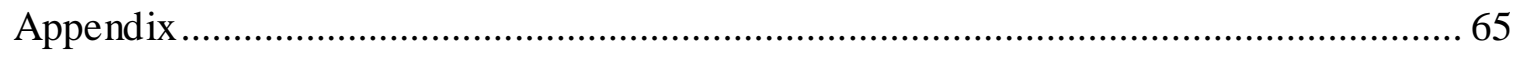

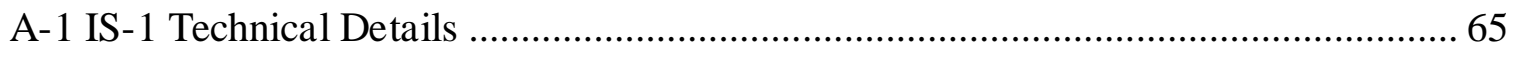

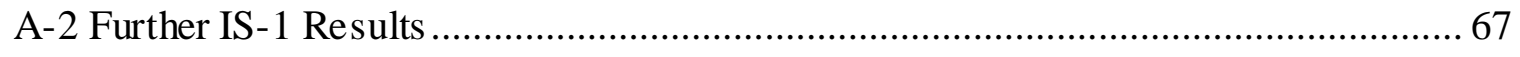

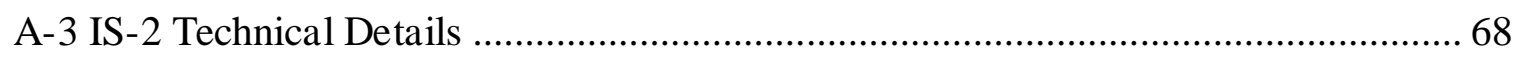

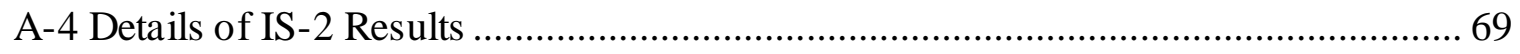

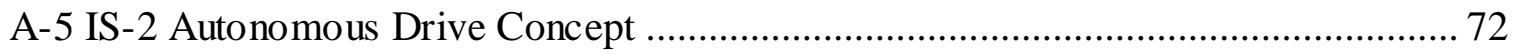


A-6 Robotic UPV Transducer Housing Detail

A-7 Details of Robotic UPV Results .

A-8 Robotic UPV Test 1 ANOVA F-Test Statistics 


\section{List of Figures}

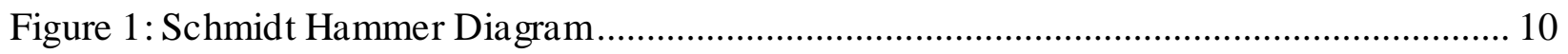

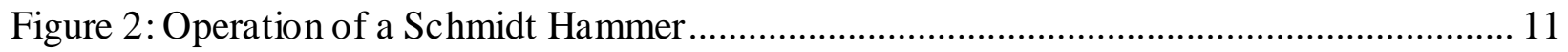

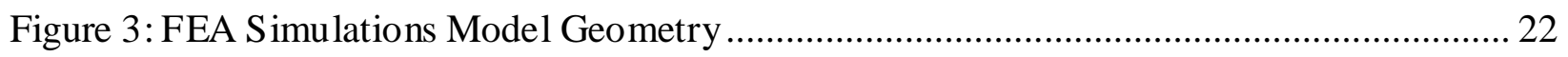

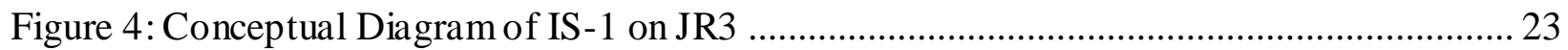

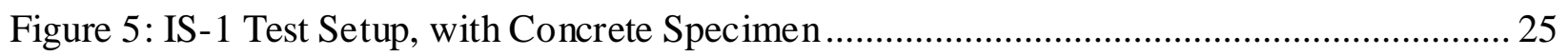

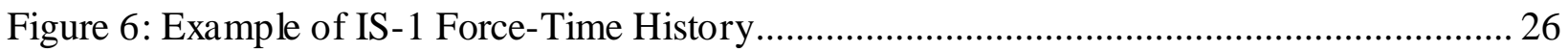

Figure 7: IS-1 Test 1, Extracted Maximum Impact Force Results ................................................ 27

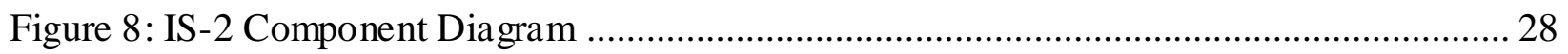

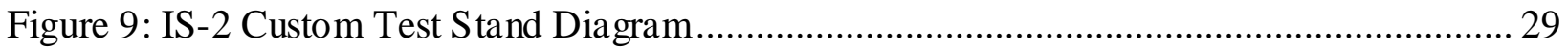

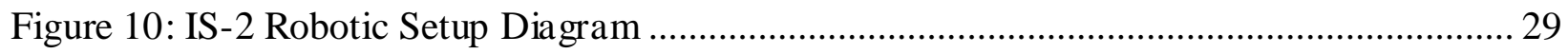

Figure 11: Proof of Concept Correlation: All Materials ......................................................... 32

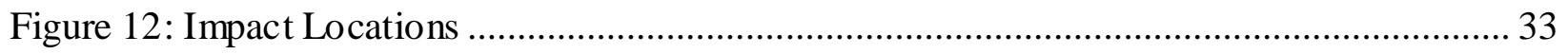

Figure 13: Horizontal F-T Histories: All Impacts Compared to Limestone .................................. 34

Figure 14: Vertical F-T Histories: All Impacts Compared to Limestone ...................................... 34

Figure 15: Specimen Geometries for Contact Geometry Test .................................................... 35

Figure 16: a.-Top) \& b.-Bottom) FT Histories of Aluminum Flat and Round Geometries: All

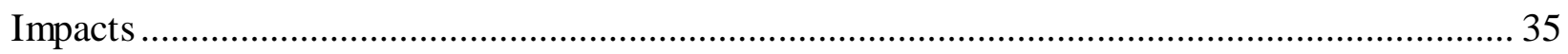

Figure 17: Refined Strength Range Test Correlation: All materials ............................................ 36

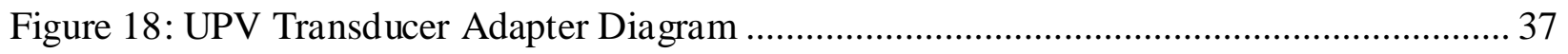

Figure 19: Baseline UPV Testing Locations ……………............................................................ 38

Figure 20: Robotic UPV System Test Set-Up …………....................................................... 39

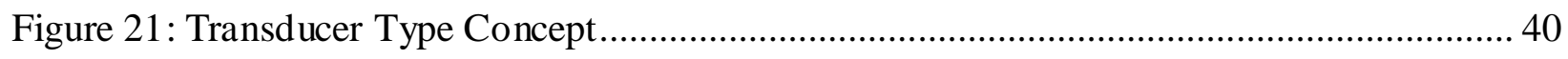


Figure 22: Test 1 Lateral Offset Diagram........................................................................ 41

Figure 23: Test 2 Angular Offset Diagram .................................................................... 41

Figure 24: Test 1 UPV Magnitudes, 24 kHz Standard Transducer-All Configurations ........... 46

Figure 25: Test 1 UPV Magnitudes, 54 kHz Standard Transducer-All Configurations ............ 48

Figure 26: Test 1 UPV Magnitudes, 54 kHz Exponential Transd ucer-All Configurations ....... 50

Figure 27: UPV Magnitudes for the 24 kHz Standard Transducer: All Tested Beams ............... 53

Figure 28: UPV Magnitudes for the 54 kHz Standard Transducer: All Tested Beams ............... 54

Figure 29: UPV Magnitudes for the 54 kHz Exponential Transducer: All Tested Beams ........... 55 


\section{List of Tables}

Table 1: Model Basis for Schmidt Hammer to UCS Correlation, from [35] ........................... 14

Table 2: Further Predictive Models of UCS from Schmidt Rebound value .............................. 14

Table 3: ASTM and ISRM stand ards for Schmidt Hammer Testing .................................... 15

Table 4: Model Basis for UCS Correlation to UPV Primary Wave Measurement, from [35] ..... 16

Table 5: Further Predictive Models of UCS from UPV Primary Wave Measurement, from [35] 16

Table 6: ASTM and ISRM Standards for UPV Testing and Data Analysis ............................ 17

Table 7: Baseline Evaluation of Rock Analogs .............................................................. 21

Table 8: Summary of FEA Simulation Results ................................................................... 23

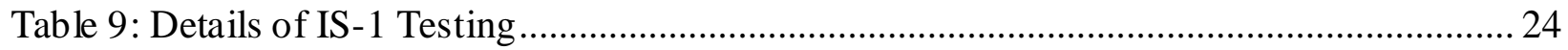

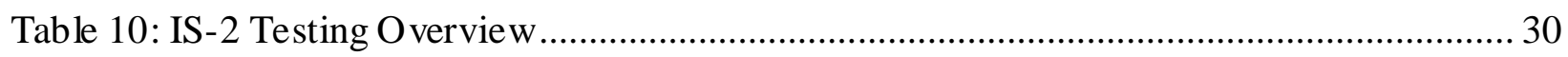

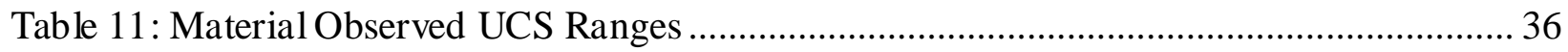

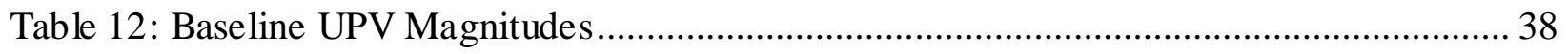

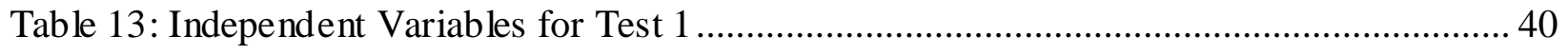

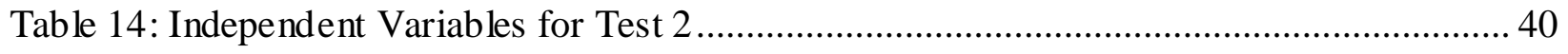

Table 15: Test 1 Repeatability Information and Results ................................................ 44

Table 16: Baseline and 24 kHz Standard Results Comparison............................................ 47

Table 17: Baseline and 54 kHz Standard Results Comparison.............................................. 49

Table 18: Baseline and 54 kHz Exponential Results Comparison ........................................ 51

Table 19: Test 2 Repeatability Information and Results .................................................5 52

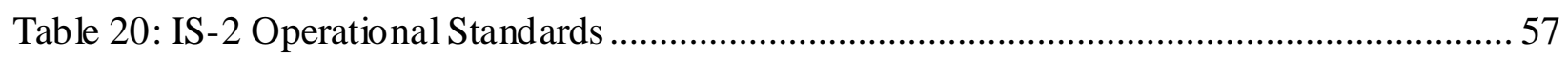

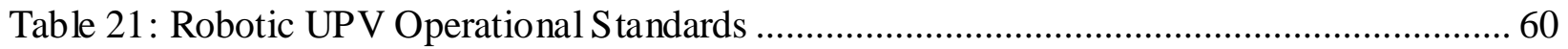




\section{Introduction}

Near earth asteroid (NEA) property characterization is beneficial to increase space exploration mission efficiency and duration. A mission's efficiency and duration can be increased if resources can be excavated from objects along the journey. Before excavation for resources, interaction (e.g. anchoring and manipulation) with NEAs is necessary. It is unwise to select an anchoring and/or drilling bit if the strength range of the material is unknown. To aid extra-terrestrial object interaction, in-situ characterization of the material must be performed. To ensure human exploration mission success, precursory robotic missions for NEA characterization and technology development are optimal.

The National Aeronautics and Space Administration's (NASA) Asteroid Redirect Robotic Mission (ARRM) is a precursory robotic mission to a crewed mission. Motioned for launch in 2020, the objective of ARRM is to retrie ve a multi-ton asteroid from a larger NEA, and place the smaller asteroid in lunar distant retrograde orbit [1] [2]. Prior to NASA spacecraft rendezvous with the NEA, information about the smaller asteroid's composition and mechanical properties will be sparse. To successfully capture, manipulate, and secure the smaller asteroid from the NEA's surface, a non-destructive system for coarse characterization of asteroid mechanical properties is advantageous.

To address needs for non-destructive asteroid property determination, in ARRM and other space exploration applications, the Robotic In-situ Surface Exploration System (RISES) has been developed. The RISES project incorporates robotic and mining non-destructive (NDT) system research. Specifically, this thesis will cover experiments with two robotic NDT systems - the Impact Sensor (IS) and robotic UPV systems. It is known that FTS and 7-DOF robotic manipulators are slated components for ARRM [1] [2]. Therefore, it was hypothesized that beneficial information could be obtained by integrating each NDT device with FTS and a 7DOF robotic manipulator to:

- Evaluate their applicability to robotic precursor missions (Proof of Concept)

- Suggest standards for operation 
To address these objectives, relevant literature will be reviewed to provide justification for the methods selected and further testing. Then the research approach, project organization, and preliminary NDT testing will be discussed. For each robotic system the following sections will provide details on the designs, tests conducted, analysis methods, and results collected. The final section will discuss the results, operational parameters, and implications for each system. 


\section{Literature Review}

\subsection{NEA Overvie w}

To properly select RISES ground test samples an understanding of the formation, composition, and properties of NEAs is necessary. The contemporary models of planet formation can be used to explain asteroid formation. The models describe the origin of planets as interstellar dust particulate within nebula gas growing from a nanometer to centimeter scale. The particulate grows randomly through continuous collision and fusion to become kilometer scale boulders. The boulders' gravitational attraction causes it to rapidly accrue objects with lesser mass. Boulders that grow to a scale of $1000 \mathrm{~km}$ or greater then form the solar system's protoplanet population. The remaining objects encompass the asteroid and comet population [3]. Of the asteroid population, NEAs are the asteroids that, at least once, "approach or cross Earth's orbit [4]."

The formation of NEAs is the initial step of proto-planet formation. Thus, the mineral building blocks of proto-planets (e.g. Earth's moon) are likely the same as NEAs. From this theory, the approach to estimating an asteroid's surface mineral composition is to perform solar photometric and spectroscopic measurements and compare them to known values of terrestrial minerals [3]. With such comparisons, NEAs can be classified by the Tholen classification scheme's S-class, C-class, and X-class asteroid groupings. The S-class is composed of asteroids with mainly siliceous content (i.e. basalt and olivine). The C-class has silicates but includes volatiles (e.g. water content and organic molecules). The X-class includes metal rich asteroids and asteroids of varying content [5]. For ARRM the current NEA candidates are C-and S-class mineral types [2].

Due to the micro-gravity environment and nature of asteroid formation, the properties of most NEAs can be analogous to a "rubble pile." The fact that solid silicates have a density of approximately $3 \mathrm{~g} / \mathrm{cm}^{3}$, and the collective NEA's average density range is $1-1.5 \mathrm{~g} / \mathrm{cm}^{3}$ validates the "rubble pile" analogy [3]. The collective average density is not surprising because the range of C- and S-class asteroid porosity estimated by Britt et. Al. was found to be 5-80\% [6]. The mass of most NEAs is on the metric multi-ton scale. The effective diameter of NEA's, calculated from analysis of the NEA's albedo, to range from $0.1 \mathrm{~km}$ to $32 \mathrm{~km}$ [3]. The diameter range of the 
selected ARRM NASA targets is $320-870 \mathrm{~m}$. Furthermore, the desired mean diameter of the smaller asteroid to be retrieved from the ARRM selected NEA is 2-4 m [2]. From the mineral composition of the S- and C-class, it can be inferred that the properties of the ARRM smaller asteroid will be the same as the properties of the selected NEA's silicates. From a spectral study of the composition of chondrites compared to asteroid spectroscopy, Dunn et. Al. found that the most abundant silicates in asteroids are pyroxenes and olivine (i.e. basalt) [7].

For successful manipulation, capture, and retrieval of the smaller asteroid the primary characteristics of concern are the bulk properties (e.g. compressive strength, density, modulus of elasticity, and Poison's ratio). Of the bulk properties the most commonly observed in terrestrial rock mechanics is the unconfined or uni-axial compressive strength (UCS). Because of varying factors (e.g. site procured, anisotropy) rock types have ranges of UCS. To discover a rock type UCS range, a compressive strength test must be performed. Typically the compressive strength test involves taking multiple core samples, usually of cylindrical shape and a specific length-todiameter ratio, and applying compressive forces at each specimen end until failure [8]. For terrestrially weathered basalt, the general range of UCS is 70-338 MPa [9] [10][11][12]. UCS testing forms the validation, or "truth" data, to correlate to non-destructive testing metrics.

\subsection{Rock Nondestructive Testing Methods Overview}

There are a variety of nondestructive testing (NDT) methods in the field of terrestrial rock mechanics [13]. These methods are applied both in the field and laboratory setting to acquire information on the material's mechanical properties and internal structure. For simplicity, rock testing NDT methods will be grouped into electrical and mechanical NDT methods [14].

\section{2-1 Electrical Methods}

Common electrical NDT methods include the: resistivity measurement [15], eddy current [16] [17] [18], and radiographic methods [14]. Because these methods were not selected for RISES evaluation, they will be generally discussed. Specifically, each method's concept and removal from RISES selection will be discussed. 
The electrical resistivity method involves calculating the apparent resistivity of a rock by introducing a direct current into the material. The apparent resistivity (in Ohm-meters) metric can correlate to the material's porosity, water content, and structure. Electrodes at the surface introduce a current to the material, and the electrical potential is measured with two more electrodes. This process is repeated for several locations. The potential differences at several locations provide a pattern to understand specimen composition and structure. A main advantage of the resistivity method is its ability to sensitively map the structure and water content of low strength specimens. However, because of the resistivity method's sensitivity, the produced results yield a multi-factor dependence. Because the method's results depend on several factors, the results tend to be arduous to understand and not repeatable. Even with extensive analysis and prior knowledge of the specimen, the resistivity method may not yield a unique result. Thus, extensive calibration of the set up and prior knowledge of specimen properties are essential for the resistivity NDT method's success [15]. Because prior information about the asteroid specimen will be sparse for ARRM, this method was not selected for RISES evaluation.

The eddy current method [16] originates from the principles of electro-magnetic induction. The standard method introduces an alternating current to an electro-magnetic coil that, in turn, induces a swirling magnetic field within a conductive material. The direction of the induced magnetic field can be inferred from Lenz's law, and the magnitude of the field can be inferred by Maxwell's equations [17]. Typically, a receiver coil is either spread out or coupled with the source coil to measure electric potential difference across the sample [14]. Other methods will analyze the uniformity of the alternating current from the induced field [16]. To analyze an anisotropic and inhomogeneous specimen's electromagnetic measurement results, three dimensional finite difference methods from Maxwell's equations are used [18]. By using a finite difference method on the results across the specimen's surface, voids and weak zones of the specimen can be found. However, if the specimen does not have conductive material, quantifiable results for the strength inferring finite difference scheme are not plausible. Furthermore this method is subject to interference from other electromagnetic devices, and thus, can yield non-unique results [14]. Due to possible electro-magnetic field interference and meager knowledge of the ARRM asteroid target's material conductance, this method is not optimal for RISES evaluation. 
The radiography based electrical NDT methods introduce "penetrating radiation" waves to the specimen and use either the reflected or collected backside radiation to approximate specimen properties. Common radiation types used in this method are electromagnetic radiation (e. g. gamma radiation, and x-radiation [16]). Where the depth/size of the specimen is not known or backside access is not available, the reflectance method is used. The radiographic reflectance NDT method uses ground penetrating radar (GPR). Where FM band radio waves are continuously emitted by the GPR, and the reflected wave's time of travel and amplitude are used to infer specimen composition and strength [14]. The collected backside radiographic NDT methods use either a film, or computer to construct a sectional image [16]. With a constructed radiographic image an understanding of specimen discontinuities and structure can be inferred. A permanent test record is created through radiographic NDT methods with little sample preparation. However, only non-conducting materials will create a test record. Furthermore, these methods require long exposures needed for record creation [14]. Thus, without knowledge of the material conductance this NDT method is not advantageous for RISES evaluation. If the spacecraft and sample do not remain anchored, the long exposure times can make radiography unsuitable for RISES evaluation.

\section{2-2 Mechanical Methods}

Common mechanical NDT methods include mechanical wave surveying [19] [20] [21] and impact response measurement [22] [23][24]. Both of these NDT methods have vast use in the fields of mining and civil engineering. More detail will be provided for these mechanical methods because they form the basis for the RISES robotic NDT systems.

Common mechanical wave surveying methods are the seismic [19], ultrasonic [20], and acoustic emission [21] methods. These methods introduce mechanical waves by piezo-electric transducers into the test specimen to obtain metrics for property estimation. The motion of a mechanical wave within a material is a phenomenon, in which, energy is transferred by harmonious particle movement. When moving on the specimen's free surface, the waves are characterized by a perpendicular movement called Love-waves or an ellipsoidal movement called Rayleigh waves. When moving through a body, the wave motion is typically characterized by two types of movement: a parallel longitudinal motion, or a perpendicular transverse motion. Because the longitudinal wave motion has been proven to be much faster than the transverse 
wave motion, the longitudinal motion waves are called primary waves and the transverse motion waves are called secondary waves.

A standard metric of primary and secondary waves used for correlation to material strength is average wave velocity. Some methods of measuring average wave velocity include direct transmission, refraction, and pulse-echo methods. The direct transmission method of measuring wave velocity uses a piezo-electric transducer to send a primary-wave through the specimen, to the receiver for viewing by a data logger. By the transient scheme, the length between transducers $(\Delta \mathrm{L})$ divided by the time delay between the transmitted and received signal $(\Delta \mathrm{T})$ is the wave's average speed $\left(\mathrm{V}_{\mathrm{p}}\right)$ (Equation 1) [14]. The steady state scheme uses several wave frequencies (f) and the ratio of length between transducers $(\Delta \mathrm{L})$ to the difference in phase angle $(\Delta \theta)$ to calculate the average wave speed $\left(\mathrm{V}_{\mathrm{p}}\right)$ Equation 2 [14].

$$
\begin{gathered}
V_{p}=\frac{\Delta \mathrm{L}}{\Delta \mathrm{T}} \\
V_{p}=f * \frac{\Delta \mathrm{L}}{\Delta \theta}
\end{gathered}
$$

Equation 1

Equation 2

For both schemes the term of attenuation has significance. Attenuation refers to internal or geometrical dissipation of wave energy (i.e. amplitudes) over the length of a medium. Internal attenuation (Equation 3) can be due to several factors (e.g. dry friction) and is modeled by the exponential law. In Equation 3, alpha $(\alpha)$ is the dissipation constant modeled by Equation 4 and $\mathrm{r}$ is the radius from the source. To calculate alpha (Equation 3), the source frequency, primary wave velocity, and the material Q-factor constant are needed. Geometrical attenuation arises from specimen dimensions and structure; it is modeled by raising the signal path distance (r) to the negative power (n) (Equation 5). The n-variable for Equation 5 is determined by wave type. For primary and secondary waves $n=1$; for Love and Rayleigh waves $n=0.5$. Understanding the internal and geometric attenuation in a specimen aids in understanding the necessary source wave frequency for direct transmission. 


$$
\begin{aligned}
& a(r)=\text { const } * e^{-\alpha * r} \\
& \text { Equation } 3 \\
& \propto=\pi * \frac{f}{Q * V_{p}} \\
& a(r)=\text { const } * r^{-n}
\end{aligned}
$$

The direct transmission analysis has the advantage of globally assessing the properties of the specimen sub-surface from average metric values. However, for certain applications, having only the average wave velocity is not optimal. Furthermore, this analysis does not provide direct information of specimen discontinuity size or location [14] [25].

The refraction analysis method of the NDT wave surveying involves estimating specimen properties by measuring refracted primary waves. To create a refracted primary wave, the wave source must create a wave that increases from the free surface (e.g. a detonation). Furthermore, for the signal path to change direction, the specimen composition must be a series of overlaid homogenous materials. Primary waves in a homogenous material follow a straight line path, and the wave path is refracted once a new material is encountered [17]. When a wave is refracted, a portion of the wave is reflected back into the previous material. A discontinuity can be perceived by the occurrence of a head wave. The head wave occurs after the wave has entered another material, and is characterized by a faster average velocity in the received wave of the previous material. At the surface of the previous material, the head wave will travel at the speed of the wave in the newly encountered material. With transducers or accelerometers at the surface and a data logger, a time-distance or travel-time diagram can be made. Extrapolation of the time-travel diagram provides a mapping to understand the depth of each layer in the specimen, and the wave velocity in each material. The travel-time diagram can also provide a mapping to understand the depth of discontinuities in the specimen. This analysis has the advantage of providing a global mapping of the specimen. However, the speed of the induced waves must be increasing from the free surface in each material of the specimen. To achieve this increasing wave velocity a large vibration or detonation is necessary [14] [25]. 
The pulse-echo, or impact-echo, analysis uses reflected waves from discontinuities. However, the wave source for the pulse-echo analysis originates from either an ultrasonic transducer or impact device instead of a detonation. If an impact device or impact hammer is used, the source impulse provides both primary and secondary waves. The transducer or accelerometer at the surface will encounter multiple series of resonant vibrations between the discontinuity and the free surface. Frequencies from the surface vibrations are measured, and with a known path/material thickness the secondary wave velocity can be approximated. This analysis has the advantage of being able to measure global and local specimen discontinuity without a large vibration or detonation source. However, continual calibration of the system is needed to determine accurate discontinuity depth [14] [25].

All of the above testing analyses apply to seismic, ultrasonic, and acoustical wave surveying. Within each testing method, the frequency range and/or equipment used can vary. A standard transmitter frequency for seismic wave surveying is 50 Hertz [14]. In contrast, ultrasonic wave surveying of rocks use frequencies on the range of 20 kilo-Hertz $(\mathrm{kHz})$ to 500 $\mathrm{kHz}$. Acoustic emission surveying uses frequencies of $10 \mathrm{Hertz}$ to approximately $20 \mathrm{kHz}$ [25]. Accelerometers with resonance range of $50 \mathrm{~Hz}$ to $40 \mathrm{kHz}$ are used in seismic wave surveying. Piezoelectric transducers are used in acoustic emission and ultrasonic wave surveying. The wave source for seismic surveying is either a resonant hammer or detonation [14][25]. For acoustic emission surveying the source of waves are micro-cracks formed by applying stress to the sample [21]. For ultrasonic wave surveying the vibration of a piezoelectric transducer provides the wave source [20]. All mechanical wave surveying methods require a data acquisition and logging system to analyze the collected waveforms. The primary wave speed for rocks in all methods can range from 1000-5000 m/s [25].

All mechanical wave surveying methods have the ability to detect global and local discontinuities, as well as, approximate material properties of the structure. However, these NDT methods can require specimen surface preparation or coupling gel for the transducers. In addition, due to the sensitivity of the equipment calibration is required. Furthermore, knowledge of the receiver lay out is needed [14]. 
Impact response NDT mechanical methods rely on metrics collected from the impact of the surface and an indenter to approximate specimen properties. Specifically metrics from the indenter's rebound are used to correlate to mechanical properties [14]. Common devices that use indenter rebound metrics to estimate properties are the Schmidt Hammer [22], Equotip/Leeb Hammer [23], and Scleroscope [26] devices. Each of these hammer devices have similarities and differences in regard to device operation and composition. Furthermore, the process of metric extraction and correlation of metrics to specimen properties are similar and different for each hammer device.

The Schmidt Hammer (SH) invention dates back to 1951 [22]. Figure 1 displays the components of a $\mathrm{SH}$. The $\mathrm{SH}$ uses a mass-spring system to control the impact energy of a hammer that impacts a plunger pressed up against the specimen. The input energy, controlled by spring extension, determines the type of SH. For rock and mineral testing, the L-type SH is used with an input energy of $0.735 \mathrm{~J}$ [23]. Operation of a standard $\mathrm{SH}$ is displayed in Figure 2.

\section{SH Ready For test}

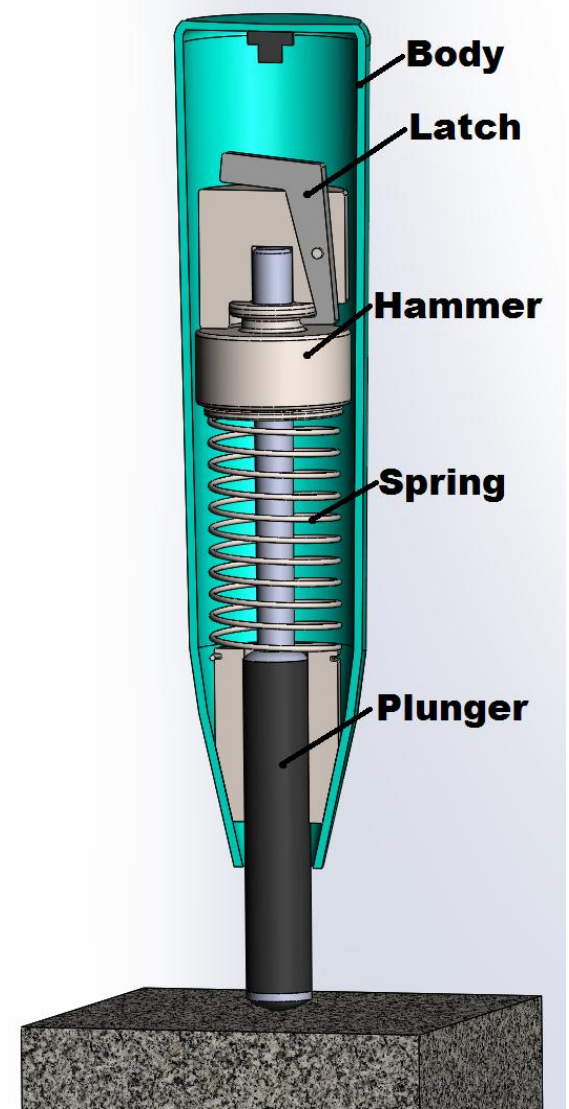

Figure 1: Schmidt Hammer Diagram
Extension of the spring is created by pressing the hammer into the sample (Figure $2(a-b)$ ). At the spring extension for desired impact energy the hammer is unlatched and driven to impact with the plunger (Figure 2 (c)). After the hammer's impact with the plunger (Figure 2 (d)), the hammer rebounds to a maximum height where the Schmidt Rebound (SR) can be measured by moving a sliding indicator or measured by a sensor system [27]. The SR is onehundred multiplied by the ratio of hammer rebound height to hammer release height [22]. 

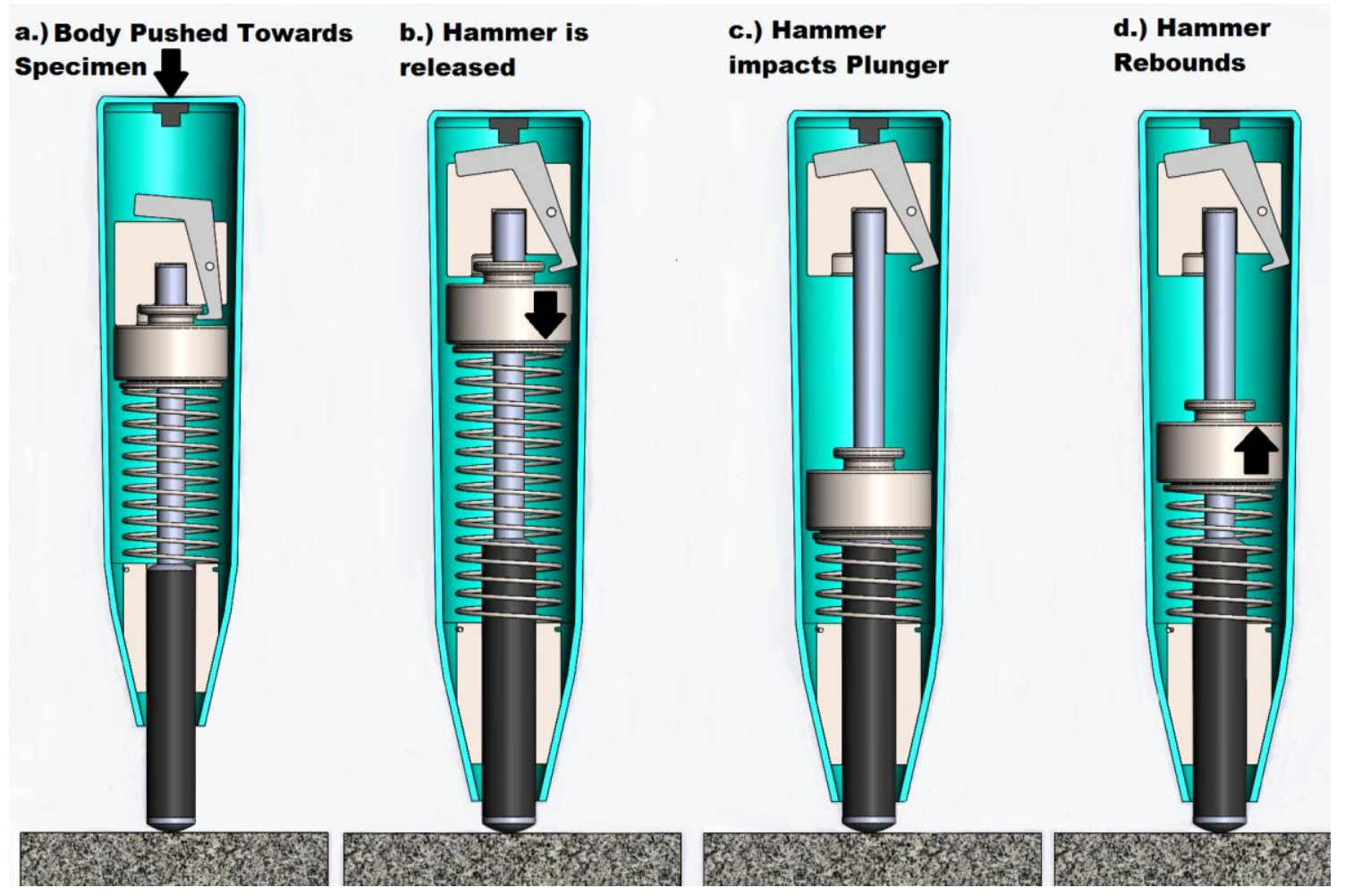

Figure 2: Operation of a Schmidt Hammer

The Equotip, a commercial Leeb Hammer (LH), uses a spring driven impact system to create an impact between a body with a spherical indenter and the specimen. However, instead of using the SH's method of pressing into the specimen to load the mass-spring system, the LH uses operator drawback and release to store elastic potential energy and begin the impact phase. The range of impact energy for an LH device is 0.003-0.2J [23] [28]. To address operator error the LH's impacting body contains a permanent magnet and inducting coil. The movement of the magnet within an inducting coil induces a current. The impact and rebound velocity are measured by monitoring the induction coil's current. The comparison of the rebound to the impact velocity multiplied by one-thousand is the LH's rebound metric, called the Leeb number [23].

The Scleroscope is quite possibly the oldest impact hammer method, dating back to 1923 , and has similar composition and operation to the LH and SH [26]. The Scelerscope was created for general purpose surface hardness testing, but has found use in rock and mineral surface strength approximation [29]. Similar to the LH, the original Scleroscope stores potential energy 
for impact by operator pullback [26]. In contrast to the LH and SH, the Scleroscope impact energy is driven by gravity instead of a spring. However, several types of Scleroscopes exist and some use a change in pressure input by a diaphragm to load and drive the hammer [29]. The Scleroscope uses a conical diamond indenter instead of a flat hammer or a spherical indenter. In the rebound phase the Scleroscope hammer is caught at the peak of its rebound by a latching mechanism. The latching mechanism also serves as an indicator, similar to SH operation, revealing a rebound metric called the Scleroscope hardness. Like the Schmidt hardness the Scleroscope hardness is a ratio of the input hammer height to output rebound hammer height, but on a scale of 0 to 140 instead of 0 to 100 .

Other hammer methods exist; however, they are more or less combinations of the equipment and processes pioneered by the $\mathrm{SH}$, LH, or Scleroscope devices. For instance, the Duroscope is another impact hammer device with the same impact procedure as a SH, but with a conical indenter-like the Scleroscope-and a lesser input impact energy-like the LH [30]. Some methods add additional technology to the standard impact hammer to improve or derive entirely new metrics. There has been testing performed with shock grade accelerometers to approximate surface UCS [14]. Shock grade sensors can measure up to $40 \mathrm{kHz}$ [31]. By attaching an accelerometer or piezoelectric sensing device to the hammer, it is theorized that the longer time duration or greater magnitude of the impulse correlates to specimen UCS [14].

To correlate the rebound metric for specific devices to a specimen UCS a number of linear, curvilinear, power, logarithmic, and exponential equations can be used depending on rock type and extraction site conditions [32] [23] [29]. Typically the average SR for slightly soft to strong rocks ranges from 10-80 [32][33]. The Leeb hammer was designed for rock testing. Thus, the Leeb rebound metric for rocks ranges from 0-1000. Because the Scleroscope was originally created to test metals, the Scleroscope hardness numbers found for rocks tend to range from 10110 [29] [24]. All of the impact hammer methods have the advantage of portability, simplicity, and time-efficiency. Each method can be used in the field or laboratory setting. However, due to the pure mechanical nature of most of these devices, continual device calibration is necessary. For a single specimen multiple impacts must be performed at several locations with an impact hammer to approximate the average surface strength [34]. Furthermore, there are still 
discrepancies in efficient procedure (e.g. number of impacts and distance between impacts) for these devices [23] [32] [24]. For the SH, low strength non-homogeneous rocks may not return a value [14]. Furthermore, each device measurement has an inherent variance for a given UCS [23] [32][24]. Especially in the field, the effects of surface roughness and various environmental influences (e.g. extreme temperatures) are not certain [34][8].

\subsection{Details of the selected supporting baseline NDT methods}

Considering equipment requirements, environmental conditions, and current available data two NDT methods were selected by the RISES research team: the impact hammer approach and ultrasonic pulse velocity (UPV) surveying. A benefit of testing both methods is the reduction of approximation error by using two metrics for UCS correlation. Using the UPV and SR to approximate specimen UCS is called the SonReb method. The SonReb method has a unique efficiency because it approximates specimen UCS from metrics relating to both surface (SR) and sub-surface (UPV) material characteristics. However, current studies for the SonReb method were conducted with limited data. One example of a SonReb UCS predictive model with primary wave velocity $\left(\mathrm{V}_{\mathrm{p}}\right)$ and $\mathrm{SR}$ inputs is given in Equation 6 [35]. To support the RISES robotic integrations, greater detail is needed on the statistical theory and standards behind the two selected methods.

$$
U C S=0.056 * V_{p}+0.312 * S R-0.46
$$

Equation 6

\section{3-1 Schmidt hamme $r$ theory and standards}

Operation of the SH and basics of the SH are given in section 2.2-2. Greater detail on the mathematics behind the Schmidt rebound number can be given by Equation 7, Equation 8, Equation 9, and Equation 10. SH theory relies on the conservation of energy principle to approximate the dissipated energy (D) from the impact (Equation 7) [17]. The energy efficiency, e, can either be approximated by comparing the input and output hammer positions or velocities (Equation 8 and Equation 9). The formal equation for the SR is described by Equation 10.

$$
D=1-e
$$




$$
\begin{gathered}
e=\left|\frac{v_{f}}{v_{i}}\right|=\sqrt{\frac{K E_{f}}{K E_{i}}} \\
e=\left|\frac{h_{f}}{h_{i}}\right|=\frac{P E_{f}}{P E_{i}} \\
\mathrm{SR}=100 * \mathrm{e}
\end{gathered}
$$

Equation 8

Equation 10

To correlate the Schmidt hammer to UCS the standard models of equations are linear, logarithmic, power, and exponential (Table 1) [35]. The predictive models in Table 1 form a basis for SR curve-fitting [35]. For reference, some predictive models for SR to UCS correlation with rock type and UCS range can be found in Table 2 [35][33]. Due to local site conditions and differences in test procedure, several models exist for specific rock types.

Table 1: Model Basis for Schmidt Hammer to UCS Correlation, from [35]

\begin{tabular}{|l|c|}
\hline \hline Model & Predictive Model \\
\hline \hline Linear & UCS $=0.678 *$ SR \\
\hline Logarithmic & UCS $=6.038 * \ln (\mathrm{SR})$ \\
\hline Power & $\mathrm{UCS}=\mathrm{SR}^{0.885}$ \\
\hline Exponential & $\mathrm{UCS}=\mathrm{e}^{0.092 * \mathrm{SR}}$ \\
\hline \hline
\end{tabular}

Table 2: Further Predictive Models of UCS from Schmidt Rebound value

\begin{tabular}{|c|c|c|}
\hline \hline Rock Type & Predictive Model & UCS Range (MPa) \\
\hline \hline Quartzite [35] & $U C S=0.64 * S R+37.5$ & $207-627$ \\
\hline Carbonates, Sandstone, Basalt [33] & $U C S=0.000004 * S R^{4.29}$ & $40-112$ \\
\hline Granite [33] & $U C S=0.00016 * S R^{3.47}$ & $11-266$ \\
\hline Prasinite [33] & $U C S=2.99 * e^{(0.06 * S R)}$ & $8-145$ \\
\hline Granite [33] & $U C S=1.45 * e^{(0.07 * S R)}$ & $6-196$ \\
\hline Limestone, Sandstone [33] & $U C S=2.21 * e^{(0.07 * S R)}$ & $11-259$ \\
\hline Coal [33] & $U C S=0.40 * S R-3.60$ & $3-13$ \\
\hline Sandstone, Siltstone, Mudstone, Seatearth [33] & $U C S=2 * S R$ & $12-73$ \\
\hline \hline
\end{tabular}


To provide a foundation for results comparison ASTM and ISRM created standards for Impact hammer testing [34] [36]. Table 3 summarizes these guidelines. These guidelines formed the procedural basis for RISES traditional and robotic integration Schmidt hammer testing. Notice the standards do not provide guidelines for testing in extreme atmospheric conditions (e.g. low temperature).

Table 3: ASTM and ISRM stand ards for Schmidt Hammer Testing

\begin{tabular}{|c|c|c|}
\hline Description & ASTM & ISRM \\
\hline $\begin{array}{l}\text { Specimen } \\
\text { Quality }\end{array}$ & $\begin{array}{c}\text { The test surface shall be free of jo ints, fractures, or } \\
\text { other obvious localized discontinuities. }\end{array}$ & $\begin{array}{l}\text { Specimens should be intact (free of visible } \\
\text { cracks), petro-graphically uniform and } \\
\text { representative of the rock mas s domain } \\
\text { being characterized. }\end{array}$ \\
\hline $\begin{array}{l}\text { Surface } \\
\text { Quality }\end{array}$ & $\begin{array}{l}\text { The test surface of all specimens shall be smooth to the } \\
\text { touch. If the surface of the test area is heavily textures, } \\
\text { grind it s mooth with an abrasive stone. }\end{array}$ & $\begin{array}{l}\text { Test surfaces should be smooth and free } \\
\text { of dust and particles. Fine sandpaper can } \\
\text { be used to smooth the surfaces of cores. }\end{array}$ \\
\hline Moisture & $\begin{array}{c}\text { Record or document moisture condition of the core } \\
\text { specimens. The qualitative condition can be reports or a } \\
\text { more exact method can be used such as ASTM } \\
\text { Standard Test Method D2216. }\end{array}$ & $\begin{array}{c}\text { Cores should be air dried or saturated } \\
\text { before testing. The degree of moistness as } \\
\text { a whole should be recorded as wet, moist, } \\
\text { or damp. }\end{array}$ \\
\hline $\begin{array}{l}\text { Specimen } \\
\text { Diameter }\end{array}$ & $\begin{array}{l}\text { Drill core specimens shall be NX }(54.7 \mathrm{~mm}) \text { or larger } \\
\text { core. }\end{array}$ & $\begin{array}{l}\text { Cores should be } \geq 54.7 \mathrm{~mm} \text { size for the } \mathrm{L}- \\
\text { type hammer. }\end{array}$ \\
\hline $\begin{array}{l}\text { Specimen } \\
\text { Length }\end{array}$ & Drill core specimens shall be at least $15 \mathrm{~cm}$ in length & $\begin{array}{l}\text { Length of cores should be large enough to } \\
\text { accommodate suggestions of testing area } \\
\text { and locations to gather } 20 \text { readings. }\end{array}$ \\
\hline Core Holder & $\begin{array}{l}\text { The core holder may be a steel V-block or steel cradle } \\
\text { with a semi-circular machined slot with a minimum } \\
\text { mas of } 20 \mathrm{~kg} \text { to which specimens are securely held } \\
\text { with some type of clamping device. }\end{array}$ & $\begin{array}{c}\text { Specimens should be clamped to a steel } \\
\text { base (weight }>=20 \mathrm{~kg} \text { ). Core specimens } \\
\text { should be placed in an arc-shaped } \\
\text { machined slot. }\end{array}$ \\
\hline $\begin{array}{c}\text { Core Hol der } \\
\text { Placement }\end{array}$ & $\begin{array}{l}\text { Place steel base on a flat, level surface that provides } \\
\text { firm, rigid support, such as a concrete floor. }\end{array}$ & $\begin{array}{c}\text { The steel base should be located on firm, } \\
\text { flat ground. }\end{array}$ \\
\hline Testing Area & $\begin{array}{l}\text { Position the hammer not less than one diameter from } \\
\text { the edge of the specimen. }\end{array}$ & $\begin{array}{l}\text { Impact points should be one radius away } \\
\text { fro } m \text { the nearest end of the core } \\
\text { specimens. }\end{array}$ \\
\hline $\begin{array}{c}\text { Test } \\
\text { Locations }\end{array}$ & $\begin{array}{l}\text { Test locations shall be separated by at least the diameter } \\
\text { of the plunger, and only one test may be taken at any } \\
\text { one point. }\end{array}$ & $\begin{array}{c}\text { Rebound values should be recorded from } \\
\text { single impacts separated by at least a } \\
\text { plunger diameter. }\end{array}$ \\
\hline \begin{tabular}{c|} 
Measurement \\
Precision
\end{tabular} & $\begin{array}{l}\text { Record the height of the plunger rebound to the nearest } \\
\text { whole nu mber. }\end{array}$ & $\begin{array}{l}\text { Mean values should be rounded off to the } \\
\text { nearest integer. }\end{array}$ \\
\hline $\begin{array}{l}\text { Number of } \\
\text { Readings }\end{array}$ & $\begin{array}{l}\text { Record ten values at representative locations on the } \\
\text { specimen. }\end{array}$ & $\begin{array}{l}\text { For data gathering, } 20 \text { rebound values } \\
\text { should be recorded, stop test when any ten } \\
\text { subsequent readings differ only by four } \\
\text { units. }\end{array}$ \\
\hline $\begin{array}{c}\text { Data } \\
\text { Reduction }\end{array}$ & $\begin{array}{l}\text { Calculate the average of the ten readings obtained for } \\
\text { each specimen to the nearest whole number. Discard } \\
\text { readings with average variance more than seven units. } \\
\text { Fro m the remain ing readings, calculate the average, } \\
\text { mode, range, and median } \mathrm{H}_{\mathrm{R}} \text { for the specimen. }\end{array}$ & $\begin{array}{l}\text { No readings should be discarded, and the } \\
\text { mean, median, mode, and range of the } \\
\text { readings should be fully presented. }\end{array}$ \\
\hline
\end{tabular}




\section{3-2 UPV Direct Transmission Theory and Standards}

With primary wave UPV measurements, the standard predictive models used for correlation to UCS are displayed in Table 4. The standard models for UPV to UCS correlation are of similar form to SR and UCS correlation. For reference, Table 5 displays some predictive models that are often used for correlating UCS to primary wave velocity. The power model in row one of Table 5 is the standard model for correlation of UPV primary velocity to UCS. The predictive models in Table 5 are for predicting UCS of different rock types [35].

Table 4: Model Basis for UCS Correlation to UPV Primary Wave Measurement, from [35]

\begin{tabular}{|l|c|}
\hline \hline Model & Predictive Model \\
\hline \hline Linear & $\mathrm{UCS}=0.005 * \mathrm{~V}_{\mathrm{p}}$ \\
\hline Logarithmic & $\mathrm{UCS}=2.327 * \ln \left(\mathrm{V}_{\mathrm{p}}\right)$ \\
\hline Power & $\mathrm{UCS}=\mathrm{V}_{\mathrm{p}}^{0.0023}$ \\
\hline Exponential & $\mathrm{UCS}=\mathrm{e}^{0.99 * \mathrm{~V}_{\mathrm{p}}}$ \\
\hline \hline
\end{tabular}

Table 5: Further Predictive Models of UCS

from UPV Primary Wave Measurement, from [35]

\begin{tabular}{|c|c|}
\hline \hline Predictive Model & Rock Type \\
\hline \hline$Y=a * V_{p}{ }^{b}$ & general \\
\hline$U C S=9.95 * V_{p}^{1.21}$ & general \\
\hline$U C S=0.78 * V_{p}^{0.88}$ & volcanic \\
\hline$U C S=0.0642 * V_{p}-117.99$ & general \\
\hline$U C S=56.71 * V_{p}-192.93$ & general \\
\hline$U C S=165.05 * e^{-4.452 / V_{p}}$ & sedimentary \\
\hline$U C S=0.133 * V_{p}-227.19$ & Coal \\
\hline$U C S=0.11 * V_{p}-515.56$ & Serpentinites \\
\hline \hline
\end{tabular}


As with the SH, UPV testing also has a set of standards to aid in results comparison [37] [38]. Table 6 displays these standards that formed the basis for baseline UPV testing and the standards for robotic UPV system testing. Notice that these guidelines also do not address UPV testing in extreme environments. Furthermore, the standards do not state a specific number for applied transducer to sample pressure or force.

Table 6: ASTM and ISRM Standards for UPV Testing and Data Analysis

\begin{tabular}{|c|c|c|}
\hline Description & ASTM & ISRM \\
\hline Specimen Quality & $\begin{array}{l}\text { Specimens cannot be } \\
\text { significantly anis otropic. }\end{array}$ & $\begin{array}{l}\text { No features that compromise the } \\
\text { integrity of the specimen. }\end{array}$ \\
\hline Surface Quality & $\begin{array}{l}\text { Smooth, flat samples are } \\
\text { preferred }\end{array}$ & Smooth, flat samples are preferred \\
\hline Moisture & $\begin{array}{l}\text { Testing can be conducted at } \\
\text { any moisture content as long as } \\
\text { it is consistent throughout } \\
\text { testing }\end{array}$ & $\begin{array}{l}\text { Can be determined at any moisture } \\
\text { content }\end{array}$ \\
\hline Specimen Dimensions & $\begin{array}{l}\text { Travel distance of the wave } \\
\text { has to be at least ten times the } \\
\text { grain size }\end{array}$ & $\begin{array}{l}\text { Length of the specimen has to be at } \\
\text { least ten times greater than the grain } \\
\text { size }\end{array}$ \\
\hline Minimum Wavelength & At least 3 times the grain size & $\begin{array}{l}\text { Determined by the shape of the } \\
\text { specimen }\end{array}$ \\
\hline $\begin{array}{l}\text { Optimum Trans ducer } \\
\text { Frequency }\end{array}$ & $\begin{array}{l}\text { Optimum frequencies are } \\
\text { determined by sample size, } \\
\text { shape, rock type, etc. but } \\
\text { commonly used frequencies } \\
\text { are between } 75 \mathrm{kHz}-3 \mathrm{MHz}\end{array}$ & $\begin{array}{l}\text { Optimu } \mathrm{m} \text { frequencies are determined by } \\
\text { sample size, shape, rock type, etc. but } \\
\text { practical frequencies are between } 50 \text { - } \\
500 \mathrm{kHz}\end{array}$ \\
\hline Calculations & Depend on one set of equations & Depend on the shape of the sample \\
\hline $\begin{array}{c}\text { Determination of Pulse Travel } \\
\text { Time }\end{array}$ & $\begin{array}{l}\text { Select on the waveform the } \\
\text { time when the first break of } \\
\text { consistent manner occurs }\end{array}$ & $\begin{array}{l}\text { Select the time which the signal from } \\
\text { the transmitter meets the receiver. }\end{array}$ \\
\hline Specimen Shape & $\begin{array}{l}\text { Any shape is acceptable as } \\
\text { long as the surface is smooth } \\
\text { and flat }\end{array}$ & $\begin{array}{l}\text { Bar, block, and slab shapes are } \\
\text { preferred. Other shapes are acceptable } \\
\text { but not discussed }\end{array}$ \\
\hline Application of Coupling gel & $\begin{array}{l}\text { May improve the energy } \\
\text { transmission between the } \\
\text { sample and transducers }\end{array}$ & $\begin{array}{l}\text { Necessary to "ensure efficient and } \\
\text { uniform" energy transfer }\end{array}$ \\
\hline Coupling stress & $\begin{array}{l}\text { Varies when testing in-situ } \\
\text { conditions }\end{array}$ & $\begin{array}{l}\text { Varies with rock type and degree of } \\
\text { micro-s tructural damage }\end{array}$ \\
\hline
\end{tabular}




\subsection{Summary}

The review of relevant literature provided insight into NEAs, NDT methods, Schmidt Hammer theory, and UPV theory. The review of NEAs provided an understanding of asteroid formation, bulk properties, classification, and composition. Noteworthy properties of NEAs are their $5-80 \%$ porosity, collective density of $1-1.5 \mathrm{~g} / \mathrm{cm}^{3}$, and $0.1-32 \mathrm{~km}$ mean diameter range[6][3]. Furthermore NEA composition typically contains basalt, which has a compressive strength range of 70-338 MPa [7][9][10][11][12]. However, the exact composition of the ARRM target specimen is unknown. The ARRM target may include several other materials, and have a greater porosity than terrestrial basalt. Thus, a NDT system that can approximate specimen strength outside the range of basalt is needed.

The review of rock NDT methods displayed information about several electrical and mechanical methods. The electrical resistivity, eddy-current, and radiographic methods were not optimal for extra-terrestrial NDT testing because they required a priori knowledge of the material's conductance, long exposure times, or extensive calibration [14][15][18][19]. While the mechanical methods may require some surface preparation (e.g. rock abrasion) and calibration, they provide relevant metrics that can correlate to the materials compressive strength — in the field or laboratory [14][27]. Thus, two mechanical methods were reviewed for the RISES project.

Because of the system requirements, environmental conditions, and available data the Schmidt Hammer (SH) and ultrasonic pulse velocity (UPV) direct transmission methods were selected for RISES development. The SH device impacts a specimen with an energy controlled by the internal hammer-spring extension. The maximum rebound height of the hammer compared to the input height is the Schmidt Rebound number (SR). The SR correlates to UCS through rock type and site specific regressions [27][32][35]. The UPV direct transmission method involves transmitting a mechanical wave between two in-line transducers to measure the signal travel time. With the known distance between transducers and measured signal travel time, the UPV magnitude can be calculated (Equation 1). Alike to the SH, UPV can correlate to UCS through rock type and site specific regressions. Because both methods can correlate to UCS, regressions the sonreb method was created to use both SR and UPV to approximate UCS. On 
average, equations using both SR and UPV to correlate to UCS are more efficient [14][20][35]. For most optimal result recording and analysis, both methods have ASTM and ISRM standards (Table 3 and Table 6) [34] [37].

Both the SH and UPV direct transmission methods are applicable for RISES development. However, SH literature does not mention using impact force-time history metrics for material or UCS correlation. Thus, the concept of coarsely approximating UCS range with an impact mechanism, force-torque sensor (FTS), data-acquisition computer, and robotic manipulator is novel. Because the signal travel time, for UPV calculation, is transmitted and received via piezoelectric transducers, correlating from force-time history data is not advantageous for the robotic UPV system. However, a commercial UPV system integrated with an FTS can be beneficial for measurement quality control. Thus, the missing information in UPV method literature are the values for the minimum transducer force, allowed transducer lateral misalignment, allowed transducer angular offset, or the maximum specimen length. For optimal measurements, all of these parameters must be evaluated prior to in-situ robotic characterization. Thus, the RISES project proposed to integrate a commercial UPV system, FTS, and a robotic manipulator to evaluate minimum UPV operational parameters. 


\section{Research Approach}

\subsection{Proposed Innovations and Project Organization}

Specifically, the proposed innovations entail two non-destructive devices integrated with a force-torque sensor (FTS) and a robotic manipulator. The first is designated as the Impact Sensor (IS) system and consists of a mass-spring end-effector. The IS system incorporates the full force-time history of the impact to retrieve metrics for structural correlation. The IS system has been supported by baseline controlled strength and low-temperature analog SH testing [39]. The L-type Rock Schmidt from Proceq Inc. was the selected device for baseline testing.

The second innovation is titled the robotic UPV system. The robotic UPV system incorporates a commercial UPV system with FTS and robotic manipulator systems. Forward kinematics of the manipulators is used to extract the distance between transducers, and signal time of travel is extracted from the UPV data acquisition system. Robotic UPV system testing is supported by baseline testing on controlled strength and low-temperature analog UPV testing. The Proceq Inc. PL-200 system has been used for all testing. Furthermore, the Proceq Inc. Pundit lab is the data acquisition and sonic viewing system used for signal emission and collection.

The RISES project consisted of two teams, the mining team and the robotics team. The mining team performed baseline and low-temperature testing with the traditional NDT devices to support and advise robotic operations. Furthermore, the mining team selected specimen for robotic testing, and performed destructive testing to validate specimen parameters. The robotics team performed design, analysis, and testing operations with the robotic integrations for NDT evaluation. This work will focus on the prototypes, analyses, and experiments conducted by the robotics team.

\subsection{Specimen Procurement}

To have an adaptable and robust characterization system, it was necessary to procure specimens that envelope a greater strength range than terrestrial basalt. In addition, the rock materials selected were based on commercial and local rock quarry availability. For all systems, the rock samples consisted of limestone, chalk, and shale. Before robotic system testing all of the samples were tested with the traditional NDT and destructive systems for baseline validation and 
evaluation. The results are summarized in Table 7 (for testing details see [39]); these results confirm that the rock samples cover a vast range of mechanical properties as predicted.

For the IS system, early tests were conducted on metal, plastic, and fibrous materials that were readily available. Further IS tests used the previous test materials, and; concrete, rock, and controlled strength cement-sand materials. For the robotic UPV system concrete specimen with varying length were tested.

Table 7: Baseline Evaluation of Rock Analogs

\begin{tabular}{|l|c|c|c|c|}
\hline \hline Property & Unit & Limestone & Barnett Shale & Austin Chalk \\
\hline \hline $\begin{array}{l}\text { Number of S pecimens } \\
\text { Tested }\end{array}$ & $(-)$ & 10 & 15 & 15 \\
\hline Schmi dt Rebound & $(--)$ & $51-62$ & $41-53$ & $19-26$ \\
\hline Density & $\left(\mathrm{g} / \mathrm{cm}^{3}\right)$ & $2.60-2.77$ & $2.47-2.62$ & $1.84-2.01$ \\
\hline P-Wave Velocity & $(\mathrm{m} / \mathrm{s})$ & $5,826-7,084$ & $4,080-5,582$ & $3,026-3,611$ \\
\hline $\begin{array}{l}\text { Uniaxial Compressive } \\
\text { Strength }\end{array}$ & $(\mathrm{MPa})$ & $43-205$ & $72-127$ & $10.6-14.8$ \\
\hline \hline
\end{tabular}




\section{The Impact Sensor (IS) System}

\subsection{The IS-1}

\section{1-1 Design Approach}

Prior to impact mechanism design, FEA simulations were conducted with ANSYS software. FEA simulations investigated estimations of impact metrics (e.g. maximum force, impulse, and duration) for different materials. Explicit dynamics simulations were executed for a steel-on-steel impact and a steel-on-elastomer impact. Explicit dynamics is a suitable analysis for non-linear contact analysis, and high/low velocity impact [40].

The simplified model shown in Figure 3 was created to simulate impact with minimal boundary condition effects. The model consists of a steel projectile measuring $19 \times 25 \mathrm{~mm}$ (diameter $\mathrm{x}$ length) with a mass of $0.056 \mathrm{~kg}$. The fixed sample (to be impacted) measured $250 \times 600 \mathrm{~mm}$ in length. The projectile was offset from the sample a distance of $0.01 \mathrm{~mm}$ and supplied an arbitrary velocity of $10 \mathrm{~m} / \mathrm{s}$. To negate effects from uneven impact, the displacement of the projectile was constrained to be normal to the samples impact surface. Force and velocity probes were attached to back of the projectile to provide data for impact metric approximation.

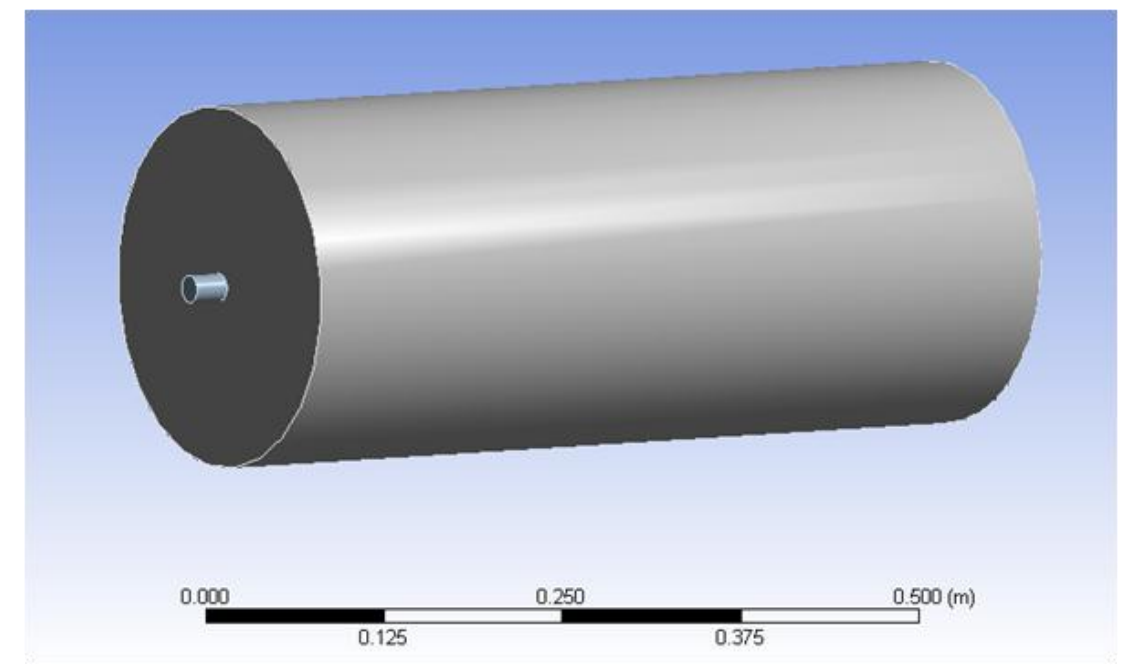

Figure 3: FEA Simulations Model Geometry 
Table 8 summarizes the results of the steel-on-steel and steel-on-elastomer FEA simulations. The impulse duration for each material was selected from the largest change in the projectile's velocity probe values. In Table 8 column 4 the average force was calculated by integrating values from the force probe date over the impulse duration. Because the average force from elastomer impact was approximately $0.19 \%$ that of the steel impact, further investigation of impact metrics via impact sensor testing was justified.

Table 8: Summary of FEA Simulation Results

\begin{tabular}{|l|l|l|l|}
\hline \hline $\begin{array}{l}\text { Sample } \\
\text { Material }\end{array}$ & Impulse, N-s & Duration, ms & Average Force, $\mathbf{N}$ \\
\hline \hline Steel & 0.433 & 0.0130 & 32,800 \\
\hline Elastomer & 0.206 & 3.35 & 61.4 \\
\hline \hline
\end{tabular}

\section{1-2 Design}

The Impact Sensor-1 (IS-1) prototype, shown in Figure 4, was designed to impact a sample with known impact energy and record the impact force-time history using a JR3 FTS. For reference, specifications for the JR3 are shown in Appendix A-1 IS-1 Technical Details. The JR3 FTS has been used for laboratory development of ARRM and satellite servicing systems. Thus, the JR3 FTS was selected to align RISES research with realistic technology used for mission development.

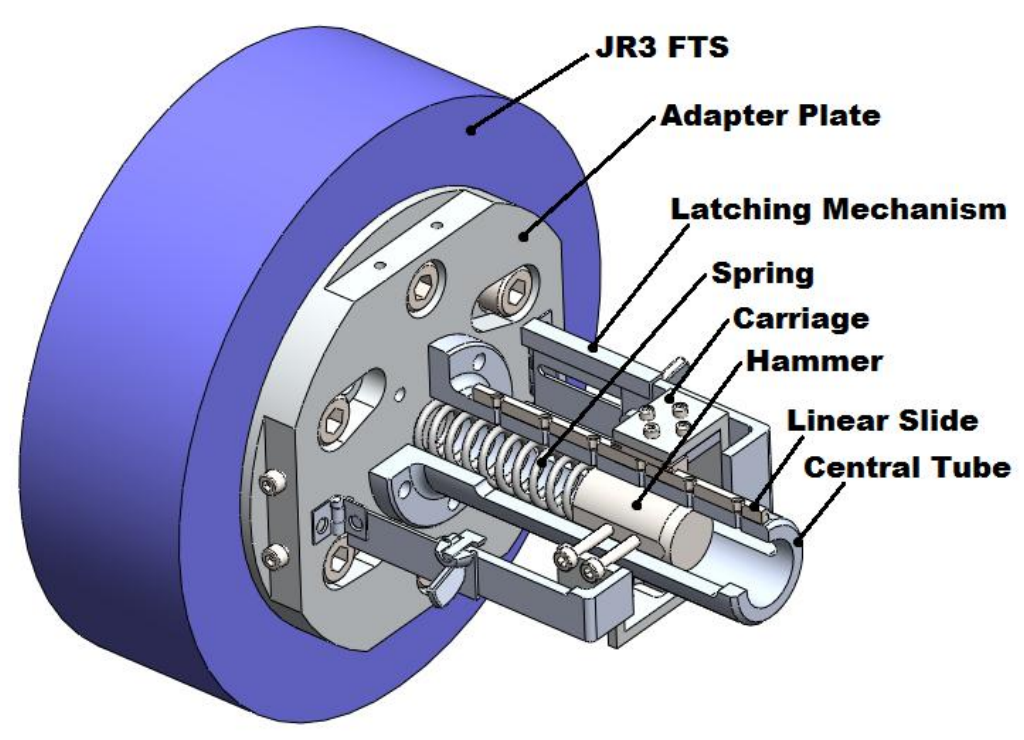

Figure 4: Conceptual Diagram of IS-1 on JR3 
The IS-1 prototype includes several components as illustrated in Figure 4. The adapter plate serves as the connection between the IS-1 and the JR3 FTS, and is used to transmit IS-1 forces to the FTS. Normal forces were recorded behind the hammer to be more analogous to probe placement from FEA simulations. The central tube houses and guides the spring-hammer mechanism, which provides the input potential energy for impact and governs the subsequent motion of the system. The selection of the spring was based on the necessary spring constant and deflection needed to reach $\mathrm{N}$ - and L-type impact energies. The carriage synchronizes the motion of the hammer to the motion of the linear slide, with minimal friction, and provides the gripping point for manual drawback of the hammer-spring system. Adjustable latches located on opposing sides of the central tube secure the carriage assembly in the desired position, and are released to initiate movement of the system.

\section{1-2 Testing}

Two tests were conducted using the IS-1 prototype. In each test, samples were impacted with N-type and/or L-type SH energy. The first test incorporated a variety of materials including: steel, aluminum, polypropylene, concrete, and pine. During this test the size and shape of the sample were not controlled. Thus, the sample boundary conditions were not consistent between materials. The second test was designed to control variance between sample materials. To control variance from material structure polypropylene, concrete, and pine from the first test were replaced with bronze and cast iron samples. To eliminate variance due to sample geometry, the second test analyzed samples of uniform shape and size. Details of the controlled variables for each test are displayed in Table 9.

Table 9: Details of IS-1 Testing

\begin{tabular}{|c|c|c|c|}
\hline \hline Test & Materials & Geometry & Impact Ene rgy \\
\hline \hline 1 & $\begin{array}{c}\text { steel, aluminum, } \\
\text { polypropylene, } \\
\text { concrete, and pine }\end{array}$ & Uncontrolled & N-Type \\
\hline 2 & $\begin{array}{c}\text { steel, aluminum, cast } \\
\text { iron, and bronze }\end{array}$ & Controlled & N-Type \& L-Type \\
\hline \hline
\end{tabular}


Testing with the IS-1 system was conducted with the West Virginia Robotic Technology Center's robotic workspace. The test procedure for IS-1 testing involved securing the IS-1system to a 7 degree of freedom (DOF) robotic manipulator, and lying the specimen on the floor. A full set up of the IS-1 test procedure is displayed in Figure 5. With IS-1 operators outside the workspace, the robotic manipulator was moved to place the IS-1 into a perpendicular position about $2 \mathrm{~mm}$ from the specimen impact surface. The IS-1 operator then entered the workspace, and ensured that the sample impact location was desirable. Force collection with the FTS was then initiated. Next the IS-1 operator drew back and latched the carriage, manually loading the mass-spring system to the desired impact energy. As soon as the system was stationary, the IS-1 operator released the latches and initiated impact. The carriage would then move with the unloading mass-spring system, directly impact the sample, and rebound. After carriage movement reached steady state, FTS recording was stopped. The specimen was moved to a different impact location, and the aforementioned impact process was repeated-for all locations and samples.

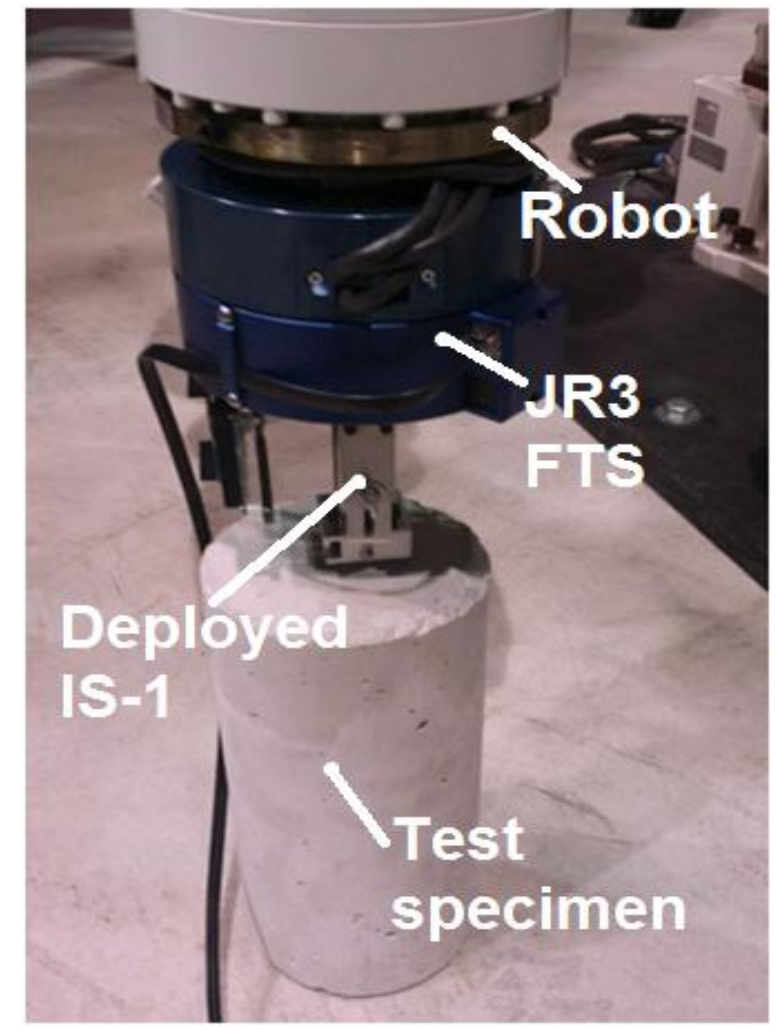

Figure 5: IS-1 Test Setup, with Concrete Specimen 


\section{1-3 Data Collection, Extraction, and Analysis Methods}

$\mathrm{C}++$ software was created to collect the data from the JR3 FTS. In addition, software used for real time force reading of the JR3 FTS was used to set the impact point at approximately 2mm spring compression. IS-1 data analysis was conducted with MATLAB. Early methods for data extraction involved user selection and interpolation of the impact force and duration. Later methods incorporated automated methods of data extraction. Specifically, the team investigated data filtering, model fitting, the root mean square between impacts, and the time between impacts. Figure 6, displays an example of the force signal components collected, specifically; the portion of the signal in the red box was the analyzed impulse. Within the red box, the data for hammer contact, impulse, and rebound are contained. The portion after the red box represents the post-impact portion of the signal - e.g. data for subsequent impacts and the motion decrement.

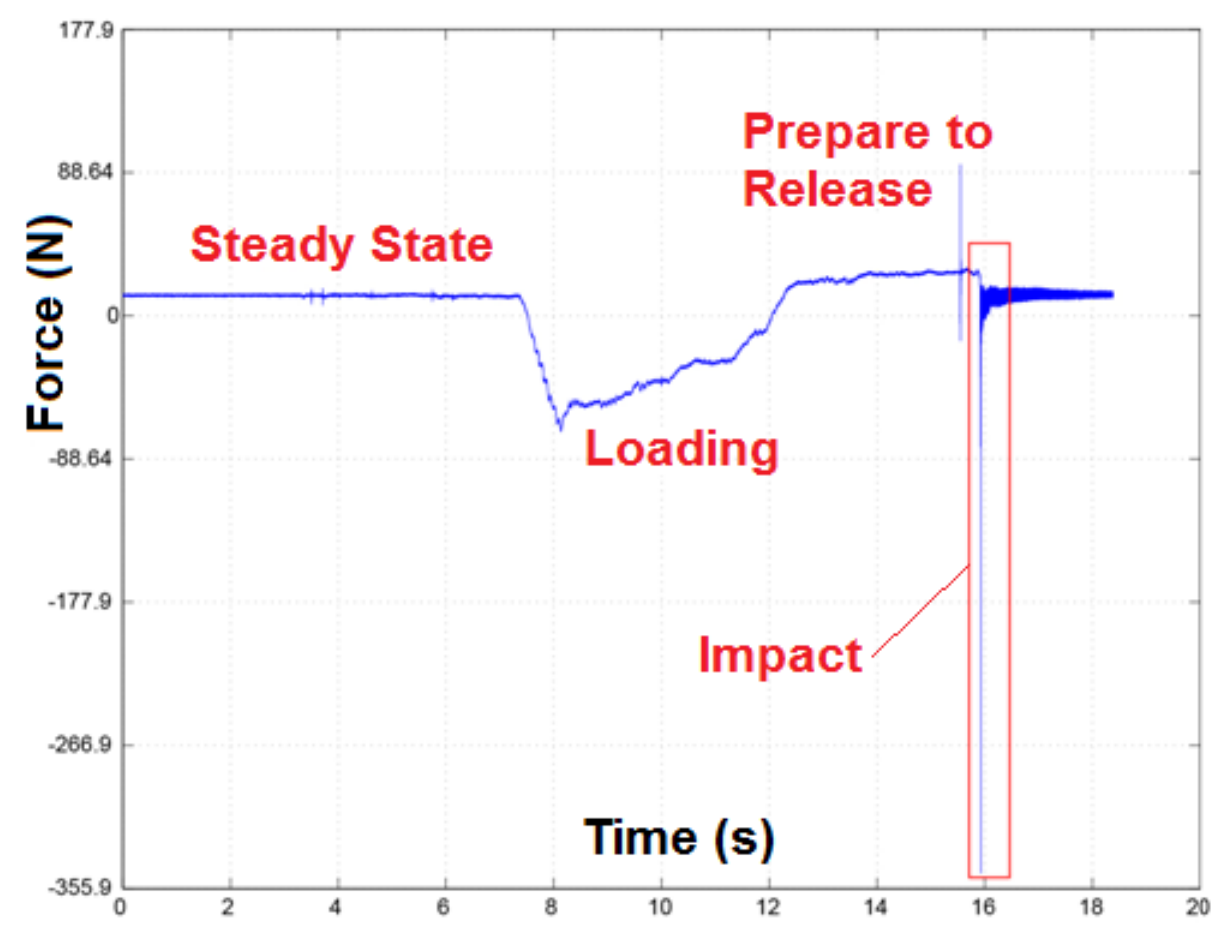

Figure 6: Example of IS-1 Force-Time History 


\section{1-4 Background of the IS-2}

Analyses of the IS-1 did not yield a distinct correlation between material and the collected metrics. For example, Figure 7 displays the maximum impact forces for each material of Test 1; the results from test 2 and other analyses yielded similar results. If the results displayed in Figure 7 were accurate, a relevant inference would be that the pine specimen was stronger than the concrete specimen. Any review of the average compressive strength for these two materials would prove this inference is unreliable. Therefore, a review of IS-1 system error was conducted. This review yielded the sources of IS-1 system error to be:

- The low FTS sampling rate

- Inconsistent hammer release

- Placement of the impact before full spring extension

- non-isolated system vibrations

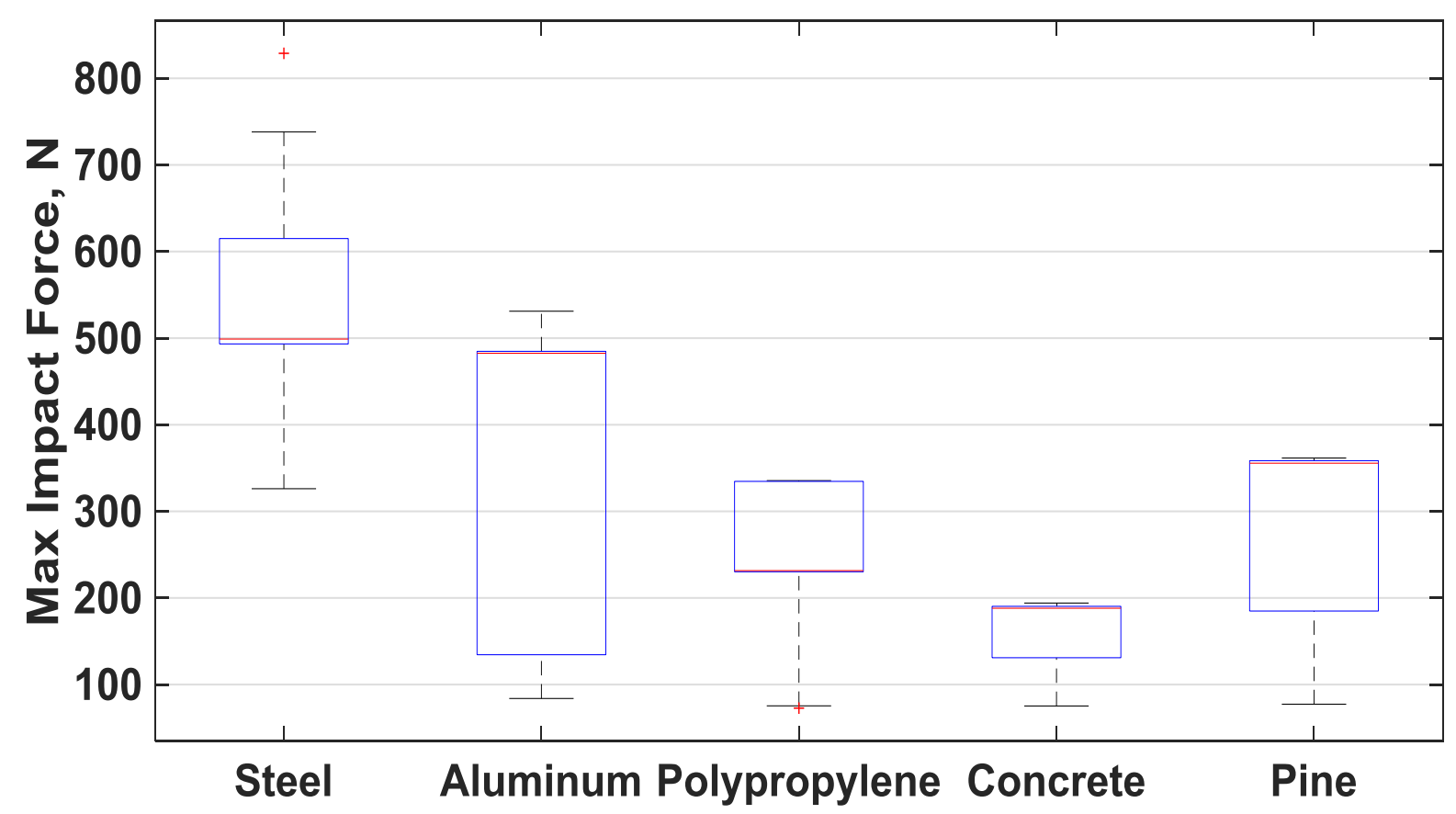

Figure 7: IS-1 Test 1, Extracted Maximum Impact Force Results 


\subsection{The IS-2}

\section{2-1 Design}

To preserve the impact sensor proof of concept, the FTS and its inherent sampling rate could not be changed. Therefore, to address IS-1 system error, the impact mechanism was redesigned. Figure 8 displays the impact mechanism redesign, titled the IS-2. The IS-2 uses the same adapter plate as the IS-1 to transmit force to the JR3 FTS interface. In contrast, the IS-2 employs a collar connected spring-hammer to create the impact. The spring-hammer mechanism is guided by a slip bearing around the central shaft. The central shaft not only guides springhammer motion, but also can be used to apply a light pre-load to secure the specimen. Specific improvements in the IS- 2 design compared to the IS- 1 are:

- Setting the location of hammer impact past the spring's resting length

- Tool release without latch delay

- Greater post impact vibrations by using the softest spring stiffness (at 332.74 $\mathrm{N} / \mathrm{m}$ ) employed

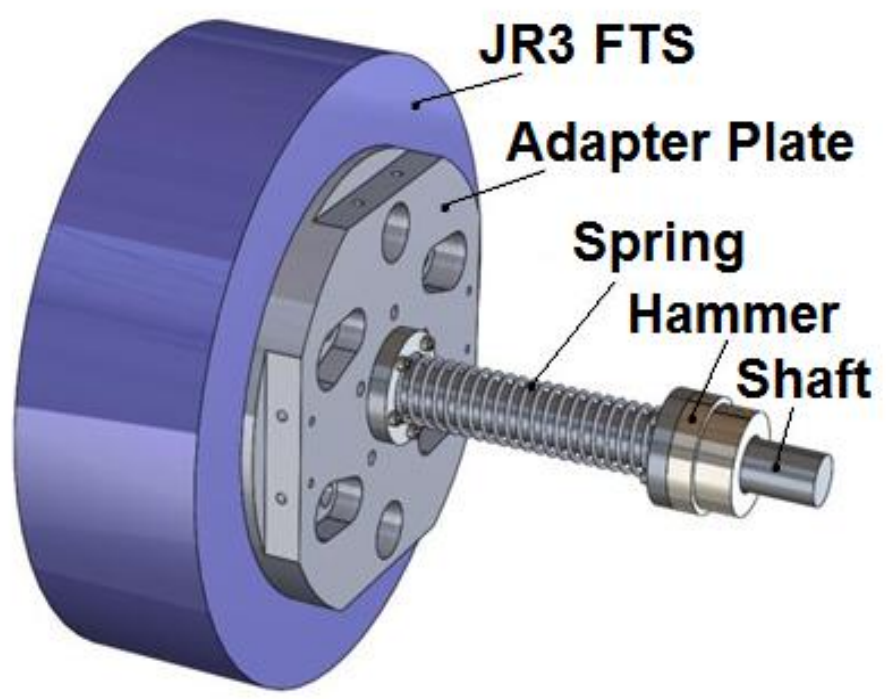

Figure 8: IS-2 Component Diagram 


\section{2-2 Testing}

The first test sought to separate materials of different strength and structure (i.e. the impact sensor proof of concept). Further tests with the IS-2 were conducted to evaluate the effects of: impact location, specimen thickness, geometry, and strength. Figure 9 displays the IS2 custom test stand, created to minimize external vibrations. In addition, the custom test stand was employed in the IS-2 robot set-up for operator pre-load control. The robot test set-up (Figure 10) was employed to evaluate the IS-2 integrated with a robotic manipulator. To preserve operator safety the robotic manipulator was inactive while using the IS-2 robot set-up. For each IS-2 test Table 10 displays the test purpose, specimen tested, number impacts, and system preload used. All tests beyond the proof of concept test used the IS-2 robot set-up.

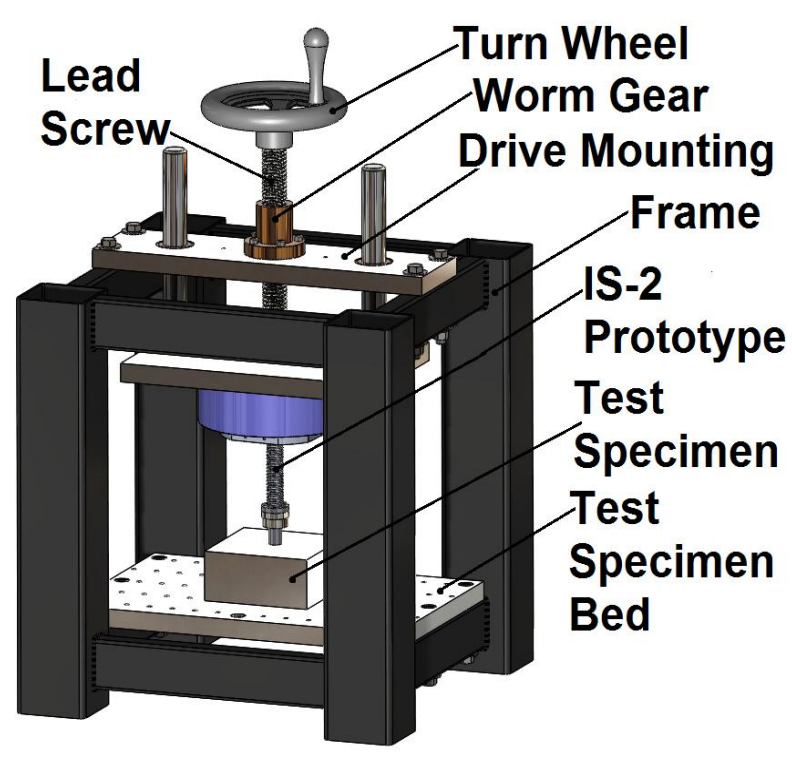

Figure 9: IS-2 Custom Test Stand Diagram

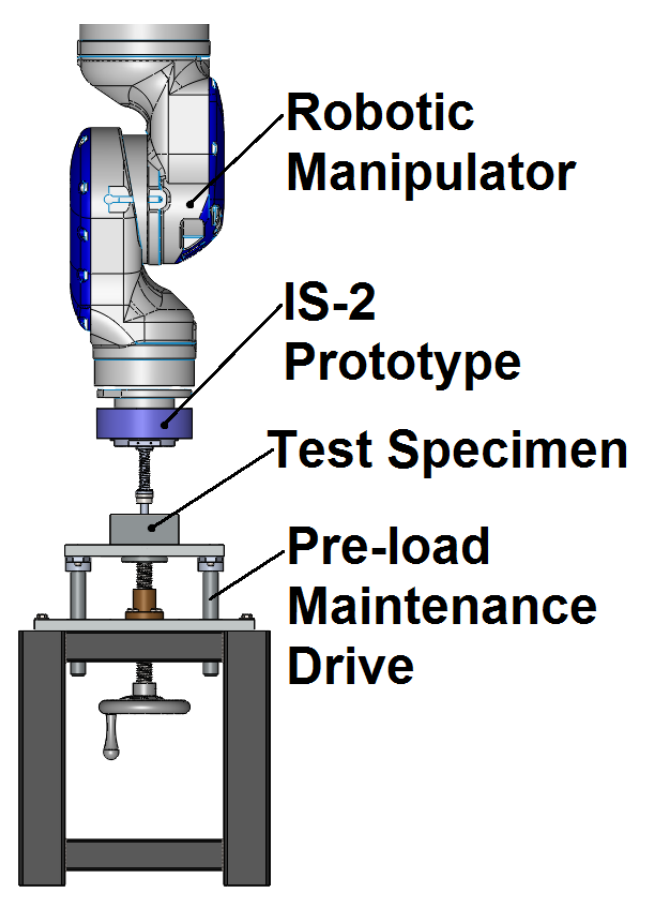

Figure 10: IS-2 Robotic Setup Diagram 
Table 10: IS-2 Testing Overview

\begin{tabular}{|c|c|c|c|c|}
\hline \hline Test & Materials Impacted & $\begin{array}{c}\text { Independent } \\
\text { Variable, } \mathbf{s}\end{array}$ & $\begin{array}{c}\text { Number Of } \\
\text { Impacts }\end{array}$ & $\begin{array}{c}\text { System } \\
\text { Preload, } \mathbf{~}\end{array}$ \\
\hline \hline 1 & pine, limestone, and steel & material & 50 & 130 \\
\hline 2 & steel & location, thickness & 20 & 130 \\
\hline 3 & aluminum & geometry & 25 & 130 \\
\hline 4 & $\begin{array}{c}\text { targeted strength concrete, chalk, } \\
\text { and shale }\end{array}$ & material, UCS & 25 & 130 \\
\hline \hline
\end{tabular}

The procedure for both IS-2 test set-ups involved, first initializing the data collection and real-time force reading JR3 FTS software from the IS-1. Then the desired pre-load was applied between the IS-2 central shaft and specimen by moving the turn wheel of the test stand drive assembly. The IS-2 operators monitored the application and maintenance of the system pre-load. The IS-2 operator then loaded the system by moving the hammer to maximum spring compaction. The hammer was then released to initialize hammer and specimen impact. When the hammer-spring system reached steady state, the previous procedures were repeated to collect the total number of impacts. After all impacts were recorded for a specimen, the JR3 FTS data collection program was terminated and all impacts were recorded to a single file. 


\section{2-3 Data Collection, Extraction, and Analysis Methods}

The C++ software from IS-1 testing was used to collect and monitor the IS-2 pre-load. The MATLAB software for the IS-2 incorporated an automated impact extraction and data analysis routine. Specifically the software isolated and extracted impact events from the FTS data with a two stage filter. The first stage scanned for impact start of impact by evaluating the differences between successive points and had a threshold of $35 \mathrm{~N}$. The second stage evaluated the standard deviation immediately preceding and following the points identified in the previous stage. If the point's post standard deviation was greater than the point's prior standard deviation by a fixed margin, a (63 ms) window following the selected impact start point was extracted (i.e. the impact shock signature). Because the IS system uses a full force-time history, several metrics can be extracted from the collected shock signals. However, four metrics were selected because

of their simplicity and similarity to SH theory. From the collected impact shock signatures the extracted metrics were:

- Maximum impact force

- Minimum impact force

- Post impact vibration magnitude

- Time between impacts (where applicable) 


\subsection{Results}

\section{3-1 Proof of Concept Test}

Figure 11 displays the relationship for the max impact force vs. post-impact vibration magnitude. Of the four metrics extracted from each material the max impact force vs. post impact vibration magnitude displayed a clear material distinction. It was clear from the proof of concept test that structurally different materials could be separated by the IS-2 post-impact response. However, result dependencies on impact location as well as specimen thickness and geometry were uncertain. Furthermore, the average compressive strength range of the selected specimen from this test is vast. Further IS-2 testing investigated if specimen with overlapping compressive strength ranges could be distinguished.

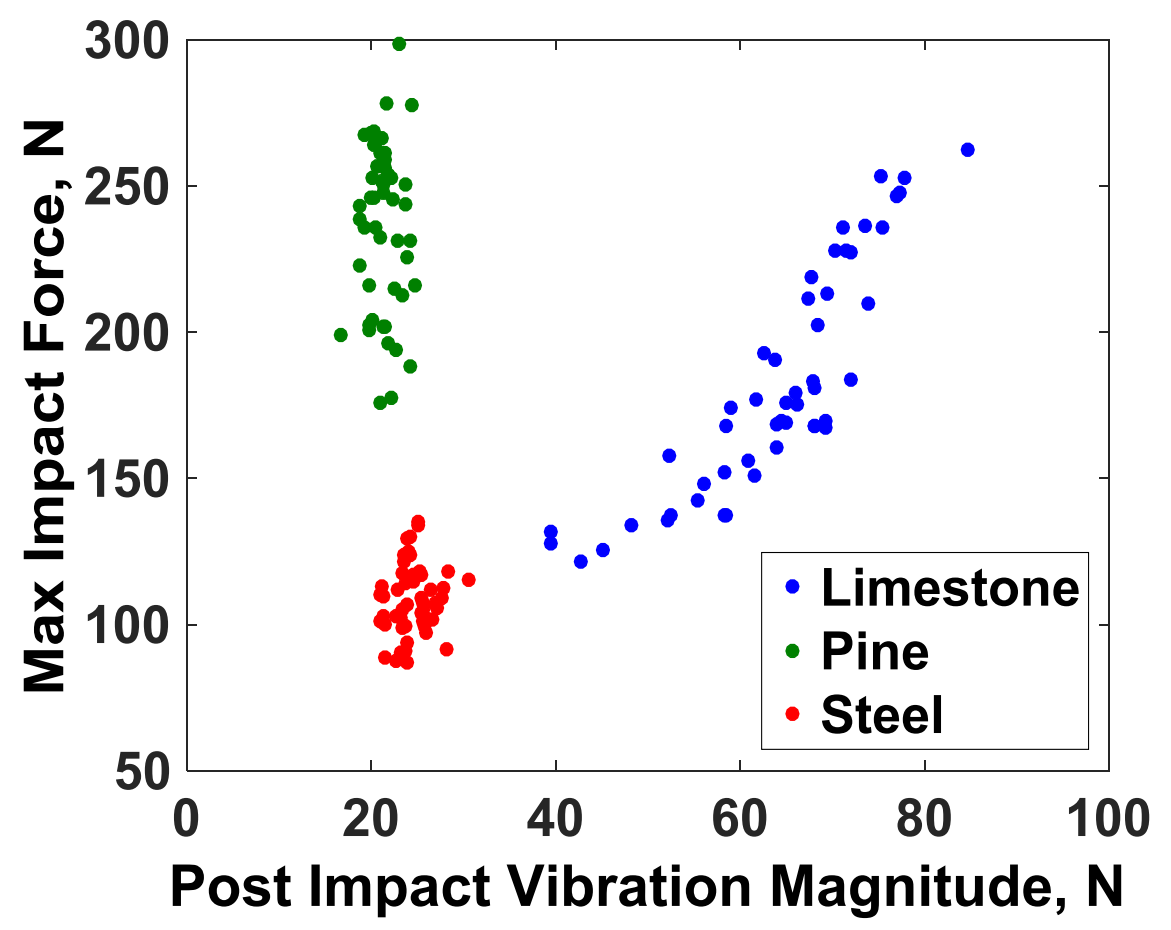

Figure 11: Proof of Concept Correlation: All Materials 


\section{3-2 Impact Location and Thickness Test}

The consistency test investigated the IS-2 system's dependence on impact location and specimen thickness. Because steel samples are used for SH calibration, the steel sample was selected for impact location and specimen thickness investigation. Figure 12 displays the six locations impacted, which were then grouped by the block orientation into the horizontal and vertical impacts.

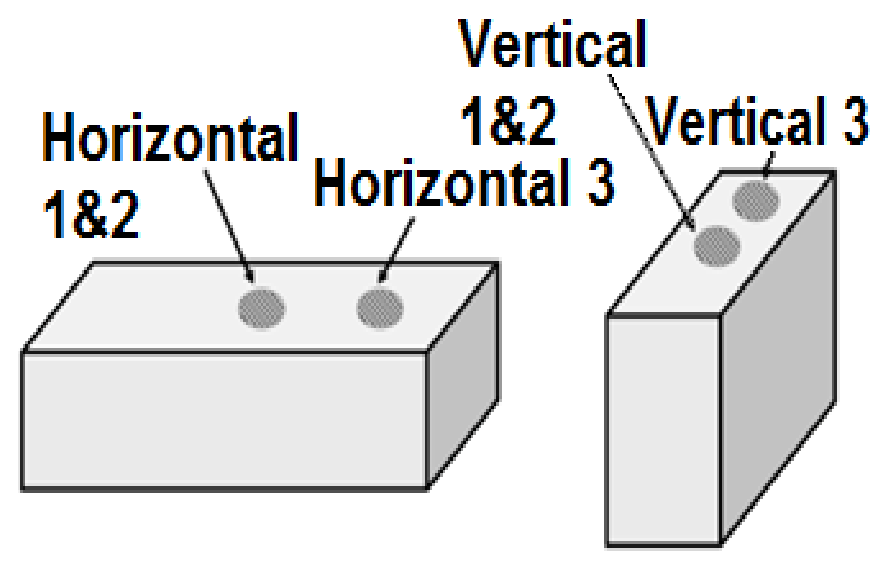

Figure 12: Impact Locations 
The varied hues of red lines in Figure 13 \& Figure 14 display the force time histories for the impacts recorded at the horizontal and vertical locations. The blue lines in Figure $13 \&$ Figure 14 display the average impact signature for limestone from the proof of concept test. There is a noticeable difference (approximately 10-15\%) in the maxima and minima of the horizontal and vertical signals. However there is a vast difference $(>20 \%)$ in the average limestone signal and steel signals in Figure 13 \& Figure 14. Therefore, IS-2 results are not grossly dependent on impact location and specimen thickness.

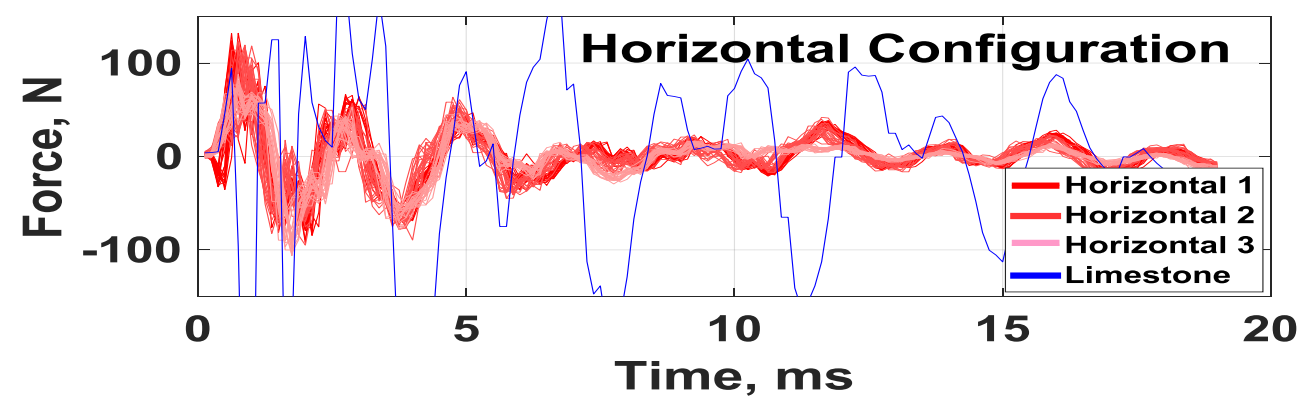

Figure 13: Horizontal F-T Histories: All Impacts Compared to Limestone

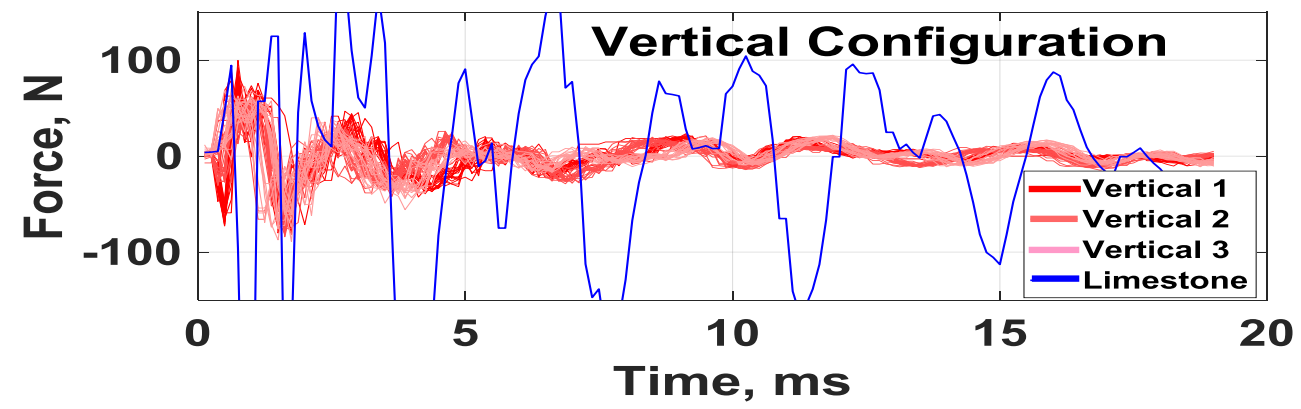

Figure 14: Vertical F-T Histories: All Impacts Compared to Limestone 


\section{3-3 Contact Geometry Test}

The effect of contact geometry on IS-2 results was not well characterized. Thus, tests were conducted to investigate the effects of contact geometry. The aluminum round and flat samples impacted during the contact geometry test are displayed in Figure 15. Figure 16(a-b) displays the full force-time histories for the flat (a.) and round (b.) contact geometry impacts. It is evident that a $\sim 20 \%$ difference exists between the round and flat impact signatures' first local minima and maxima (average signal comparison graph in A-4 Details of IS-2 Results). However comparing the FT histories to that of limestone from Figure $13 \&$ Figure 14, there is a greater than $20 \%$ difference between both geometry's impact signatures and the average limestone impact signature. Therefore, IS-2 results are not grossly dependent on impact geometry.

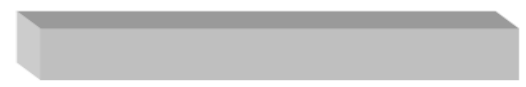

Flat

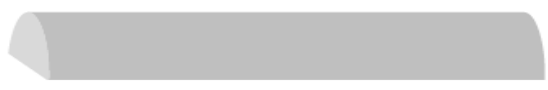

Round

Figure 15: Specimen Geometries for Contact Geometry Test
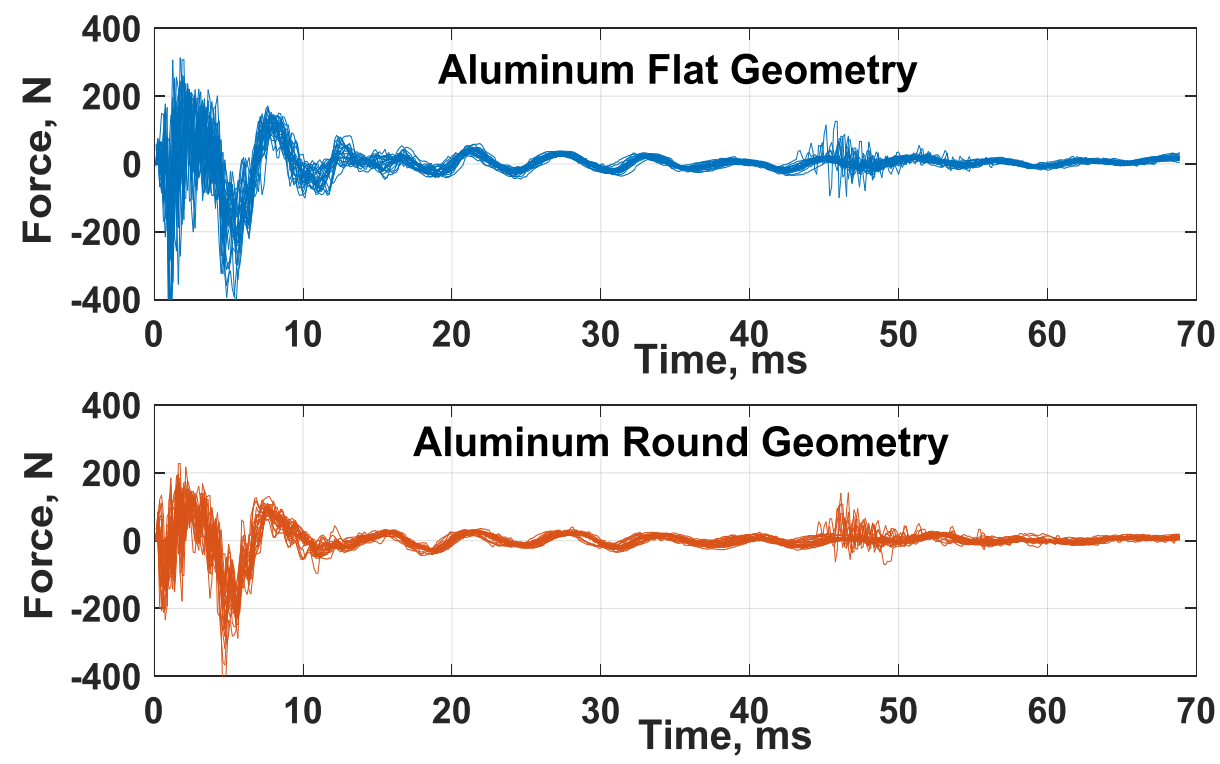

Figure 16: a.-Top) \& b.-Bottom) FT Histories of Aluminum Flat and Round Geometries: All Impacts 


\section{3-4 Refined Strength Range Test}

The final test with the IS-2 system was conducted to determine if low compressive strength materials could be differentiated. To align testing with ARRM mission objectives, rock specimen with overlapping UCS ranges were selected. Specifically chalk, and controlled strength concrete-sand analogs $(1,4$, and $5 \mathrm{MPa})$. Figure 17 displays the minimum impact force vs. the post impact vibration magnitude for all test specimens. All metrics displayed variance in averages. However, the most evident correlation between materials occurred by comparing minimum impact force and post-impact vibration magnitude. Specifically, the evident correlation in Figure 17 is that materials of greater strength have greater minimum reaction force. For validation, Table 11 displays the observed compressive strength of the specimen for comparison to the Figure 17 metrics. During this test, specimen fracture occurred on the Chalk 1 core specimen. It is possible that the Chalk 1 specimen is an outlier to the presented observed compressive strength range of chalk in Table 11.

Table 11: Material

Observed UCS Ranges

\begin{tabular}{|c|c|}
\hline \hline Material & $\begin{array}{c}\text { UCS } \\
\text { (MPa) }\end{array}$ \\
\hline \hline $1 \mathrm{MPa}$ & $0.8-1.0$ \\
\hline $4 \mathrm{MPa}$ & $0.9-4.4$ \\
\hline $5 \mathrm{MPa}$ & $4.1-5.1$ \\
\hline Chalk & $11-15$ \\
\hline Shale & $72-127$ \\
\hline \hline
\end{tabular}

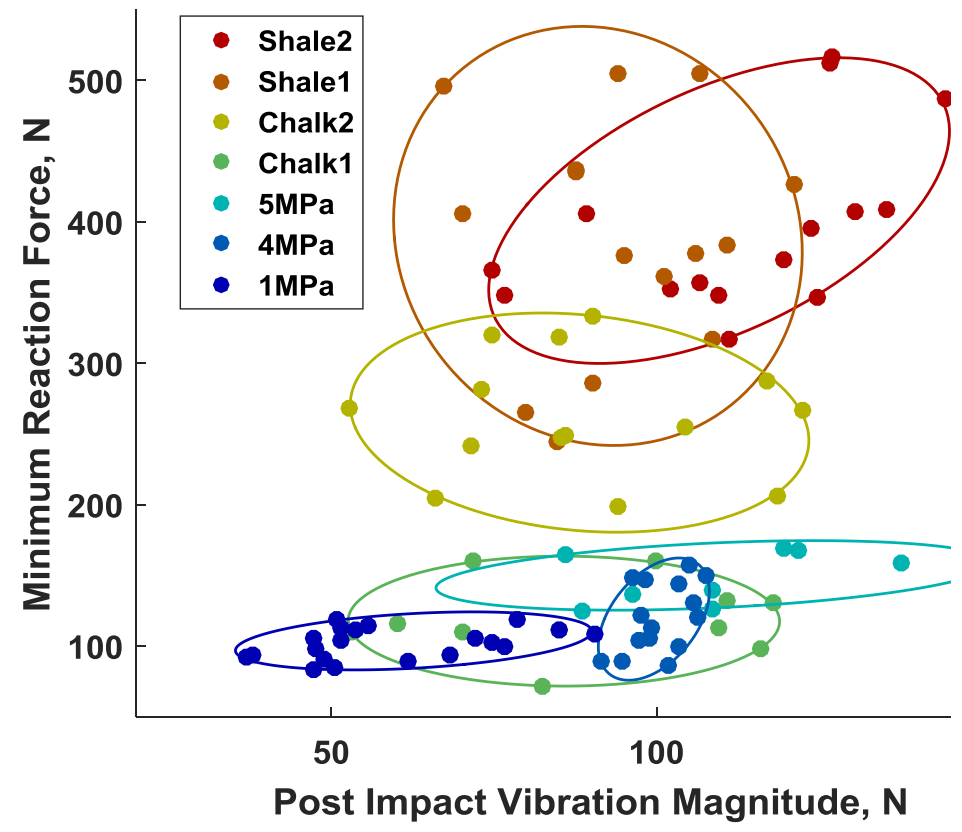

Figure 17: Refined Strength Range Test Correlation: All materials 


\section{The Robotic UPV System}

\subsection{Robotic System Integration}

In order to integrate Proceq's commercial PL-200 system for the robotic Ultrasonic Pulse Velocity (UPV) system, an adapter holder was created to house and secure the transducers. Figure 18 displays the transducer housing design, and the housing's connection to the adapter plate, JR3 FTS, and robotic manipulator.

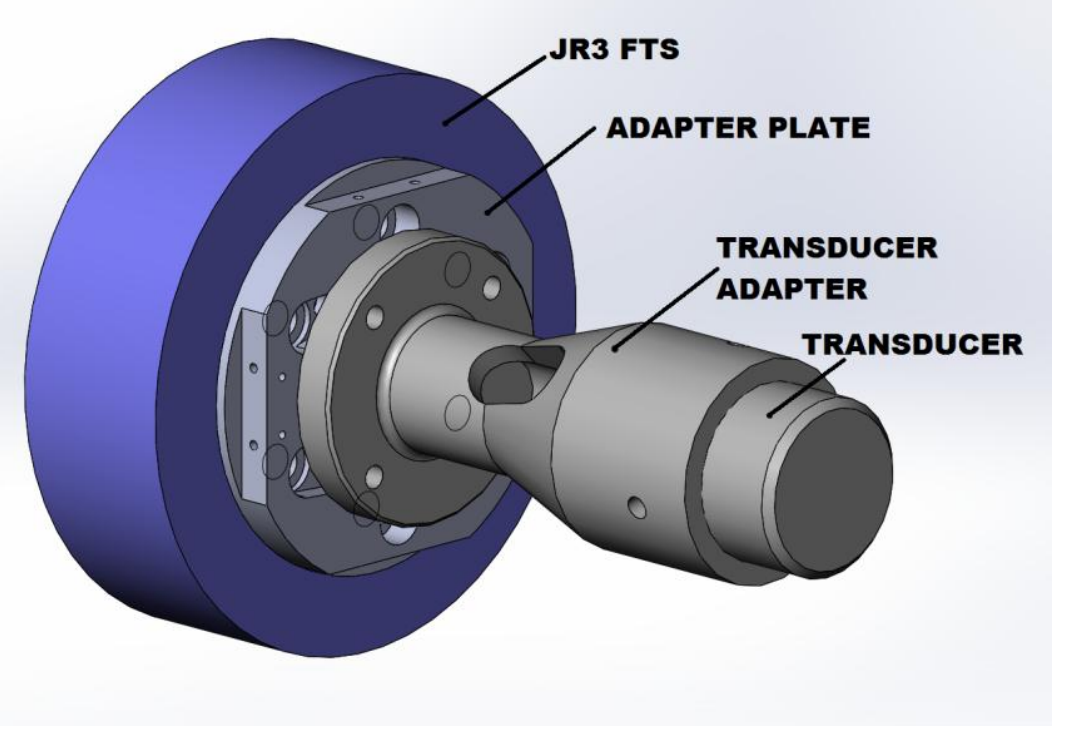

Figure 18: UPV Transd ucer Adapter Diagram

\subsection{Test Specimen}

To best align testing with ARRM mission specifications, the specimen selected for robotic UPV testing were 1,3 , and $6 \mathrm{~m}$ concrete beams - with approximately a $0.289 \times 0.289 \mathrm{~m}$ cross section. A medium strength ( 27-28MPa) commercial concrete mix was poured into the desired molds by a local concrete supplier. The concrete mix was vibrated and compacted into the molds by technicians hitting the sides of the molds with rubber mallets. For concrete to achieve its optimal strength it must undergo a curing process. After a day of open air cure for the top of the beams, burlap cloth was placed over the beam tops. The total water cure for all beams was 28 days. Each day during the water cure, at approximately the same time, water was poured over the beam tops to soak into the burlap cloth and continually water cure the beam. 


\subsection{Baseline Sample Evaluation}

Baseline testing with the PL-200 system, human operators, and coupling gel was conducted to provide values for comparison to robotic UPV testing. Signals were passed across the width of the beam $(0.289 \mathrm{~m})$ at $25 \%, 50 \%$, and $75 \%$ of the beam length (Figure 19). Four travel times were recorded for each beam location and transducer type. Equation 1 was used to calculate the UPV magnitude, with the variable P equal to the beams width $(0.289 \mathrm{~m})$. Table 12 displays the average UPV magnitude for each beam organized by transducer type. Notably, the $54 \mathrm{kHz}$ standard transducer has the largest UPV magnitudes, and the $54 \mathrm{kHz}$ Exponential has the smallest UPV magnitudes. Internal differences in transducer piezoelectric elements and uncontrolled contact conditions (e.g. pressure) are possible explanations for transducer UPV magnitude variance. The $3 \mathrm{~m}$ beam has the smallest UPV magnitudes for each transducer type. Therein, the $3 \mathrm{~m}$ is most likely the least internally consistent beam tested. The $6 \mathrm{~m}$ beam displayed the largest UPV magnitudes for each transducer type. Therefore, the $6 \mathrm{~m}$ beam is the most internally consistent beam tested. The average UPV magnitude of all beams (Table 12 column 5) varies by at most 2.8\% from each beam's average UPV Magnitude. Thus for general comparison of RISES UPV testing and baseline testing, the average beam UPV magnitude for each transducer type is sufficient.

Table 12: Baseline UPV Magnitudes

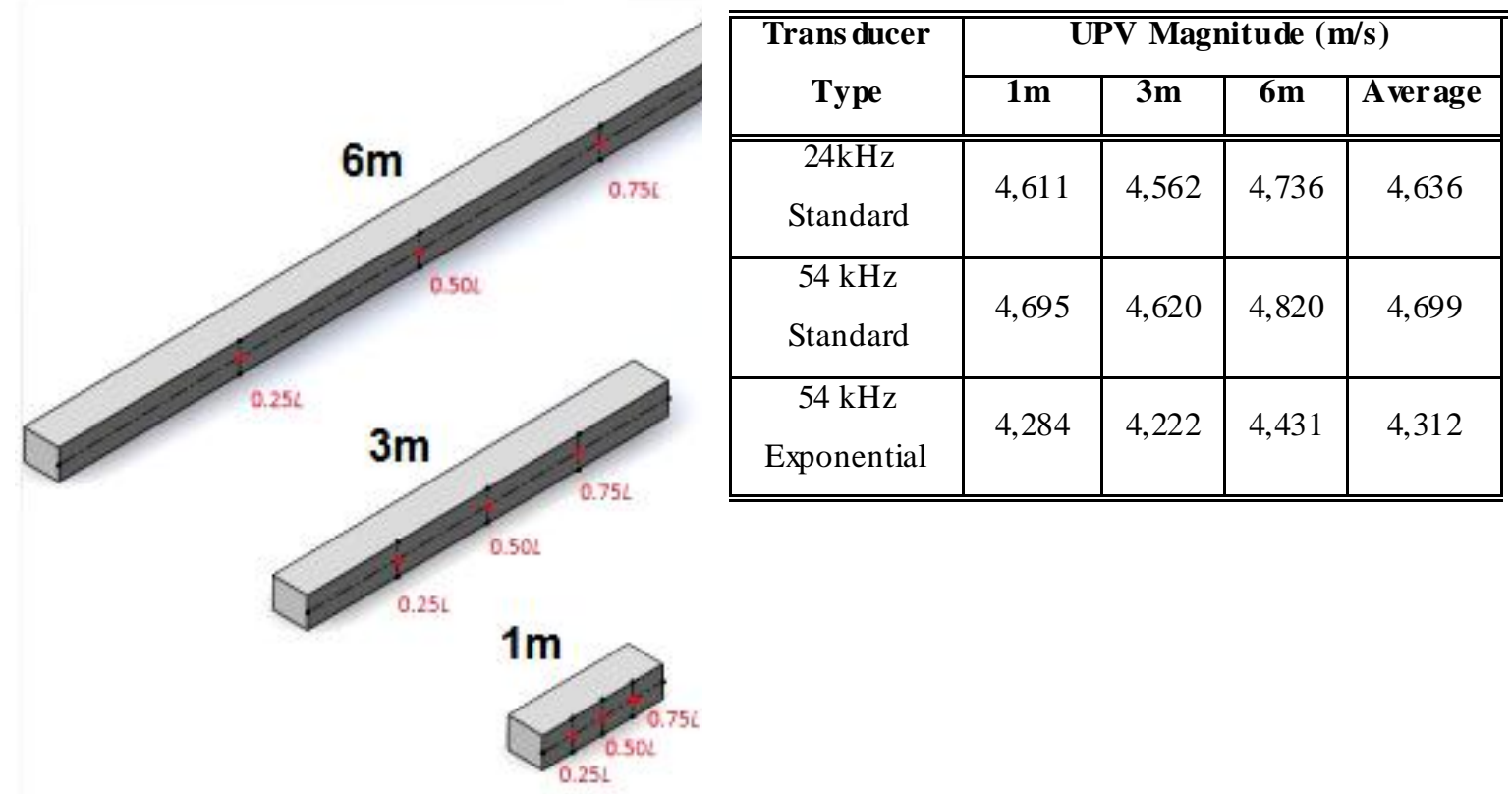

Figure 19: Baseline UPV Testing Locations 


\subsection{System Testing}

\section{3-1 Robotic System Testing}

Figure 20 displays an example of the test setup, with the $1 \mathrm{~m}$ beam, for the robotic UPV System. Due to robot workspace limitations, only one robotic manipulator was used during testing. Therein, the receiving transducer's (receiver's) horizontal location and applied force were controlled by the IS-2 custom test stand drive assembly. To control the receiver's vertical location, the IS-2 custom test stand frame was bound to a hydraulic lift. The transmitting transducer's (transmitter's) location and applied force were always controlled by the 7-DOF robotic manipulator.

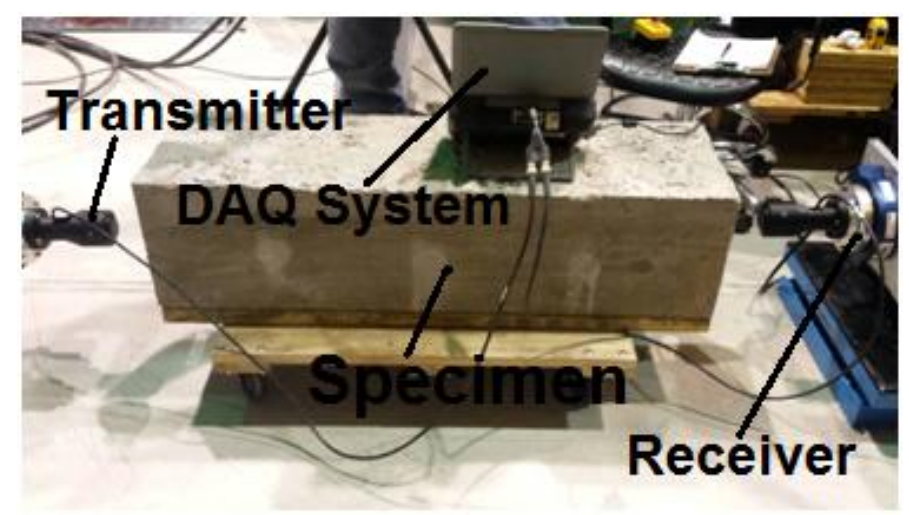

Figure 20: Robotic UPV System Test Set-Up

Two tests were conducted with the Robotic UPV system. For all beams, the first test controlled the parameters of transducer: type, applied force, and lateral offset. For each test 1 parameter, three sublevels were selected for evaluation. Table 13 displays all the selected sublevel values for the test 1 parameters. Figure 21 illustrates a concept of the standard and exponential transducer type. Compared to the standard type, the exponential type transducer has a $\sim 99 \%$ reduction in the contact interface. Because of its reduced contact interface, the exponential type transducer is recommend for UPV testing where coupling gel may not be applicable (e.g. very rough surfaces). For the 1 and $6 \mathrm{~m}$ beams, the second test varied parameters of transducer type and angular offset. Table 14 displays the values investigated for all test 2 parameter sublevels. The test 2 fixed transducer applied force (at $60 \mathrm{~N}$ ) was selected because of observations from test 1 results. For reference, Figure 22 and Figure 23 display diagrams of the test 1 lateral offset locations and the test 2 transmitter offset angle. 
Table 13: Independent Variables for Test 1

\begin{tabular}{|l|l|l|l|}
\hline \hline Parameter & Sublevel 1 & Sublevel 2 & Sublevel 3 \\
\hline \hline Beam Length $(\mathrm{m})$ & 1 & 3 & 6 \\
\hline Applied Force $(\mathrm{N})$ & 20 & 60 & 100 \\
\hline Transducer Type $(\mathrm{kHz})$ & 24 Standard & 54 Standard & 54 exponential \\
\hline Lateral Offset $(\mathrm{cm})$ & 0 & $7.6(3 \mathrm{in})$. & $10.2(4 \mathrm{in})$. \\
\hline \hline
\end{tabular}

Table 14: Independent Variables for Test 2

\begin{tabular}{|l|l|l|l|l|}
\hline \hline Parameter & Sublevel 1 & Sublevel 2 & Sublevel 3 & Sublevel 4 \\
\hline \hline Beam Length (m) & 1 & 6 & $\mathrm{n} / \mathrm{a}$ & $\mathrm{n} / \mathrm{a}$ \\
\hline Applied Force (N) & 60 & $\mathrm{n} / \mathrm{a}$ & $\mathrm{n} / \mathrm{a}$ & $\mathrm{n} / \mathrm{a}$ \\
\hline Transducer Type (kHz) & 24 Standard & 54 Standard & 54 exponential & $\mathrm{n} / \mathrm{a}$ \\
\hline Angular Offset & $0^{\circ}$ & $5^{\circ}$ & $10^{\circ}$ & $20^{\circ}$ \\
\hline \hline
\end{tabular}

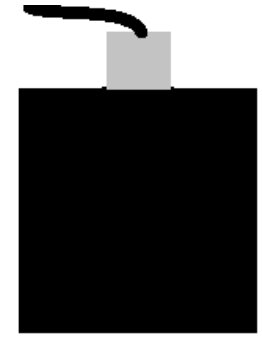

Standard Type Transducer

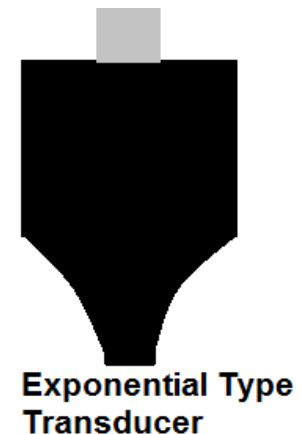

Transducer

Figure 21: Transducer Type Concept 


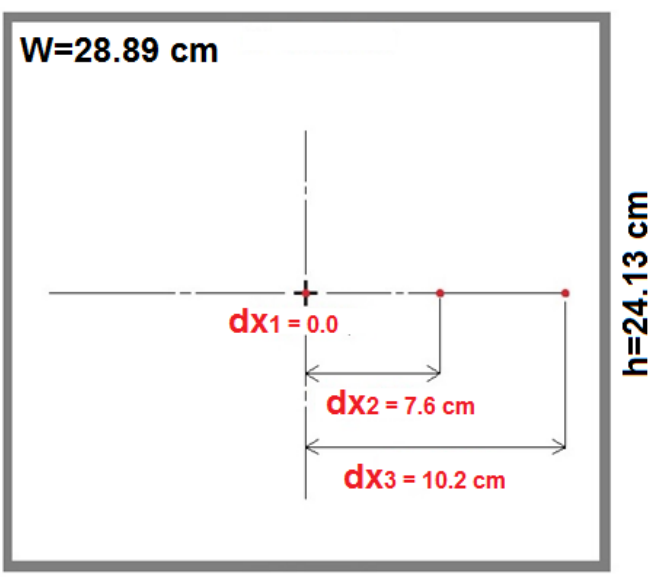

Figure 22: Test 1 Lateral Offset Diagram

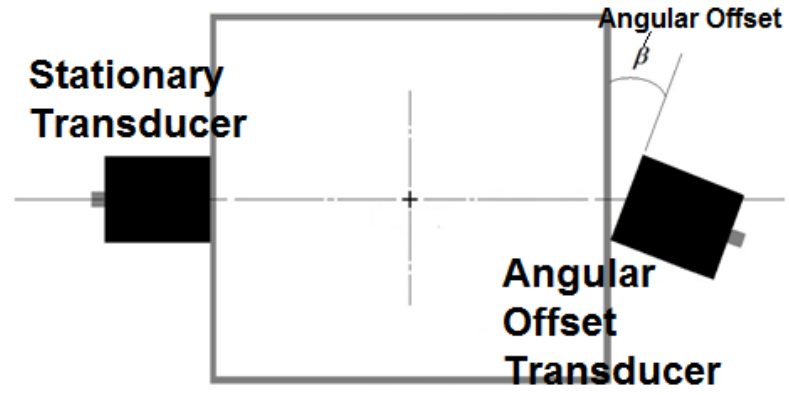

Figure 23: Test 2 Angular Offset Diagram

The following description will cover the procedure for a single test trial (i.e. the testing of one sublevel configuration for all test levels). The primary difference for a test 1 and 2 single trial procedure is the transmitter lateral and angular offset, respectively. Therefore, this procedure will simply refer to the transmitter lateral and angular offset as "desired offset."

Before any test procedural steps were conducted, transducer housings and JR3 FTSs were installed on the manipulator and IS-2 test stand. Then the desired pair of transducers were secured into their respective housings, and connected to the signal source and acquisition system - the Pundit Lab viewer. Settings in the Pundit Lab for transducer type, measurement of signal travel time, and file information were set before each trial. Next, the test specimen was placed at the desired location within reach of the robotic manipulator. Then the IS- 2 test stand was placed within reach of the beam. A Leica laser tracking device and robot spatial navigation software were used to measure and align transducer positions-respectively. To measure the start position of the receiver, the hydraulic lift of the IS-2 test stand was raised to maximum height. Next, a technician moved a laser reflector across the arc of the transducer face so a continuous measurement could establish the position of the receiver. Next, the hydraulic lift was lowered, and the receiving transducer moved into contact with the beam (this change in position due to the lowering of the lift was previously characterized using the laser tracker so that the final position of the receiving transducer is known). Because it was not applicable to space atmospheric conditions, no coupling gel was used during robotic UPV system testing. This could induce decreased wave transmittance into the sample, therein; increasing the signal travel time. 
From the laser tracking measurements and manipulator forward kinematics, the transmitter's position was aligned with the receiver's position. This alignment was referred to as "center" position, or for test 1 , " 0 " transmitter offset. With the transducers at "center," if applicable, the desired transmitter offset was applied by moving the robotic manipulator laterally (test 1) or angularly (test 2). Then the transmitter was moved into contact with the beam. Next, the initial applied force was set by a technician operating the turn wheel driven gear system. Applied transducer force was monitored on the back end of both end tools. When the test stand FTS read the desired force, the manipulator FTS was checked. Typically, the next step would involve force release or application, one drive system at a time, until both technician and robotic operator confirmed that applied transducer forces were within $\sim 5 \mathrm{~N}$ of the target value.

With both transducers at the desired offset and applied force, robotic UPV testing commenced. In essence, the Pundit Lab was run and used to manually gather three measurements - with settings at 400 volts and 10000 times gain. When all of the measurements were collected for a given offset position, the transmitter was moved, via the robotic manipulator, to the next offset. At each offset the applied transducer force and measurement processes were repeated. Each one of the aforementioned processes was repeated for each transducer set, and each beam specimen. Tests for repeatability measurement were selected at random from the test plan, and repeated after all trials with the specified transducer type.

During robotic operation and data collection, a technician remained in the robot workspace-the workspace technician. To ensure technician safety, observers and two emergency stops were used. During testing, one emergency stop resided with the robotic operator and one emergency stop resided with the workspace technician.

\subsection{Robotic UPV System Data Extraction and Analysis Methods}

For each test, exported measurement files were placed in a folder hierarchy to associate the measurement with a sublevel configuration (e.g. $20 \mathrm{~N}$ applied force (where applicable), 0 offset, and $1 \mathrm{~m}$ beam). The sublevel information for transducer type, waveform data, and measured signal travel time could be extracted from the exported files. MATLAB software 
extracted the measured signal travel times, grouped measurements by associated sublevel information, calculated UPV magnitudes, and plotted the UPV magnitudes for evaluation.

Equation 11 displays the calculation for UPV magnitude. Because a lateral offset was applied to the transmitter in test 1, distance between transducers is a relationship of average beam length (L) and lateral offset ( $\mathrm{dx}$ ). For the trials at "center" and in test 2, there was no later offset. Thus, the distance between transducers was solely the beam length for " 0 " lateral offset and all test 2 trials.

$$
U P V=\frac{\sqrt{L^{2}+\mathrm{dx}^{2}}}{T}
$$

Equation 11

Trials were randomly selected from the each test plan for repetition, and a MATLAB code was used to extract results and compute the average difference. Equation 12 displays the calculation of the average difference. In Equation 12, the original mean signal travel time $\left(\mathrm{T}_{0}\right)$ is subtracted from the repeated mean travel time $\left(\mathrm{T}_{\mathrm{r}}\right)$. The absolute value of the difference is then compared to the original signal travel time, and that value is then converted to a percentage.

$$
\% \text { Difference }=\left|\frac{T_{r}-T_{0}}{T_{0}}\right| * 100
$$

Averages for parameter configurations (e.g. $60 \mathrm{~N}$ applied Transduce r Force, 0 offset) for each transducer type and beam were calculated and compared to the average baseline value for each transducer type (Table 12 column 5). Equation 13 displays the calculation for average difference between RISES UPV system and beam short dimension UPV magnitudes. In Equation 13, the average robotic UPV magnitude $\left(U_{R}\right)$ is subtracted from the average baseline UPV magnitude $\left(\mathrm{U}_{\mathrm{B})}\right.$. The absolute value of the difference is then compared to the average beam baseline UPV magnitude, and that value is then converted to a percentage.

$$
\% \text { Difference }=\left|\frac{U_{R}-U_{B}}{U_{B}}\right| * 100
$$




\subsection{Robotic UPV System Results}

\section{4-1 Test 1}

Table 15 displays the test 1 repeatability results. Table 15 columns 2-5 display information about the repeated test. All parameter values were selected at random from the test matrix. The range of the repeated tests' average difference is $0.19-12.31 \%$. The highest average difference occurred with the $24 \mathrm{kHz}$ standard transducer. Possible sources of the $24 \mathrm{kHz}$ standard's average difference are varying contact condition and internal incons istency within the beam. On average the $54 \mathrm{kHz}$ exponential transducer displayed the lowest percent difference, and therein the highest repeatability.

Table 15: Test 1 Repeatability Information and Results

\begin{tabular}{|c|c|c|c|c|}
\hline \hline $\begin{array}{c}\text { Average } \\
\text { Difference }\end{array}$ & Beam & Transducer ty pe & $\begin{array}{c}\text { Transducer } \\
\text { Force }\end{array}$ & $\begin{array}{c}\text { Transducer } \\
\text { Alignment }\end{array}$ \\
\hline \hline $1.33 \%$ & $1 \mathrm{~m}$ & $24 \mathrm{kHz}$ Standard & $20 \mathrm{~N}$ & Center \\
\hline $3.28 \%$ & $1 \mathrm{~m}$ & $24 \mathrm{kHz}$ Standard & $20 \mathrm{~N}$ & Center \\
\hline $12.31 \%$ & $3 \mathrm{~m}$ & $24 \mathrm{kHz}$ Standard & $100 \mathrm{~N}$ & Center \\
\hline $7.40 \%$ & $3 \mathrm{~m}$ & $54 \mathrm{kHz}$ Standard & $20 \mathrm{~N}$ & Center \\
\hline $0.34 \%$ & $3 \mathrm{~m}$ & $54 \mathrm{kHz}$ exponential & $60 \mathrm{~N}$ & Center \\
\hline $0.33 \%$ & $6 \mathrm{~m}$ & $54 \mathrm{kHz}$ exponential & $100 \mathrm{~N}$ & Center \\
\hline $1.79 \%$ & $6 \mathrm{~m}$ & $54 \mathrm{kHz}$ Standard & $60 \mathrm{~N}$ & Center \\
\hline $0.19 \%$ & $6 \mathrm{~m}$ & $24 \mathrm{kHz}$ Standard & $60 \mathrm{~N}$ & Center \\
\hline \hline
\end{tabular}


Figure 24, Figure 25, and Figure 26 display the UPV magnitudes for their respective transducer type (figure title) grouped by transmitter lateral offset and beam length (black dashed lines). Figure 24, Figure 25, and Figure 26 separate measurements made on each beam specimen, respectively, by the applied transducer forces of $20 \mathrm{~N}, 60 \mathrm{~N}$, and $100 \mathrm{~N}$ with red, green, and blue points. A transmitter offset of " 0 " refers to no lateral offset. Transmitter offsets of " 3 " and " 4 " refer to 3 and $4 \mathrm{in}$. lateral offsets, respectively. The red line, in each figure, represents the the average UPV magnitude from baseline testing (Table 12).

For each transducer type Table 16, Table 17, and Table 18 display the average \% difference between the baseline beam testing and robotic UPV test 1 results. The average \% difference was calculated with Equation 13 and organized by applied transducer force, and beam length. The transmitter lateral offset was not included as an organizational parameter, because analysis of test 1 parameter mean variance (see Appendix A-8 Robotic UPV Test 1 ANOVA FTest Statistics) displayed that transmitter offset was not significantly affecting the result mean. 
For all beam lengths, Figure 24 displays a decrease in UPV magnitude as beam length increases. Conversely, the $24 \mathrm{kHz}$ transducer in all configuarations displays in Figure 24 that UPV magnitude increases as applied transducer force increases. Because all UPV values are below the baseline testing value, the difference between $24 \mathrm{kHz}$ standard transducer values and baseline results increases with increasing beam length. However, Figure 24 does not display a correlation between UPV magnitude and transmitter offset.

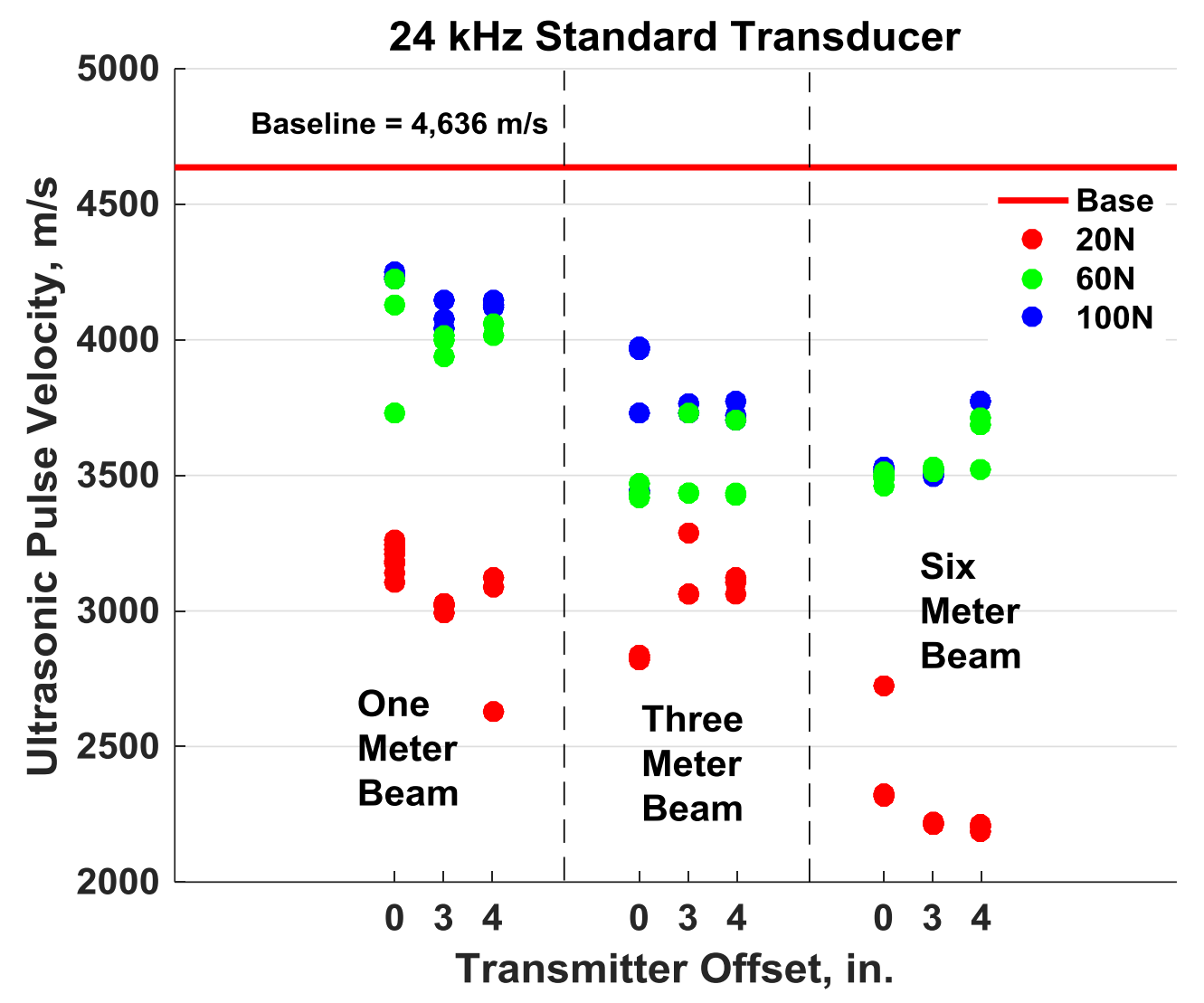

Figure 24: Test 1 UPV Magnitudes, 24 kHz Standard Transducer-All Configurations 
Table 16 displays that the average difference between the baseline and $24 \mathrm{kHz}$ standard transducer results. The average diference is greatest at $20 \mathrm{~N}$ on the $6 \mathrm{~m}$ beam. The least average difference is at $100 \mathrm{~N}$ on the $1 \mathrm{~m}$ beam. There is at most a $26.9 \%$ variance between the $20 \mathrm{~N}$ and $60 \mathrm{~N}$ Transducer force average difference values. For a single beam length, the $60 \mathrm{~N}$ and $100 \mathrm{~N}$ transducer force average differences vary by at most $4.5 \%$. Thus, it is plausible that $60 \mathrm{~N}$ minimum applied transducer force is sufficient for RISES UPV testing with the $24 \mathrm{kHz}$ standard transducer. Decreased wave transmission (i.e. lack of coupling gel) or large variance in path lengths may be the source the greater than $10 \%$ difference between baseline and RISES UPV testing with the $24 \mathrm{kHz}$ Transducers.

Table 16: Baseline and $24 \mathrm{kHz}$ Standard Results Comparison

\begin{tabular}{|c|c|c|}
\hline \hline Average Difference & Transducer Force, N & Beam Length, m \\
\hline \hline $33.10 \%$ & 20 & 1 \\
\hline $32.72 \%$ & 20 & 6 \\
\hline $50.58 \%$ & 20 & 1 \\
\hline $13.41 \%$ & 60 & 3 \\
\hline $23.91 \%$ & 60 & 6 \\
\hline $23.72 \%$ & 60 & 1 \\
\hline $10.46 \%$ & 100 & 6 \\
\hline $19.37 \%$ & 100 & 3 \\
\hline $22.31 \%$ & 100 & 6 \\
\hline \hline
\end{tabular}


Figure 25 displays a decreasing trend between UPV magnitude and beam length. Because all of UPV magnitudes are below the baseline testing value, difference in baseline and $54 \mathrm{kHz}$ standard values increases with increasing beam length. There is not a certain increasing trend between UPV magnitude and applied transducer force in Figure 25. The trend between UPV magnitude and transducer force is uncertain because, at the lateral offset " 3 " on the $6 \mathrm{~m}$ beam, the $100 \mathrm{~N}$ UPV magnitudes are less than the 60N UPV magnitudes. It is possible that the lack of coupling gel, and low pressure between the sample and transmitter interface lead to zero wave transmission. The $1 \mathrm{~m}$ beam results display a $\sim 5 \%$ decreasing trend between UPV magnitude and transmitter lateral offset. However, this trend is not observable for the $3 \mathrm{~m}$ and $6 \mathrm{~m}$ beams. When testing with the $54 \mathrm{kHz}$ standard transducer type, lateral offset appears to be less significant as beam length increases.

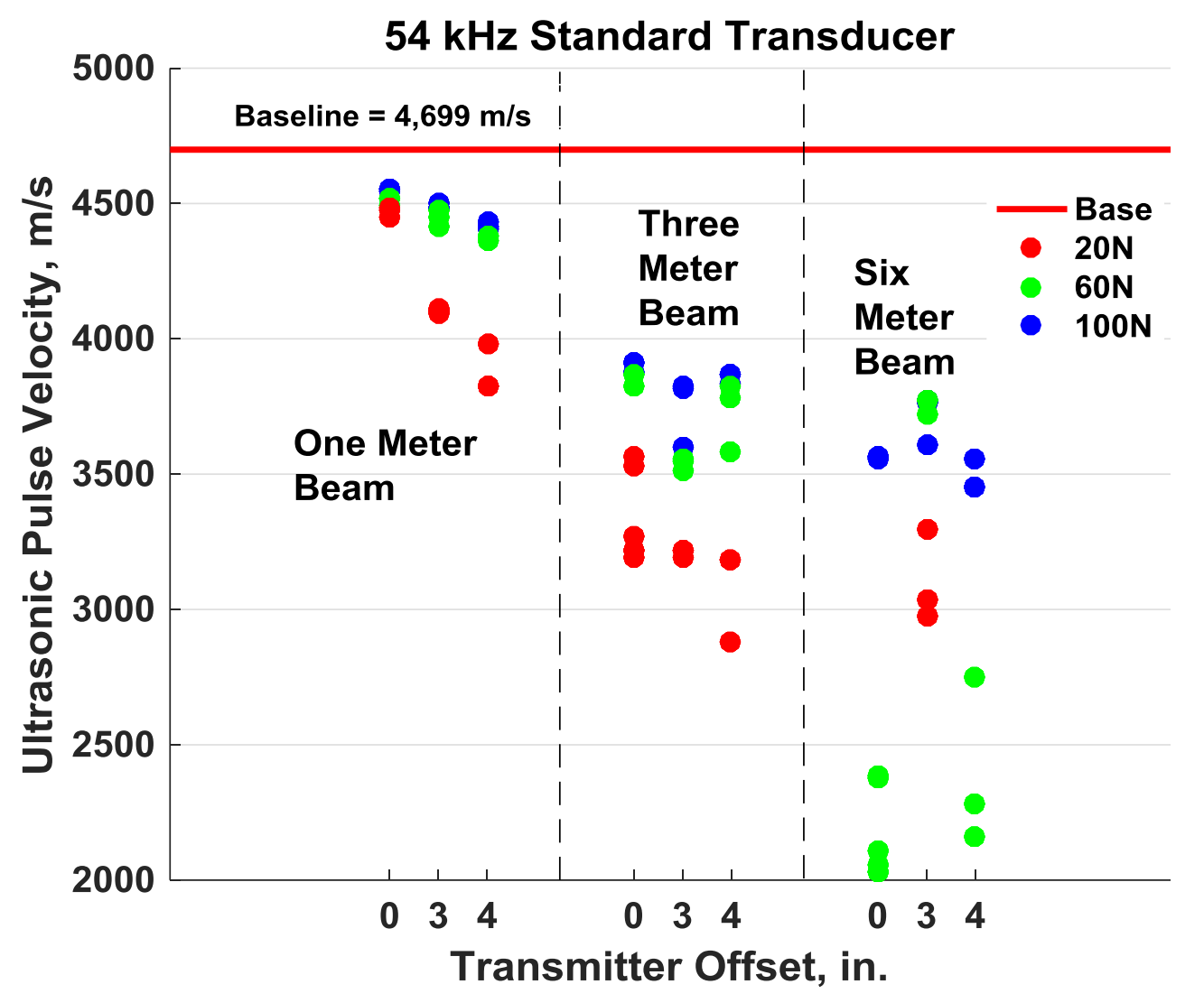

Figure 25: Test 1 UPV Magnitudes, 54 kHz Standard Transducer-All Configurations 
Table 17 displays the average difference between baseline and $54 \mathrm{kHz}$ standard UPV magnitudes. The average difference between baseline and the $54 \mathrm{kHz}$ standard results is greatest at $60 \mathrm{~N}$ transducer force and on the $6 \mathrm{~m}$ beam. It is possible that this finding is incorrect. The lack of $20 \mathrm{~N}$ values at the " 0 " and " 4 " lateral offset, on the $6 \mathrm{~m}$ beam, allude that if a value were recorded at $20 \mathrm{~N}$ it would have greater variance from the baseline results than the $60 \mathrm{~N}$ values. The smallest average difference, at $4.55 \%$, occurred with $100 \mathrm{~N}$ transducer force on the $1 \mathrm{~m}$ bea $\mathrm{m}$. Excluding the results from the $6 \mathrm{~m}$ beam, there is at most $3.6 \%$ variance in the $60 \mathrm{~N}$ and $100 \mathrm{~N}$ average differences - respective to a single beam length. There is approximately a $10.4 \%$ variance in the $20 \mathrm{~N}$ and $60 \mathrm{~N}$ average difference values for a single beam length. Thus, RISES UPV system testing with the $54 \mathrm{kHz}$ transducers produces more comparable results to the baseline testing with a minimum of $60 \mathrm{~N}$ transducer force.

Table 17: Baseline and $54 \mathrm{kHz}$ Standard Results Comparison

\begin{tabular}{|c|c|c|}
\hline \hline Average Difference & Transducer Force, $\mathbf{~}$ & Beam Length, m \\
\hline \hline $11.67 \%$ & 20 & 1 \\
\hline $33.03 \%$ & 20 & 3 \\
\hline $34.00 \%$ & 20 & 6 \\
\hline $5.27 \%$ & 60 & 1 \\
\hline $22.66 \%$ & 60 & 3 \\
\hline $44.24 \%$ & 60 & 6 \\
\hline $4.55 \%$ & 100 & 1 \\
\hline $19.07 \%$ & 100 & 3 \\
\hline $23.65 \%$ & 100 & 6 \\
\hline \hline
\end{tabular}


Similar to other transducer types, Figure 26 displays a decreasing trend between UPV magnitude and beam length with the $54 \mathrm{kHz}$ exponential transducers-for all configurations. There is not a clear trend between the $54 \mathrm{kHz}$ transducer and baseline testing results. In addition, Figure 26 displays an increasing trend between UPV magnitude and applied transducer force. With the exception of the $6 \mathrm{~m}$ beam, Figure 26 displays a similar decreasing trend between UPV magnitude and transmitter offset- for all configurations. Thus, transmitter lateral offset matters more for the $54 \mathrm{kHz}$ exponential transd ucer than other transducers.

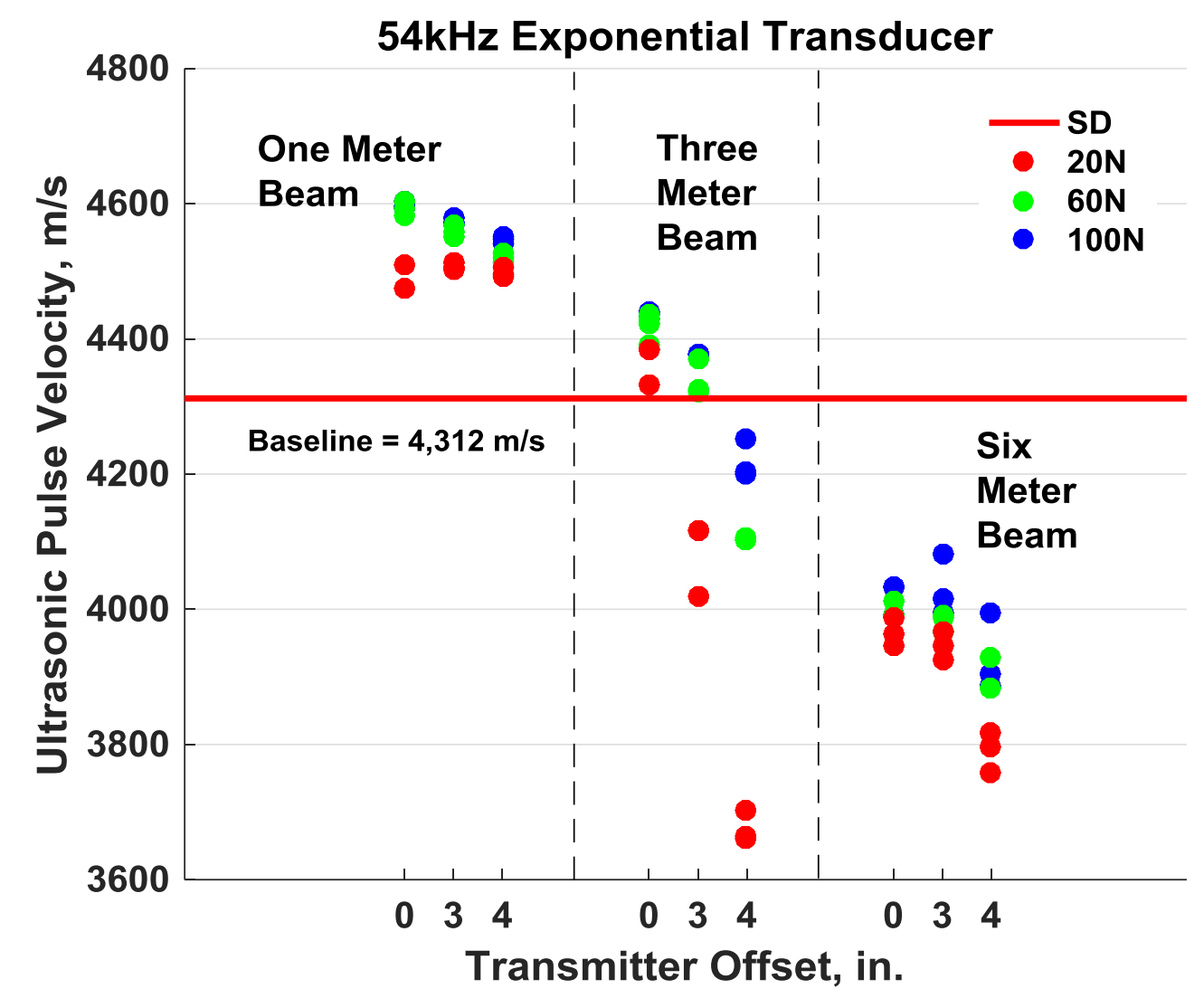

Figure 26: Test 1 UPV Magnitudes, 54 kHz Exponential Transd ucer-All Configurations 
Table 19 displays that the greatest variance between the average baseline UPV magnitude and $54 \mathrm{kHz}$ exponential transducer results occurs at $20 \mathrm{~N}$ transducer force on the $3 \mathrm{~m}$ beam. The greatest average difference most likely occurred during $3 \mathrm{~m}$ beam testing due to the effects of the 3 and 4 in. lateral offsets (Figure 26). The least average difference value occurred from trials at $100 \mathrm{~N}$ transducer force on the $3 \mathrm{~m}$ beam. When comparing the $20 \mathrm{~N}, 60 \mathrm{~N}$, and $100 \mathrm{~N}$ transducer force average differences from the baseline results, the $60 \mathrm{~N}$ and $100 \mathrm{~N}$ only vary by $\sim 1 \%$ and the $20 \mathrm{~N}$ and $60 \mathrm{~N}$ vary by $\sim 7.3 \%$. Thus, for the $54 \mathrm{kHz}$ exponential transducer a minimum applied for of $60 \mathrm{~N}$ is favorable for comparison to baseline results. The $54 \mathrm{kHz}$ exponential transducers are the only transducers to produce greater UPV magnitudes than the baseline testing. It is possible that the robotic UPV System applied higher pressures to the $54 \mathrm{kHz}$ exponential transducers than human operators can comfortably maintain. The increased pressure between the transmitter interface and sample may cause the robotic UPV system to have greater signal transmittance.

Table 18: Baseline and $54 \mathrm{kHz}$ Exponential Results Comparison

\begin{tabular}{|c|c|c|}
\hline \hline Average Difference & Transducer Force, & Beam Length, m \\
\hline \hline $4.36 \%$ & 20 & 1 \\
\hline $10.01 \%$ & 20 & 3 \\
\hline $9.54 \%$ & 20 & 6 \\
\hline $5.69 \%$ & 60 & 1 \\
\hline $2.73 \%$ & 60 & 3 \\
\hline $8.19 \%$ & 60 & 6 \\
\hline $6.05 \%$ & 100 & 1 \\
\hline $1.83 \%$ & 100 & 3 \\
\hline $7.33 \%$ & 100 & 6 \\
\hline \hline
\end{tabular}




\section{4-2 Test 2}

Table 19 displays the relevant information about the repeated tests and the results of the repeatability analysis. Table 19 column 1 displays the calculated percent difference between the average of the repeated and original test values. Table 19 columns 2-3 display information about the repeated test. Notably, the $0^{\circ}$ angular offset was randomly selected for every repeated test. All transducer types were selected for the repeated tests. The range of the repeated tests' average difference is from $0.18-17.85 \%$. On average the $54 \mathrm{kHz}$ exponential type transducer displayed the most repeatable test 2 measurements. The least repeatable measurements were obtained on the $6 \mathrm{~m}$ beam with the $54 \mathrm{kHz}$ standard transducer. The source of error in the $54 \mathrm{kHz}$ standard transducers could be inherent to the contact conditions or specimen internal consistency.

Table 19: Test 2 Repeatability Information and Results

\begin{tabular}{|l|l|r|r|}
\hline \hline $\begin{array}{c}\text { Average } \\
\text { Difference }\end{array}$ & Beam & Transducer type & $\begin{array}{c}\text { Angular } \\
\text { Offset }\end{array}$ \\
\hline \hline $3.04 \%$ & $1 \mathrm{~m}$ & $54 \mathrm{kHz}$ Standard & $0^{\circ}$ \\
\hline $15.17 \%$ & $1 \mathrm{~m}$ & $24 \mathrm{kHz}$ Standard & $0^{\circ}$ \\
\hline $0.18 \%$ & $1 \mathrm{~m}$ & $54 \mathrm{kHz}$ Exponential & $0^{\circ}$ \\
\hline $17.85 \%$ & $6 \mathrm{~m}$ & $54 \mathrm{kHz}$ Standard & $0^{\circ}$ \\
\hline $2.04 \%$ & $6 \mathrm{~m}$ & $24 \mathrm{kHz}$ Standard & $0^{\circ}$ \\
\hline $0.62 \%$ & $6 \mathrm{~m}$ & $54 \mathrm{kHz}$ Exponential & $0^{\circ}$ \\
\hline \hline
\end{tabular}

Figure 27, Figure 28, and Figure 29 display the calculated UPV magnitudes for their respective transducer type (figure title) grouped by beam length (black lines) and angular offset. The points are positioned over the respective number corresponding to their angular offset. For instance, " 5 " refers to a $5^{\circ}$ offset between the specimen surface and transducer face. The red line, in each figure, represents the average baseline UPV magnitude for each transducer type. 
Figure 27 does not display any global trends. However, within the $1 \mathrm{~m}$ beam grouping, a general decreasing trend appears between UPV magnitude and angular offset. Therefore, for shorter path lengths the transmitter angular offsets can affect the $24 \mathrm{kHz}$ standard's UPV magnitude. Also, as the $1 \mathrm{~m}$ beam angular offset increases the difference between test 2 and baseline results increases. Variation in the incidence angle of the transmitted ultrasonic wave could explain the decreased $1 \mathrm{~m}$ UPV magnitudes in Figure 27.

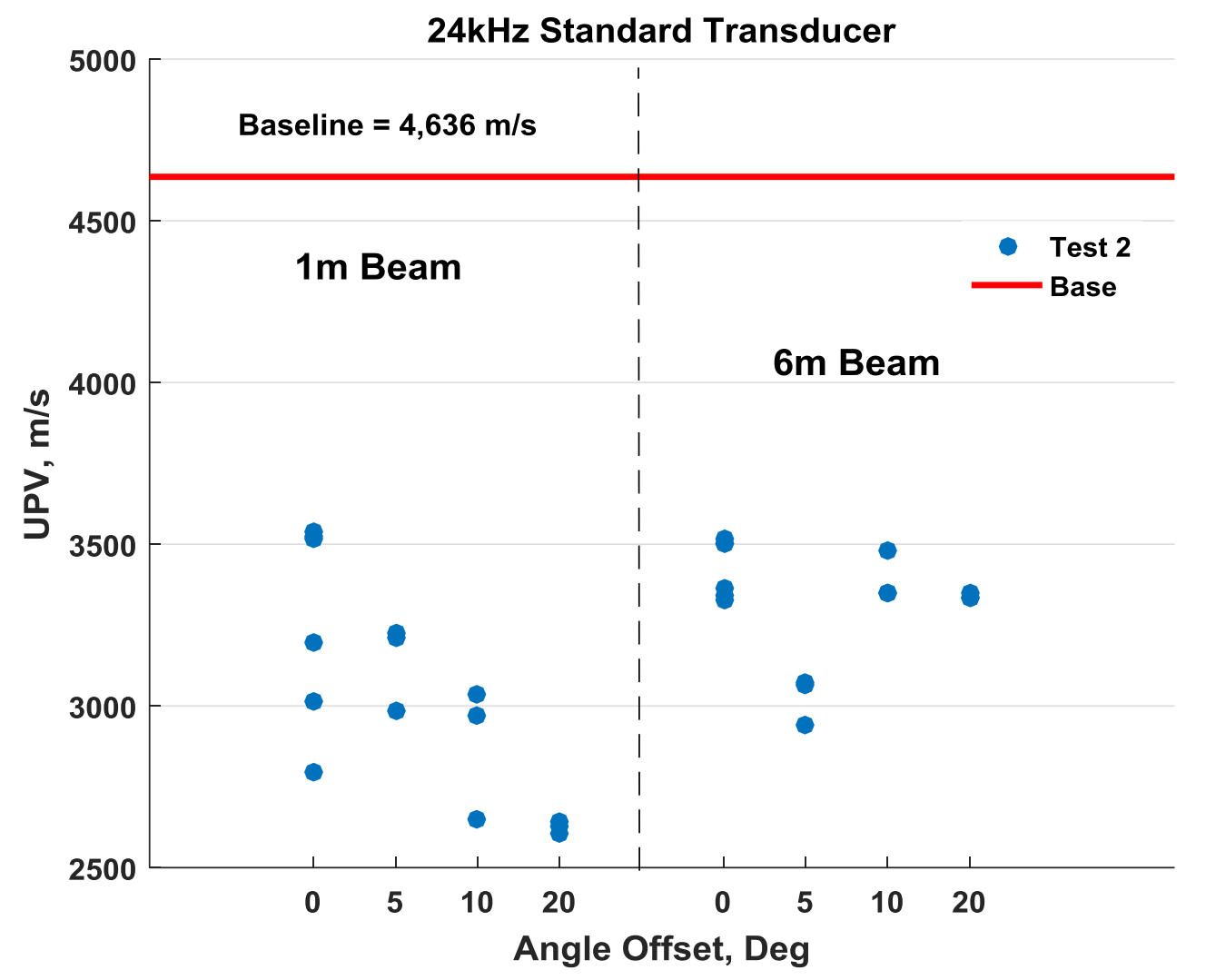

Figure 27: UPV Magnitudes for the $24 \mathrm{kHz}$ Standard Transducer: All Tested Beams 
Figure 28 displays a general decreasing trend for UPV magnitude and beam length. In addition, Figure 28 displays a decreasing UPV magnitude as angular offset increases. Thus, Figure 28 displays that the difference between baseline and $54 \mathrm{kHz}$ standard UPV magnitudes increase as angular transmitter offset increases. Note that Figure 28 does not display UPV values at the $20^{\circ}$ angular offset on the $6 \mathrm{~m}$ beam, because signals were not received. Signals on the $6 \mathrm{~m}$ beam may not have been received, because at the $20^{\circ}$ offset only the outside chamfer of the 54 $\mathrm{kHz}$ transducer was in contact with the specimen. On the $6 \mathrm{~m}$ beam, there is about a $24 \%$ mean UPV difference between the average at $0^{\circ}$ offset and increments that are greater than $5^{\circ}$. The changing incident angle of the wave transmission combined with beam wave attenuation could explain the general angular offset mean differences.

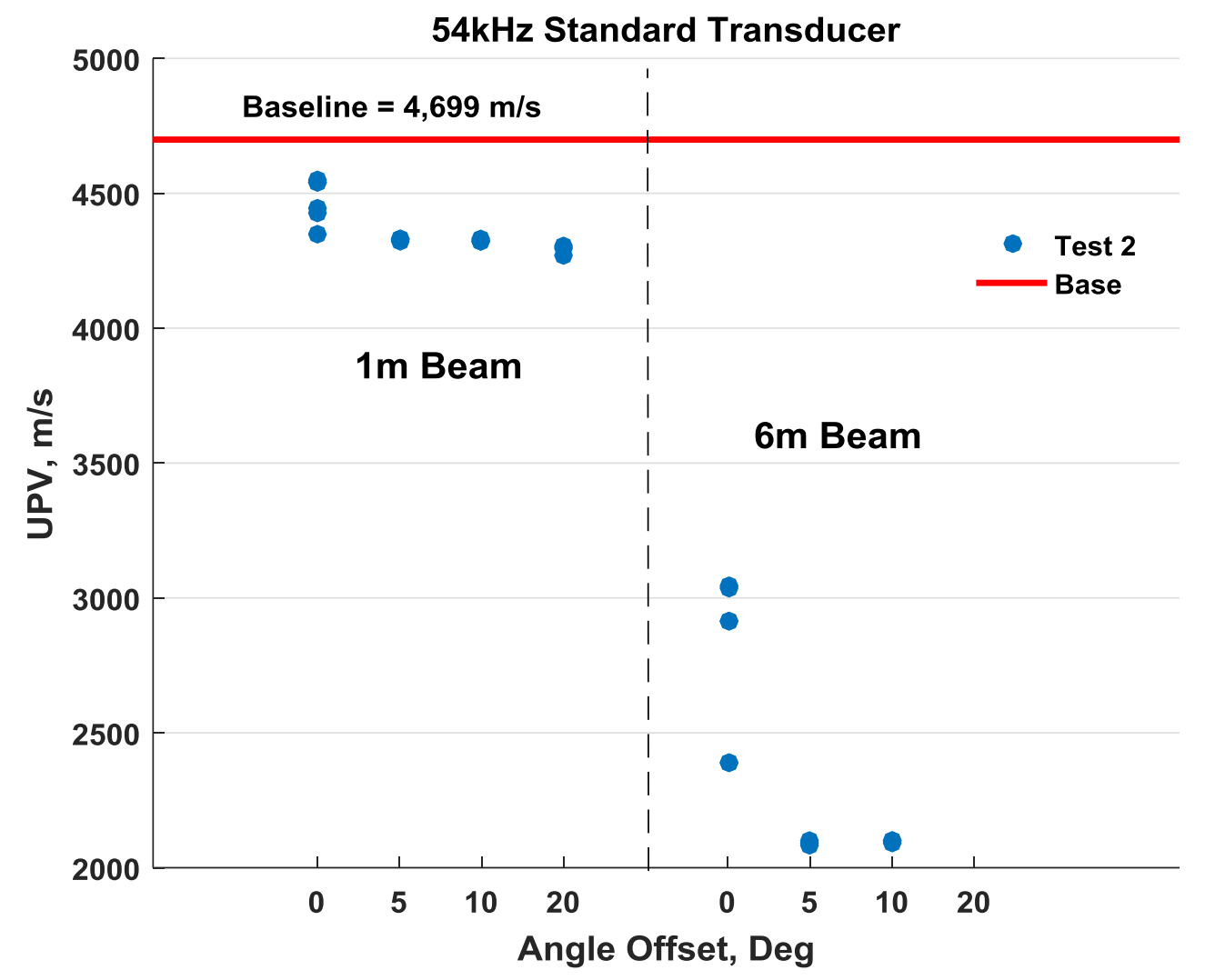

Figure 28: UPV Magnitudes for the $54 \mathrm{kHz}$ Standard Transducer: All Tested Beams 
In Figure 29 there appears to be a global decreasing trend between UPV magnitude and beam specimen. However, with the $54 \mathrm{kHz}$ exponential transducer, there is not trend between test 2 and baseline results. Within each beam specimen, Figure 29 displays a decreasing trend between UPV magnitude and angular offset. For the $6 \mathrm{~m}$ beam, the greatest decrease in mean UPV magnitude $(\sim 12 \%)$ occurs at the $20^{\circ}$ offset. The decrease in mean UPV magnitude at the $20^{\circ}$ offset could be attributed to incident angle of the transmitted wave. At angular offsets greater than $0^{\circ}$, it is possible that the focused transmitted wave takes a longer path to reach the receiver. In addition, energy is lost where the wave path rebounds against the beam free-boundaries. Thus, the disparities between the $6 \mathrm{~m}$ beam and the $1 \mathrm{~m}$ beam at angular offsets greater than $0^{\circ}$ could be explained by extended signal travel path from incident wave angle.

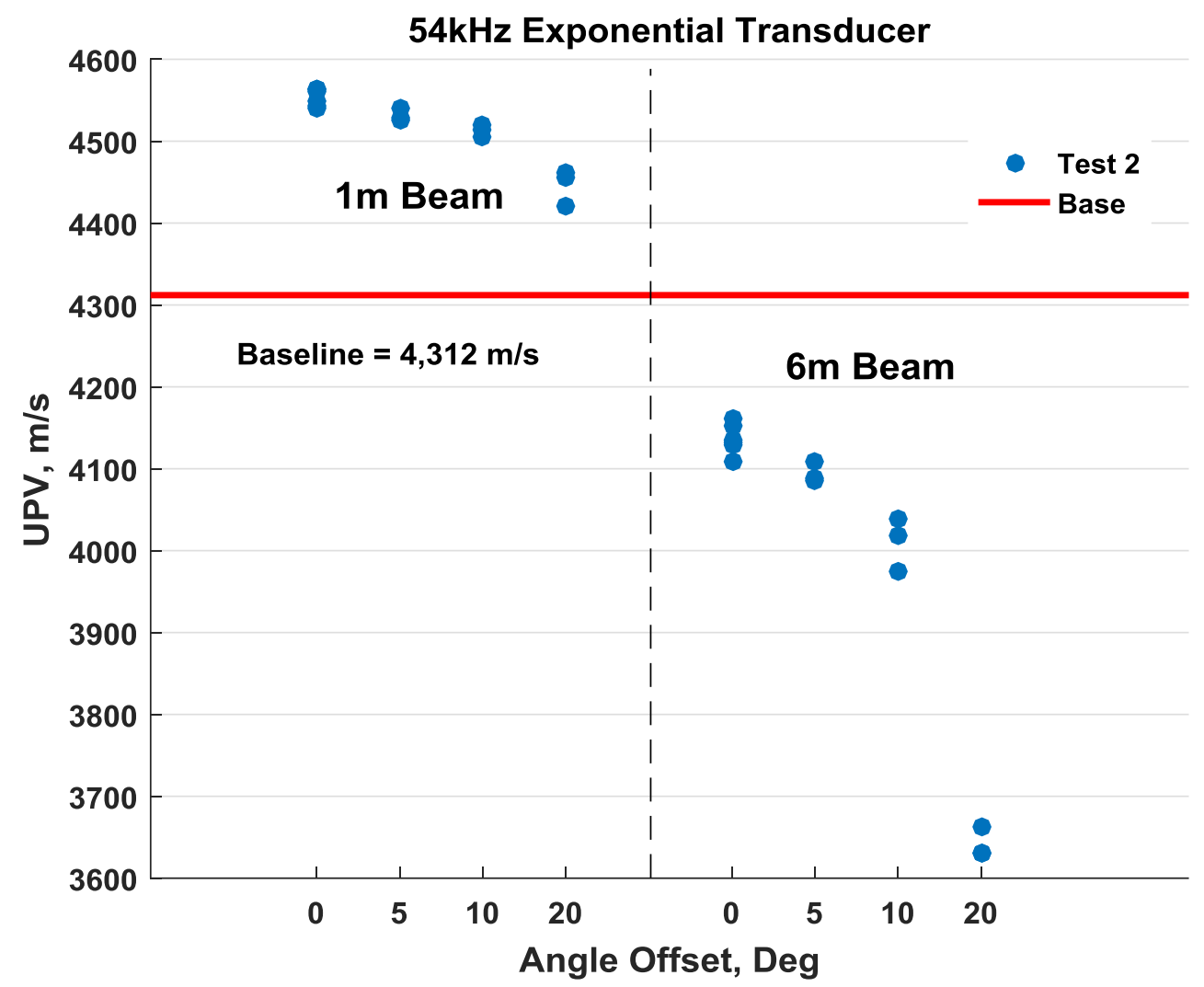

Figure 29: UPV Magnitudes for the $54 \mathrm{kHz}$ Exponential Transducer: All Tested Beams 


\section{Discussion of Results and Implications}

\subsection{The IS-2 system}

\section{1-1 Summary of IS-2 Results}

The proof of concept for the Impact Sensor system has been proven through IS-2 testing. With an impact mechanism, FTS, and 7-DOF robotic manipulator materials with different compressive strengths are distinguishable from IS-2 data correlations (Figure 11 \& Figure 17). In addition IS-2 results are not adversely affected by impact location, specimen thickness, or contact geometry (Figure 13, Figure 14, and Figure 16). For further result details on all IS-2 tests, see appendix (A-2 Further IS-1 Results).

It may be concerning to see that maximum or minimum impact forces recorded with the IS-2 are, at times, greater than $200 \mathrm{~N}$. Thus, it must be noted that IS-2 force metrics are essentially instantaneous and impart less than 0.08 Ns impulse to the system. However, all IS-2 metrics could be greater. There is missing information in all IS-2 result force-time histories, because the JR3 FTS is under sampling the data. The graph of the numbered limestone impacts from the proof of concept test, in Appendix A-4 Details of IS-2 Results, alludes that there is nonsequential variance for all impacts taken at a single location. Common knowledge would lead one to believe that a trend should occur from multiple impacts at one location. Thus, missing information from under sampling is a possible explanation of greater than $20 \%$ metric variance at a single impact location.

\section{1-2 IS-2 Operational Parameters}

To achieve further meaningful results operational guidelines for the IS-2 must be established. Relevant parameters and suggested standards specific to IS-2 test trials are displayed in Table 20. Regarding the system pre-load, data outliers occurred when the applied load from the central shaft decreased by greater than $40 \mathrm{~N}$ following impact. It is recommended that the preload be set at a minimum of $130 \mathrm{~N}$, and reapplied whenever a preload decrease greater than $40 \mathrm{~N}$ occurs. 
While Schmidt Hammer theory provided the basis for the IS-2 methodology, the IS-2 system is not a Schmidt Hammer (SH). Thus, it should be noted that IS-2 testing deviates from ASTM and ISRM recommended SH guidelines. The greatest IS-2 deviation from SH ASTM and ISRM recommendations is the standard of 20 repeated impacts per location. To avoid variance from micro-structural destruction, ASTM and ISRM SH guidelines suggest taking at least 10 impacts at separate locations [34][36]. However, the impact location and thickness test results (Figure 13 \& Figure 14) display that repeated impact locations vary by less than $10 \%$. In addition, the graph of numbered limestone sequential impacts (in Appendix A-4 Details of IS-2 Results) displays that a correlation does not exist between metric variance and repeated impacts. Thus, multiple repeated impacts with the IS-2 can be performed without invalidating material metric correlations.

To minimize frictional forces and maximize input gravitation potential energy in the mass-spring system, the orientation of the IS-2 impact mechanism was always vertical—with little to no deviation. For optimal results further ground testing of the IS-2 system should ensure that the IS-2 impact mechanism's orientation is vertical. Finally, the drawback of the IS-2 system by manual operator involved minimizing any non-vertical loads and consistently drawing the system back by a two point grip. Thus, for comparable results, any autonomous IS-2 drive device must possess a dual contact point drive system that minimizes lateral input forces. In addition, any IS-2 drive system cannot add mass or additional vibrations to the IS-2 impact mechanism. For reference, a suggested IS-2 drive system concept is provided in Appendix (A-5 IS-2 Autonomous Drive Concept).

Table 20: IS-2 Operational Stand ards

\begin{tabular}{|c|c|}
\hline Parameter & IS-2 Standard \\
\hline Pre-load & $\begin{array}{c}\text { 130N minimum should be applied and } \\
\text { maintained }\end{array}$ \\
\hline Number of Repeated Impacts & 20 minimum \\
\hline Impact Mechanism Orientation & Vertical \\
\hline Mass-Spring Loading & $\begin{array}{l}\text { The device should be loaded with a two point } \\
\text { grip and minimal lateral forces. Then, at the } \\
\text { solid length of the spring, the grip should be } \\
\text { released simultaneously. }\end{array}$ \\
\hline Data Analysis & $\begin{array}{l}\text { A multi-dimensional generalized regression } \\
\text { neural network is suggested }\end{array}$ \\
\hline
\end{tabular}


Due to the deviation in standards, and missing impact information it is imprudent to directly compare the Schmidt Rebound number and IS-2 metrics. Comparing the Schmidt Hammer and IS-2 methodologies, the advantage of the IS-2 is that a multitude of metrics can be extracted from a force-time history. Within this thesis, two-dimensional correlations were displayed to fundamentally validate the IS system proof of concept. However, all extracted metrics with the IS-2 system provide material correlations. Thus, a multi-dimensional algorithm is beneficial to increase IS-2 accuracy. For increased accuracy with high dimensions of data, a generalized regression neural network (GRNN) is optimal. The GRNN, in parallel, maps multidimensional spaces from higher to lower dimensions. The mapping or estimation accuracy is governed by the data used to train the network. The GRNN's estimation becomes more accurate as the training data set becomes larger. Thus, the IS-2's multitude of metrics is optimal for use in a GRNN, because it can provide more than sufficient training data for the network. Furthermore the GRNN neural network "learns" in one pass, making it a "fast learning neural network." Fast learning neural networks will be more advantageous for an autonomous robotic system, because it reduces computational cost. The simple GRNN has four layers: input, pattern, summation, and estimation output - with several "neurons" to estimate the output [41].

If the simple GRNN structure was applied to IS-2 data analysis, it would have several pattern and summation "neurons" to estimate the material and/or UCS. In essence, every pattern "neuron" can either be a mapping of IS-2 metrics to material or UCS. The summation layer, with weighted adjustment parameters, would then create an estimation of the output from the combination of all "neurons" [41]. In addition, it is possible that multiple pattern and summation layers could be developed to first classify the IS-2 input data into a material type, and then approximate a UCS with the following layers. Therein, the development of a GRNN for IS-2 results would increase estimation accuracy from IS-2 results. 


\subsection{The Robotic UPV System}

\section{2-1 Robotic UPV System Results Summary}

Test 1 results (Figure 24, Figure 25, and Figure 26) displayed that for all transducer types, and most trials, UPV magnitude decreased with increasing beam length. This trend is most likely a result of lost wave energy from compounding ultrasonic signal interference (i.e. attenuation). For most test 1 trials, UPV magnitude increased as transducer force increased. A general trend was not found between UPV magnitude and transmitter offset. Four-way ANOVA analysis (in Appendix (A-8 Robotic UPV Test 1 ANOVA F-Test Statistics)) performed on the Test 1 results displayed that the transducer type, transducer applied force, and beam length parameters affected UPV magnitude average. Therefore, test 1 validated that a robotic system with approximately a 4in. misalignment will not significantly affect UPV magnitude. Some signals with the $54 \mathrm{kHz}$ standard transducer were not received at $20 \mathrm{~N}$ applied transducer force. The results of Table 16, Table 17, and Table 18 displayed that the average difference between Test 1 and Baseline results was essentially the same for force intervals of $60 \mathrm{~N}$ to $100 \mathrm{~N}$, but more variant for intervals of $20 \mathrm{~N}$ to $60 \mathrm{~N}$. Furthermore, because force was identified as a significant test parameter, an approximate applied transducer force of $60 \mathrm{~N}$ is suggested for robotic UPV system operation. The test 1 repeatability analysis displayed that the $54 \mathrm{kHz}$ exponential transducers were the most repeatable (Table 15). In addition, the least average difference between baseline and test 1 UPV magnitudes were attained from $54 \mathrm{kHz}$ exponential transducer measurements. Test 1 validated the proof of concept that a robotic UPV system can receive ultrasonic signals over the full specimen size range specified for ARRM [2].

The minimum $60 \mathrm{~N}$ applied transducer force was applied to all test 2 trials. Test 2 results (Figure 27, Figure 28, and Figure 29) displayed a general decreasing UPV magnitude between the $0^{\circ}$ and $5^{\circ}$ angular offsets. At angular offsets greater than $5^{\circ}$, only the $54 \mathrm{kHz}$ exponential type transducer displayed decreasing UPV magnitude as angular offset increased. This trend is most likely due to a longer wave path, caused by the wave's incident transmission angle. Contact between the $54 \mathrm{kHz}$ standard transmitter and specimen was lost at the $20^{\circ}$ offset, and thus,

ultrasonic signals were not received. The test 2 repeatability analysis displayed that the $54 \mathrm{kHz}$ exponential transducer was the most repeatable (Table 19). The results of test 2 validated that a robotic UPV system can receive signals with single point transmitter contact conditions. 


\section{2-2 Robotic UPV System Suggested Ope rational Parameters}

The results of robotic UPV system testing formed the basis for the suggested operational parameters. To reiterate, approximately $60 \mathrm{~N}$ applied transducer force was suggested for system operation. When the wave path is at least $1 \mathrm{~m}$ long, test 1 results confirm that transducer pairs can be misaligned by at most $10 \mathrm{~cm}$ (4in.) without significantly affecting UPV magnitude $(<10 \%)$. In addition, test 1 confirmed that the robotic UPV system can operate on specimen up $6 \mathrm{~m}$ long. The test 2 results confirm that the transmitter angular offsets up to $20^{\circ}$, for the $54 \mathrm{kHz}$ exponential transducer, will slightly $(<15 \%)$ affect the UPV magnitude. The transducer type repeatability results from both tests display that the $54 \mathrm{kHz}$ exponential transducer was the most repeatable. Furthermore, a review of Table 18 displays that the results of the $54 \mathrm{kHz}$ exponential type have the least variance from baseline results. Thus, the $54 \mathrm{kHz}$ exponential transducer is the most optimal transducer for current operation of the robotic UPV system. Because $54 \mathrm{kHz}$ exponential UPV magnitudes were greater than the baseline testing, further data analysis suggests using only robotic UPV system testing for baseline results. However, it is plausible that the higher $54 \mathrm{kHz}$ exponential UPV magnitudes were attained because the robotic UPV system applied a higher pressure than possible with the baseline (human operator) system. The higher transducer pressure may cause greater wave transmittance, and therein faster signal travel times. Thus, as opposed to transducer force, investigation of transducer pressure may benefit robotic UPV operational standards.

Table 21: Robotic UPV Operational Standards

\begin{tabular}{|l|l|}
\hline \hline Parameter & Robotic UPV Standard \\
\hline \hline Transducer Type & $\begin{array}{l}\text { From test } 1 \text { and } 2 \text { results, the 54kHz exponential type is the most optimal } \\
\text { (all further standards developed for this trans ducer type and suggested } \\
\text { transducer force) }\end{array}$ \\
\hline Transducer Force & $60 \mathrm{~N}$ minimu $\mathrm{m}$ \\
\hline Lateral Offsets & $\begin{array}{l}\text { Will slightly affect the UPV magnitude }(<10 \%), \text { offsets below 4in. will } \\
\text { produce the most optimal results }\end{array}$ \\
\hline Angular Offsets & $\begin{array}{l}\text { Will slightly affect the UPV magnitude }(<15 \%), \text { offsets }<5^{\circ} \text { will produce } \\
\text { the most optimal results }\end{array}$ \\
\hline Specimen Lengths & $\begin{array}{l}\text { Increasing specimen length by 5m, will decrease UPV magnitude }(>10 \%) . \\
\text { When comparing length 5m or greater, investigation of a correction factor } \\
\text { is suggested }\end{array}$ \\
\hline Coupling gel use & $\begin{array}{l}\text { For further result comparison and extra -terrestrial environments, use is not } \\
\text { recommended }\end{array}$ \\
\hline Data Analysis & Further test results should be compared to solely robotic UPV system tests \\
\hline \hline
\end{tabular}




\subsection{General Conclusions}

Both systems have the ability to provide useful information about the specimen under test, and have contributed to the field of robotic non-destructive testing. Experiments with the IS-2 system provided that correlations between impact force-time history metrics and different strength materials can be acquired. In its current state, the IS-2 correlations (Figure 11 \& Figure 17) are most suitable for coarse UCS range approximation. Thus the IS-2 system is currently applicable to robotic precursor applications where concise precision of strength is not necessary (e.g. characterization for drilling or anchoring bit selection). The IS-2 system can be refined by the creation of an autonomous drive system (Appendix A-5 IS-2 Autonomous Drive Concept). Furthermore, IS-2 data analysis and estimation accuracy can be refined by the development of a custom generalized IS-2 regression neural network. The robotic UPV system contributed to future robotic UPV testing by providing operational standards (Table 21). In addition, robotic UPV test 1 results confirmed that UPV signals are retrievable at ARRM and robotic precursor

mission specimen lengths. Investigation of transducer pressure may aid robotic UPV operational standards. Because higher UPV magnitudes than the baseline testing value were recorded, it is suggested that further results use robotic UPV testing results as baseline results.

The experiments provided in this thesis have by no means fully developed the matured flight systems. For instance, neither robotic system has been tested in relative environments to the final application. However, they have provided the basis of understanding that will be built upon to develop RISES technology for space exploration objectives and beyond. 


\section{References}

[1] National Aeronautics and Space Administration, "What Is NASA's Asteroid Redirect Mission?," National Aeronautics and Space Administration, 30 July 2015. [Online]. Available:

https://www.nasa.gov/sites/default/files/files/NextSTEP_ARM_Reference.pdf. [Accessed 2015].

[2] National Aeronuatics and Space Administration, "Asteroid Redirect Mission Status," 8 April 2015. [Online]. Available:

http://www.nasa.gov/sites/default/files/files/20150408-NAC-Gates-ARM-v81_TAGGED.pdf. [Accessed 2015].

[3] W. Grandl and A. Bazso, "Near Earth Asteroids-Prospection, Orbit, Modicfication, Mining, and Habitation," in Asteroids, Berlin, Springer-Verlag, 2013, pp. 415-438.

[4] M. Elvis, "Prospecting Asteroid Resources," in Asteroids, Berlin, Springer-Verlag, 2013, pp. 81-130.

[5] D. Tholen, "Asteriod toxonomic classifications.," in Asteroids II, Tucson, University of Arizona Press, 1989, pp. 1139-1150.

[6] D. Britt, D. Yeomans, K. Housen and G. Consolmagno, "Asteroid Density, Porosity, and Structure," in Asteroids III, Tucson, The University of Arizona Press, 2002, pp. 485500.

[7] T. Dunn, T. S. J. McCoy and H. McSween Jr, "A Co-ordinated Mineralogical, Spectral and Compositional Study of Ordinary Chondrites: Implications for Asteroid Spectroscopic Classification.," Icarus, vol. 208, no. 2, pp. 789-797, 2010.

[8] ASTM, Standard Test Methods for Compressive Strength and Elastic Moduli of Intact Rock Core Specimens under Varying States of Stress and Temperatures, West Conshohoken: ASTM International, 2014.

[9] B. Thompson, J. Hurowitz, L. Baker, N. Bridges, A. Lennon, G. Paulsen and K. Zacny, "The effects of weathering on the strength and chemistry of Columbia River Basalts and their implications for Mars Exploration Rover Rock Abrasion Tool (RAT) results," Earth and Planetary Science Letters, vol. 400, pp. 130-144, 2014.

[10] E. Winkler, Stone: Properties, Durability in Man's Environment Second Edition, New York: Springer-Verlag, 1975.

[11] M. Smith, Stone: Building Stone, Rock Fill and Armorstone in Construction, London: The Geological Society, 1999.

[12] E. M. Winkler, Stone in Architecture, Properties, Durability, Berlin: Springer-Verlag, 1994.

[13] R. D. Lama and V. Vutukuri, Handbook on Mechanical Properties of Rocks-Techniques and Results Volume II, vol. II, Trans Tech Publications, 1978.

[14] A. Bodare, "Non Destructive Test Methods of Stone and Rock," Geo Texts, 1998, p. 32.

[15] A. e. a. Samouelian, "Electrical Resistivity Survey in Soil Science: A Review," in Soil and Tillage Research 83.2, 2005, pp. 173-193.

[16] The American Society for Nondestructive Testing, "Introduction to Nondestructive Testing," The American Society for Nondestructive Testing, 2015. [Online]. Available: https://www.asnt.org/MinorSiteSections/AboutASNT/Intro-to-NDT. 
[Accessed 2016].

[17] R. A. Freedman and H. D. Young, University Physics 12th Edition, San Francisco: Pearson Education Inc., 2008.

[18] S. Davydycheva, V. Druskin and T. Habasky, "An Efficient finite Difference Scheme for Electromagnetic Logging In 3D Anisotropic Inho mogeneous Media," Geophysics, vol. 68, no. 5, pp. 1525-1536, 2003.

[19] M. Toksoz, D. Johnston and A. Timur, "Attenuation of Seismic Waves in Dry and Saturated Rocks: I. Laboratory Measurements," in Attenuation of Seismic Waves in Dry and Saturated Rocks: I. Laboratory Measurements, 1979, pp. 681-690.

[20] U. Wiberg, "Material Characterizaion and Defect Detection in Concrete by Quantitative Ultrasonics," Royal Institute of Technology, Dept. of Structural Engineering, TRITA$B K N$, no. Bulliten 7, p. 152, 1993.

[21] H. J. Hardy, "Applications of Acoustic Emission Technigques to Rock and Rock Structures: A State-of-the -Art Review," Acoustic Emissions in Geotechnical Engineering Practice, pp. 4-92, 1981.

[22] E. O. Schmidt, "A Non-destructive Concrete Tester," Concrete, vol. 59, no. 8, pp. 34-35, 1951.

[23] H. Viles, A. Goudie, S. Grab and J. Lalley, "The use of the Schmidt Hammer and Equotip for rock hardness assessment in geomorphology and heritage science: a comparative analysis," Earth Surface Processes and Landforms, vol. 36, pp. 320-333, 2011.

[24] R. Altindag and A. Guney, "Effect of the specimen size on the determination of consistent Shore hard ness values," International Journal of Rock Mechanics and Mining Sciences, vol. 42, no. 1, pp. 153-160, 2004.

[25] J. Krautkramer and H. Krautkramer, Ultrasonic testing of materials, 4th fully revised edition, Berlin: Springer-Verlag, 1990.

[26] H. T. A, "Scleroscope". United States of America Patent US1446620 A, 27 February 1923.

[27] E. O. Schmidt, "Apparatus for testing the surface hard ness of construction materials". US Patent US2664743 A, 5 June 1954.

[28] Proceq, "Equotip 550 Leeb U," Proceq USA, Inc., 2016. [Online]. Available: http://www.proceq.com/nondestructivetestequipment/paperfilmsfoils/equotip-550leeb-u.html. [Accessed 2015].

[29] T. Holmgeirsdottir and P. Thomas, "Use of the D-762 Shore Hardness Scleroscope for Testing Small Rock Volumes," International Journal of Rock Mechanics and Mining Sciences, vol. 35, no. 1, pp. 85-92, 1988.

[30] A. Torok, "Surface strength and mineralogy of weathering crusts on limestone buildings in Budapest," Building and Environment, vol. 38, no. 9-10, pp. 1185-1192, 2003.

[31] P. L. Walter, "Selecting Accelerometers for Mechanical Shock Measurement," Sound and Vibration, pp. 14-18, December 2007.

[32] K. Karaman and A. Kesimal, "A comparative study of Schmidt hammer test methods for estimating the uniaxial compressive strength of rocks," Bulletin of Engineering Geology and the Environment, vol. 74, no. 2, pp. 507-520, 2015.

[33] A. Aydin and A. Basu, "The Schmidt Hammer in Rock Material Characterization," Engineering Geology, vol. 81, no. 1, pp. 1-14, 2005. 
[34] ASTM, "Standard Test Method for determinations of Rock Harness by Rebound Hammer Method," ASTM Stand, vol. 04, no. 09, 2001.

[35] B. A. K. Minaeian, "Estimation of uniaxial compressive strength based on P-wave and Schmidt Hammer Rebound using a Statistical Method," Arab Journal of Geoscience, vol. 6, no. 6, pp. 1925-1931, 2013.

[36] A. Aydin, "The ISRM Suggested Methods for Rock Characterization," Testing and Monitoring, vol. 293, no. 53, p. 218, 2015.

[37] ASTM, "Standard Test Method for Laboratory Determination of Pulse Velocities and Ultrasonic Elastic Constants of Rock," ASTM Stand., vol. 04, no. 08, 2008.

[38] A. Aydin, "Upgraded ISRM suggested method for determining sound velocity by ultrasonic pulse transmission technique," Rock Mechanics and Rock Engineering, vol. 47, no. 10, pp. 244-259, 2014.

[39] K. A. Savage, Nondestructive Methods to Characterize Rock Mechanical Properties at Low-Temperature: Applications for Asteroid Capture Technologies, Morgantown: West Virginia University, 2016.

[40] ANSYS, Inc., "Explicit Dynamics Solutions," 2011. [Online]. Available: http://resource. ansys.com/staticassets/ANSYS/staticassets/resourcelibrary/brochure/ ansys-explicit-dynamic s-brochure-14.0.pdf. [Accessed 2015].

[41] R. Singh, V. Vishal, T. N. Singh and P. Ranjith, "A comparative study of generalized regression neural network approach and adaptive neuro-fuzzy inference systems for prediction of unconficed compressive strength of rocks, "Neural Computation \& Application, vol. 23, pp. 499-506, 2013.

[42] Engineering Statistics Handbook, "F-Test for Equality of Two Variances, " Colleges of NanoScale Science and Engineering Suny Polytechnic Institute, [Online]. Available: www.itl.nist.gov/div898/handbook/eda/section3/eda359.htm. [Accessed Ma y 2016]. 


\section{Appendix}

\section{A-1 IS-1 Technical Details}

\section{JR3 Specifications}

\begin{tabular}{|c|c|}
\hline PARAMETER & VALUE \\
\hline $\begin{array}{l}\text { NOMINAL ACCURACY (\% MEASURING } \\
\text { RANGE) }\end{array}$ & $+/-0.25$ \\
\hline $\begin{array}{l}\mathrm{F}_{Z} \text { STANDARD MEASUREMENT RANGE } \\
(\mathrm{N})\end{array}$ & $+/-2000$ \\
\hline $\mathrm{F}_{\mathrm{Z}}$ STANDARD RESOLUTION (N) & 0.25 \\
\hline $\mathrm{F}_{\mathrm{Z}} \mathrm{STIFFNESS}(\mathrm{N} / \mathrm{M})$ & 470E6 \\
\hline SAMPLING RATE $(\mathrm{kHz})$ & 8 \\
\hline
\end{tabular}

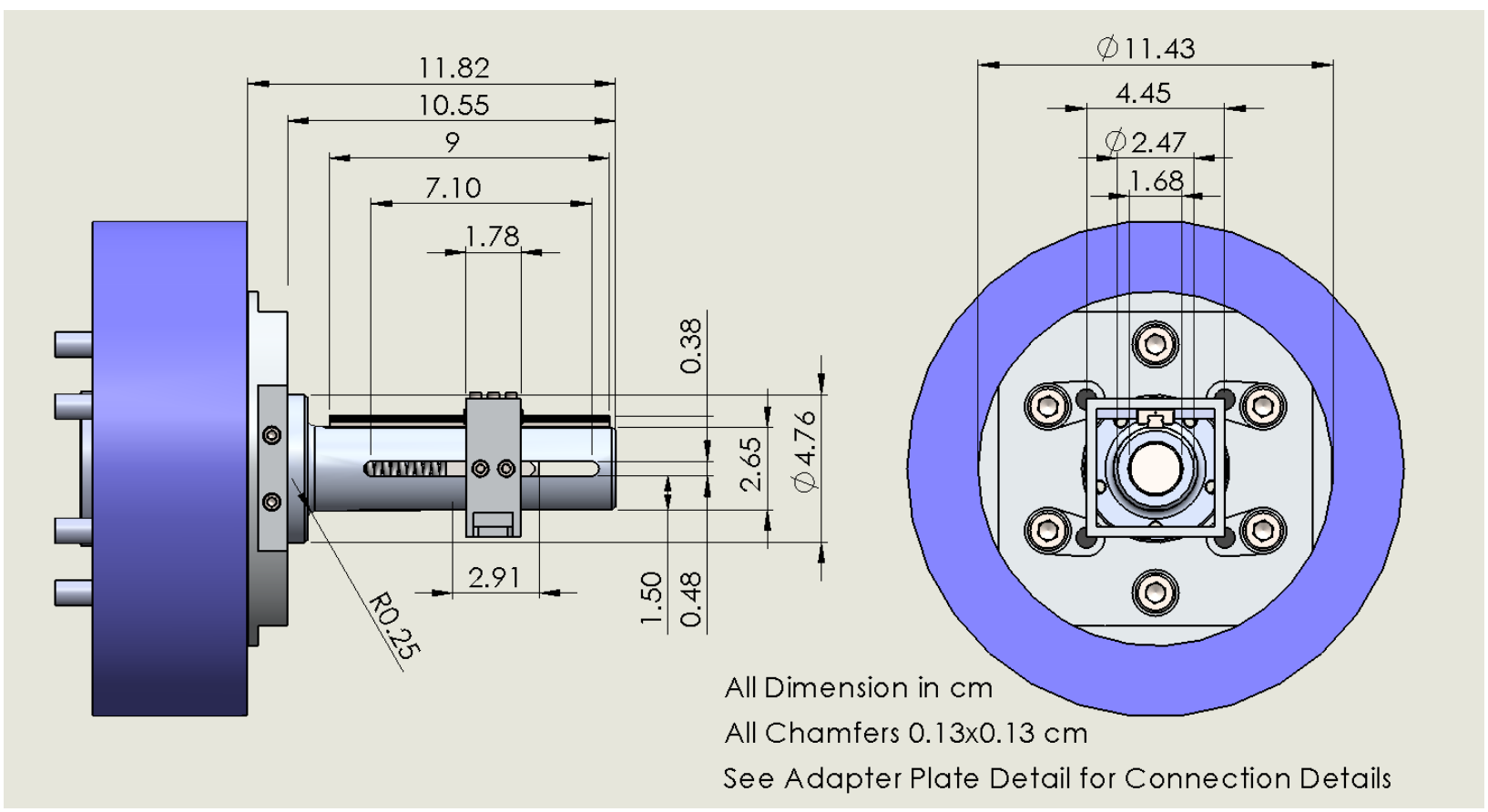




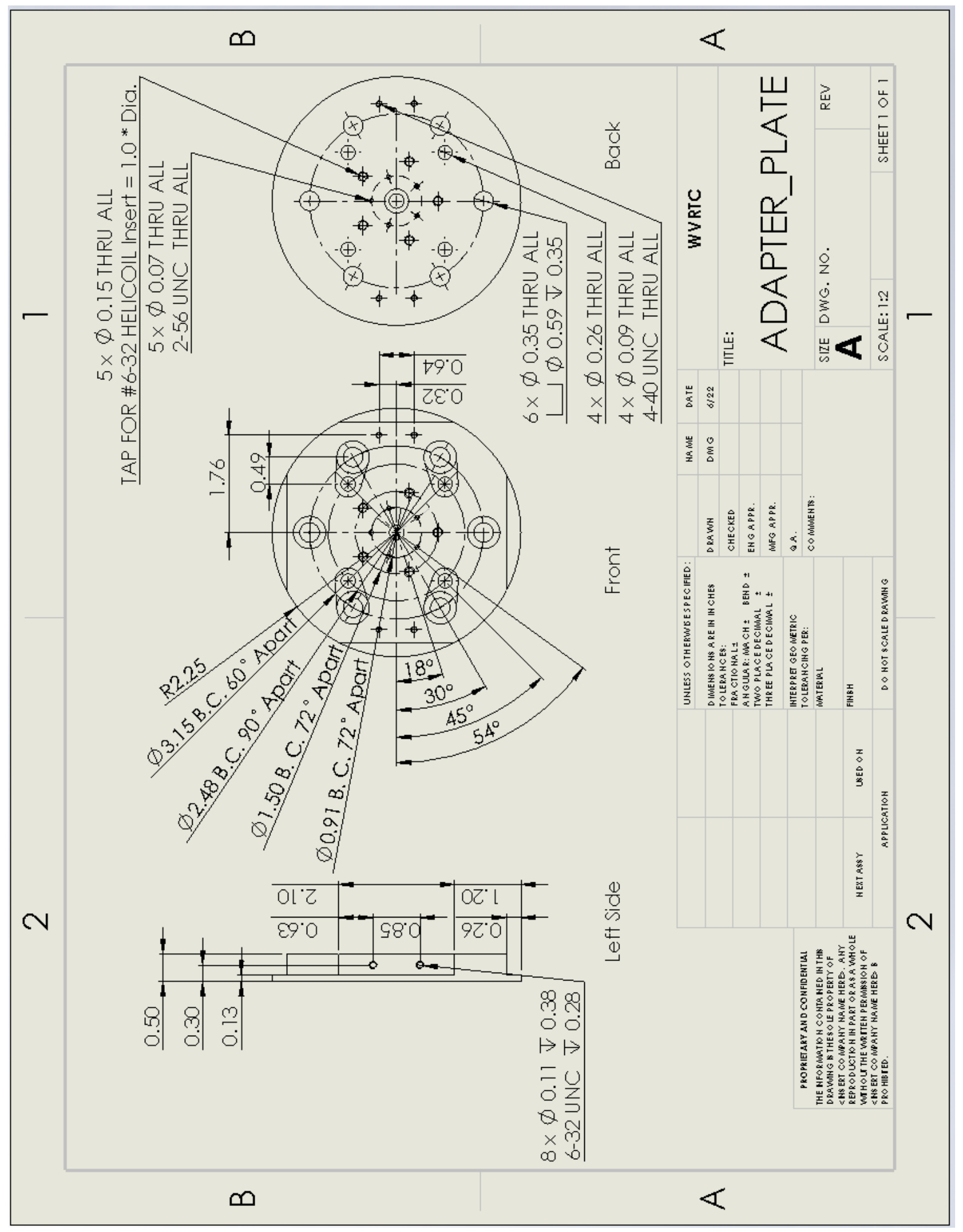




\section{A-2 Further IS-1 Results}

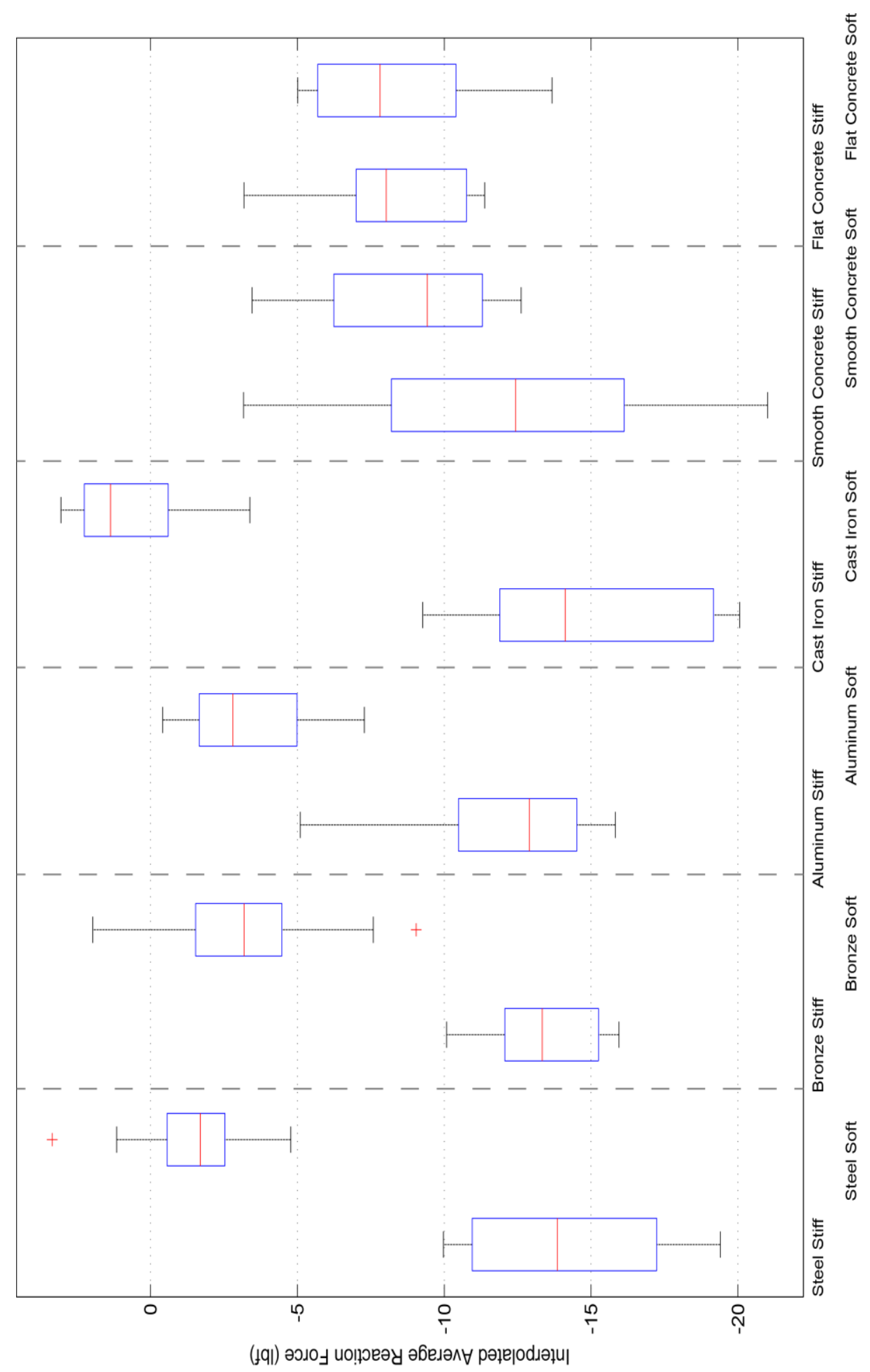

IS- 1 Test 2 Results 


\section{A-3 IS-2 Technical Details}
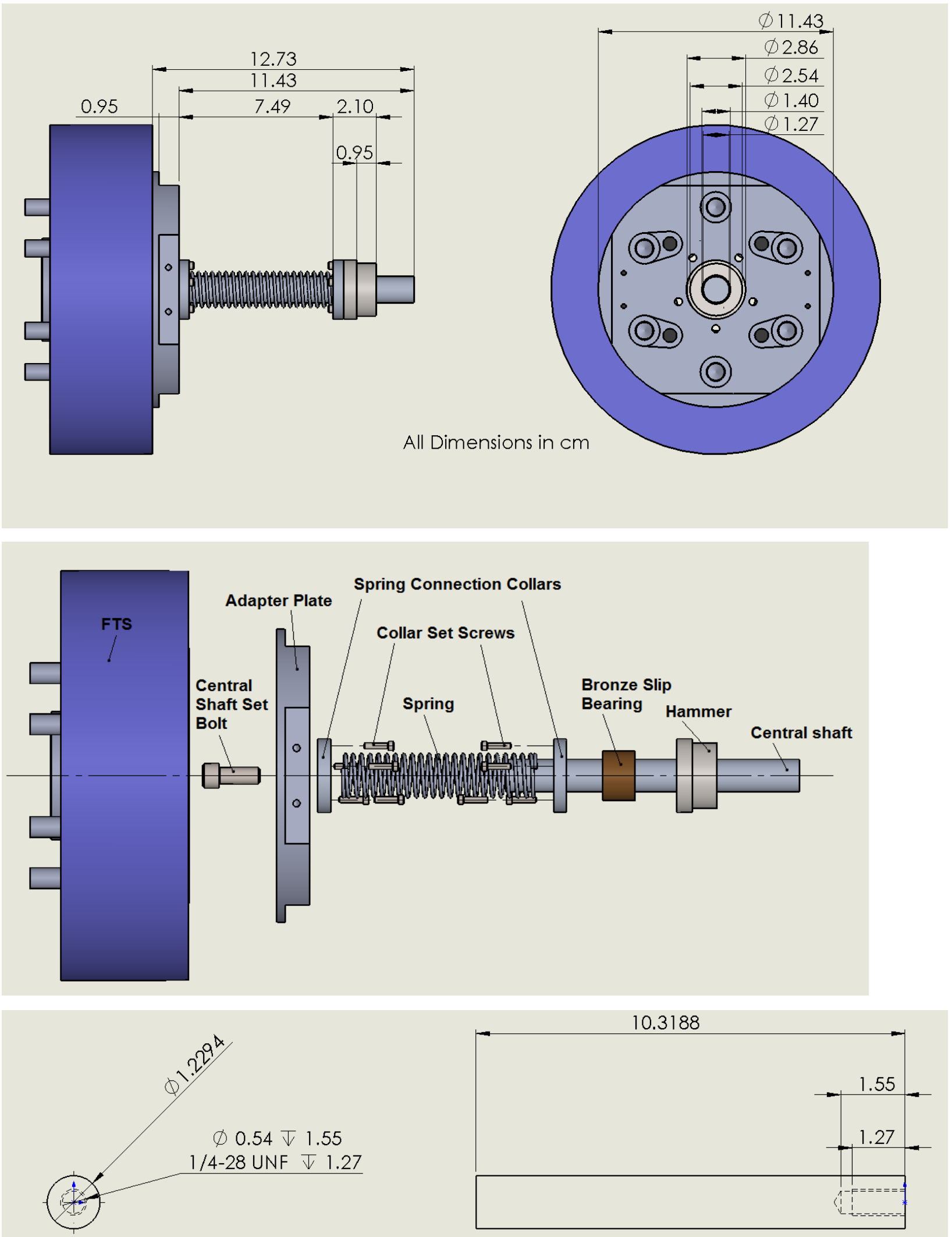


\section{A-4 Details of IS-2 Results}

\section{Proof of Concept Test Campaign}

\begin{tabular}{|c|c|c|c|c|}
\hline \multirow[t]{2}{*}{ Specimen } & \multicolumn{4}{|c|}{ "Metric Ranges (min, max) } \\
\hline & $\begin{array}{l}\text { Time Between } \\
\text { Impacts, ms }\end{array}$ & $\begin{array}{c}\text { Post Impact } \\
\text { Vibration } \\
\text { Magnitude, N }\end{array}$ & $\begin{array}{c}\text { Max Impact Force, } \\
\mathrm{N}\end{array}$ & Min Impact Force, $\mathrm{N}$ \\
\hline Limestone & $\mathrm{n} / \mathrm{a}$ & $39.90,86.10$ & $121.49,262.40$ & $-183.67,-395.03$ \\
\hline Pine & $\mathrm{n} / \mathrm{a}$ & $23.13,33.60$ & $175.79,298.24$ & $-81.18,-227.79$ \\
\hline Steel & $\mathrm{n} / \mathrm{a}$ & $28.81,42.03$ & $87.15,135.07$ & $-78.87,-163.98$ \\
\hline
\end{tabular}

\section{Consistency Test Campaign}

\begin{tabular}{|c|c|c|c|c|}
\hline \multirow[t]{2}{*}{ Specimen } & \multicolumn{4}{|c|}{ "Metric Ranges (min, max) } \\
\hline & $\begin{array}{l}\text { Time Bet ween } \\
\text { Impacts, ms }\end{array}$ & $\begin{array}{c}\text { Post Impact } \\
\text { Vibration } \\
\text { Magnitude, N }\end{array}$ & $\begin{array}{c}\text { Max Impact Force, } \\
\mathrm{N}\end{array}$ & Min Impact Force, $\mathrm{N}$ \\
\hline Horizontal 1 & $\mathrm{n} / \mathrm{a}$ & $15.64,18.86$ & $84.97,131.00$ & $-62.17,-93.12$ \\
\hline Horizontal 2 & $\mathrm{n} / \mathrm{a}$ & $14.84,19.21$ & $79.95,123.67$ & $-64.75,-95.16$ \\
\hline Horizontal 3 & $\mathrm{n} / \mathrm{a}$ & $10.84,17.62$ & $58.24,87.83$ & $-58.78,-106.16$ \\
\hline Vertical 1 & $\mathrm{n} / \mathrm{a}$ & $15.89,19.72$ & $52.56,99.82$ & $-60.30,-80.12$ \\
\hline Vertical 2 & $\mathrm{n} / \mathrm{a}$ & $14.16,16.76$ & $48.62,63.83$ & $-51.88,-84.06$ \\
\hline Vertical 3 & $\mathrm{n} / \mathrm{a}$ & $8.98,12.23$ & $45.75,72.63$ & $-51.86,-89.19$ \\
\hline
\end{tabular}

\section{Contact Geometry Test Campaign}

\begin{tabular}{|c|c|c|c|c|}
\hline \hline Specimen & \multicolumn{4}{|c|}{ Metric Ranges (min, max) } \\
\hline \hline & Time Between & Post Impact & & Min Impact Force, \\
& Impacts, ms & Vibration & Maxnitude, $N$ & $\mathrm{~N}$ \\
& & Magnact Force, N & \\
\hline \hline Aluminum Flat & $\sim 45$ & $44.51,82.41$ & $160.86,312.90$ & $-164.39,-632.59$ \\
\hline Aluminum Round & $\sim 45$ & $38.10,80.22$ & $123.94,226.97$ & $-474.71,-158.28$ \\
\hline \hline
\end{tabular}




\section{Analogous Materials Test Campaign}

\begin{tabular}{|c|c|c|c|c|}
\hline \multirow[t]{2}{*}{ Specimen } & \multicolumn{4}{|c|}{ "Metric Ranges (min, max) } \\
\hline & $\begin{array}{l}\text { Time Between } \\
\text { Impacts, ms }\end{array}$ & $\begin{array}{c}\text { Post Impact } \\
\text { Vibration } \\
\text { Magnitude, N }\end{array}$ & $\begin{array}{c}\text { Max Impact Force, } \\
\mathrm{N}\end{array}$ & Min Impact Force, $\mathrm{N}$ \\
\hline 1MPa Concrete & n/a & $36.80,90.44$ & $69.26,105.93$ & $-83.79,-118.42$ \\
\hline 4MPa Concrete & $\mathrm{n} / \mathrm{a}$ & $87.59,107.69$ & $94.38,123.72$ & $-86.24,-157.94$ \\
\hline $5 \mathrm{MPa}$ Concrete & $\mathrm{n} / \mathrm{a}$ & $85.83,167.58$ & $74.42,108.51$ & $-125.34,-187.14$ \\
\hline Chalk 1 & $\mathrm{n} / \mathrm{a}$ & $53.10,118.01$ & $63.69,159.30$ & $-71,43,-160.11$ \\
\hline Chalk 2 & $\mathrm{n} / \mathrm{a}$ & $52.69,141.37$ & $37.89,113.94$ & $-175.19,-333.67$ \\
\hline Shale 1 & $\mathrm{n} / \mathrm{a}$ & $67.22,141.51$ & $90.72,151.69$ & $-244.72,-504.51$ \\
\hline Shale 2 & $\mathrm{n} / \mathrm{a}$ & $74.56,144.49$ & $99.68,187.68$ & $-316.69,-517.00$ \\
\hline
\end{tabular}

\section{Proof of Concept Repeated Impact Validation}

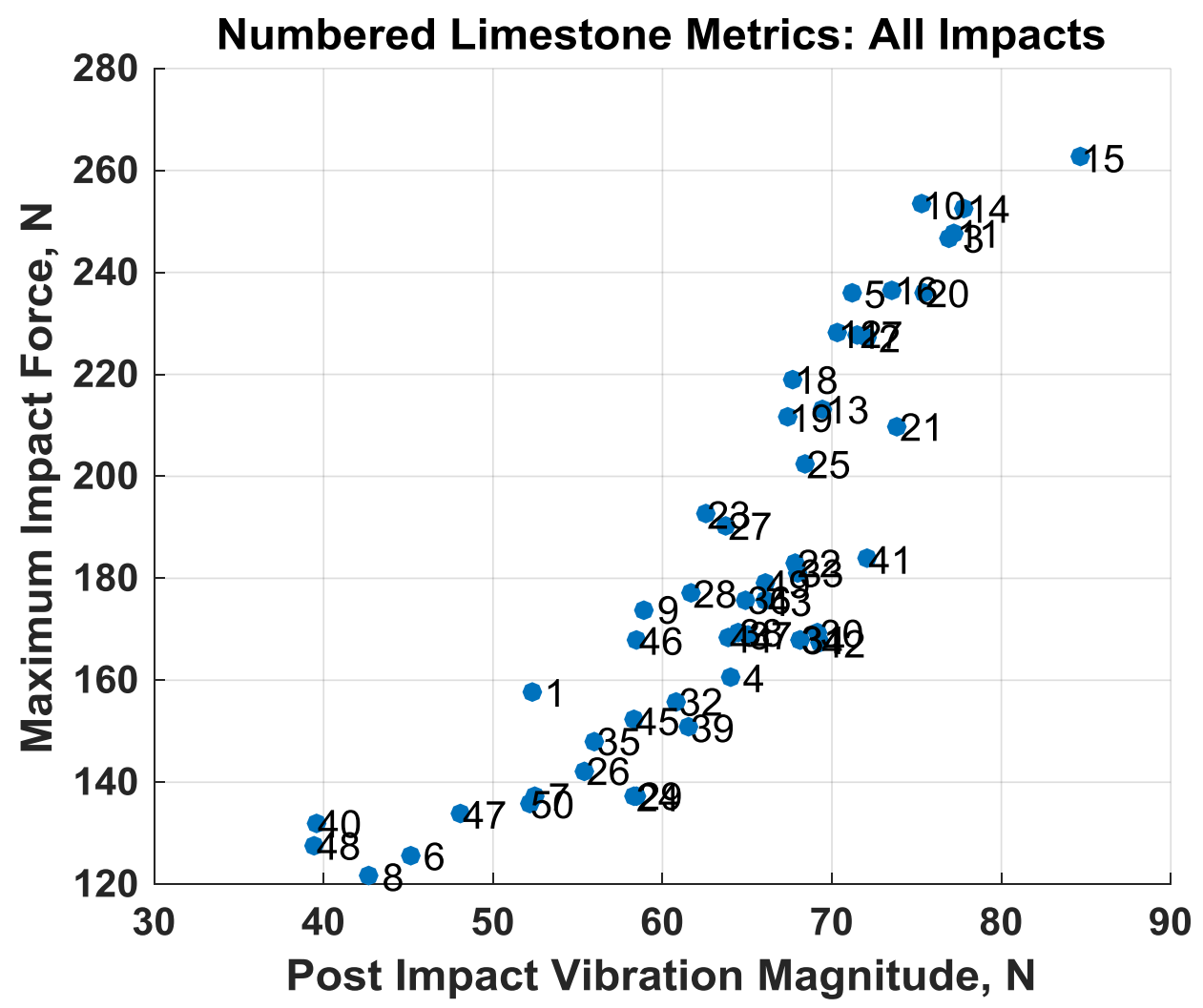




\section{Contact Geometry Comparison Validation}

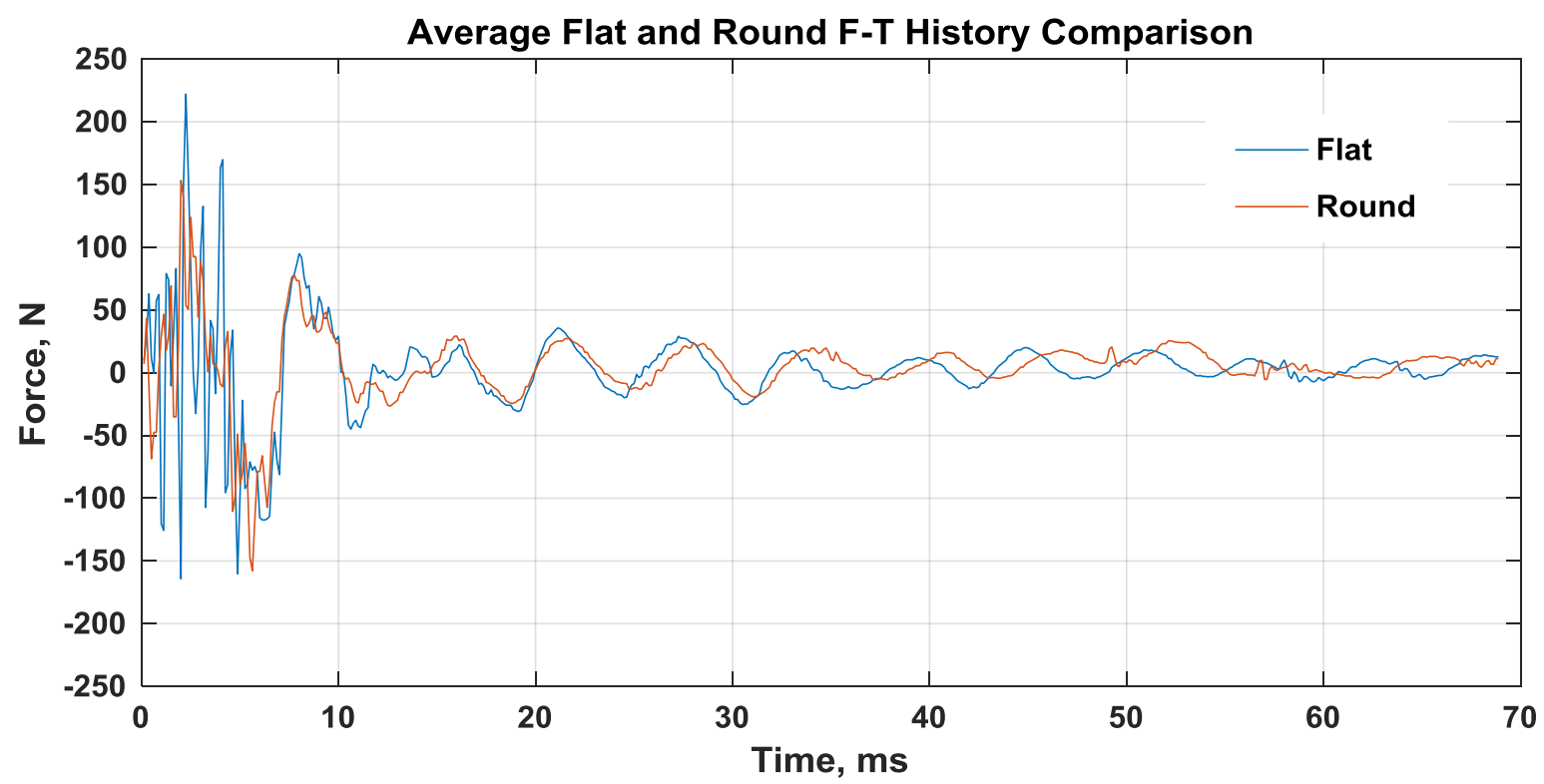


A-5 IS-2 Autonomous Drive Concept

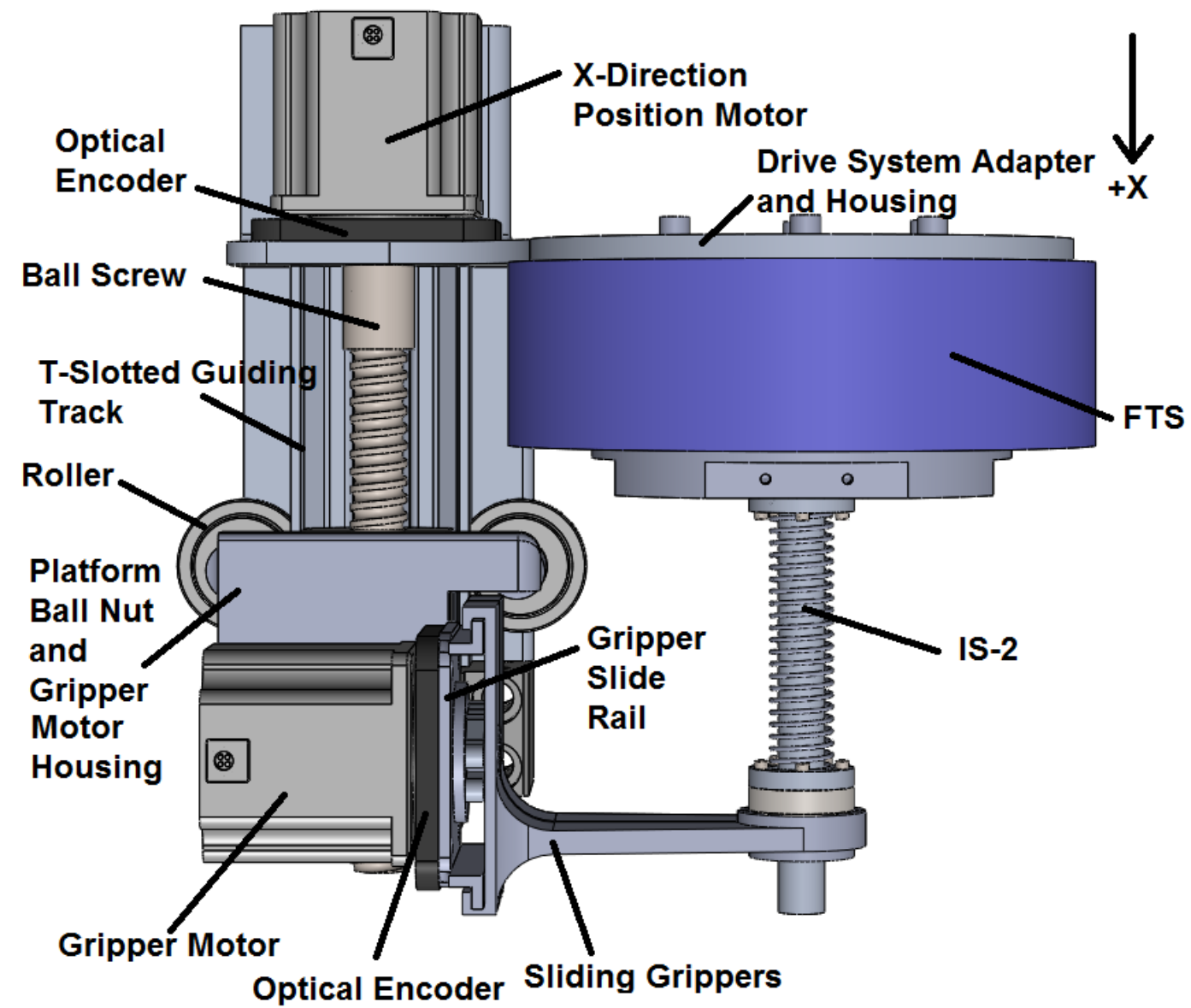

IS-2 Autonomous Drive: Top View

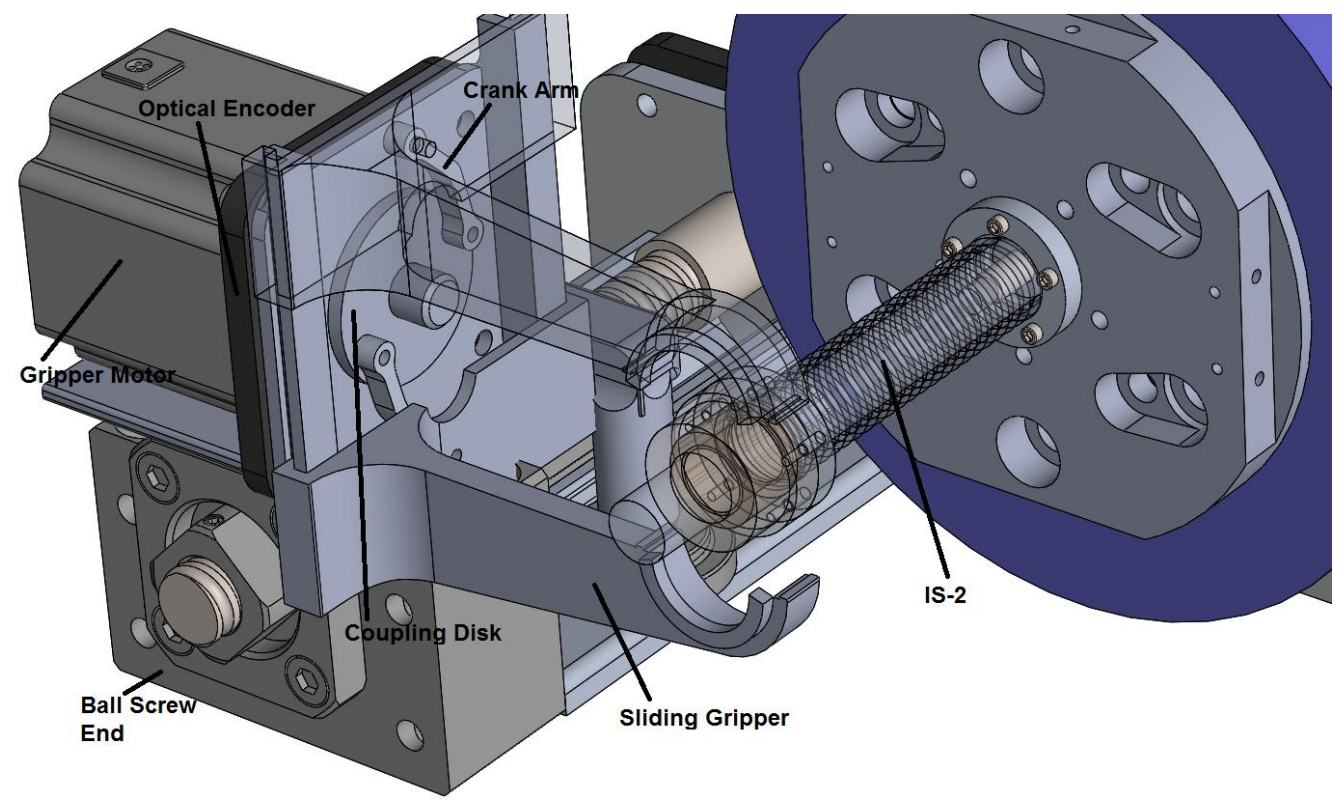

IS-2 Autonomous Drive: Gripper Detail 
A-6 Robotic UPV Transducer Housing Detail

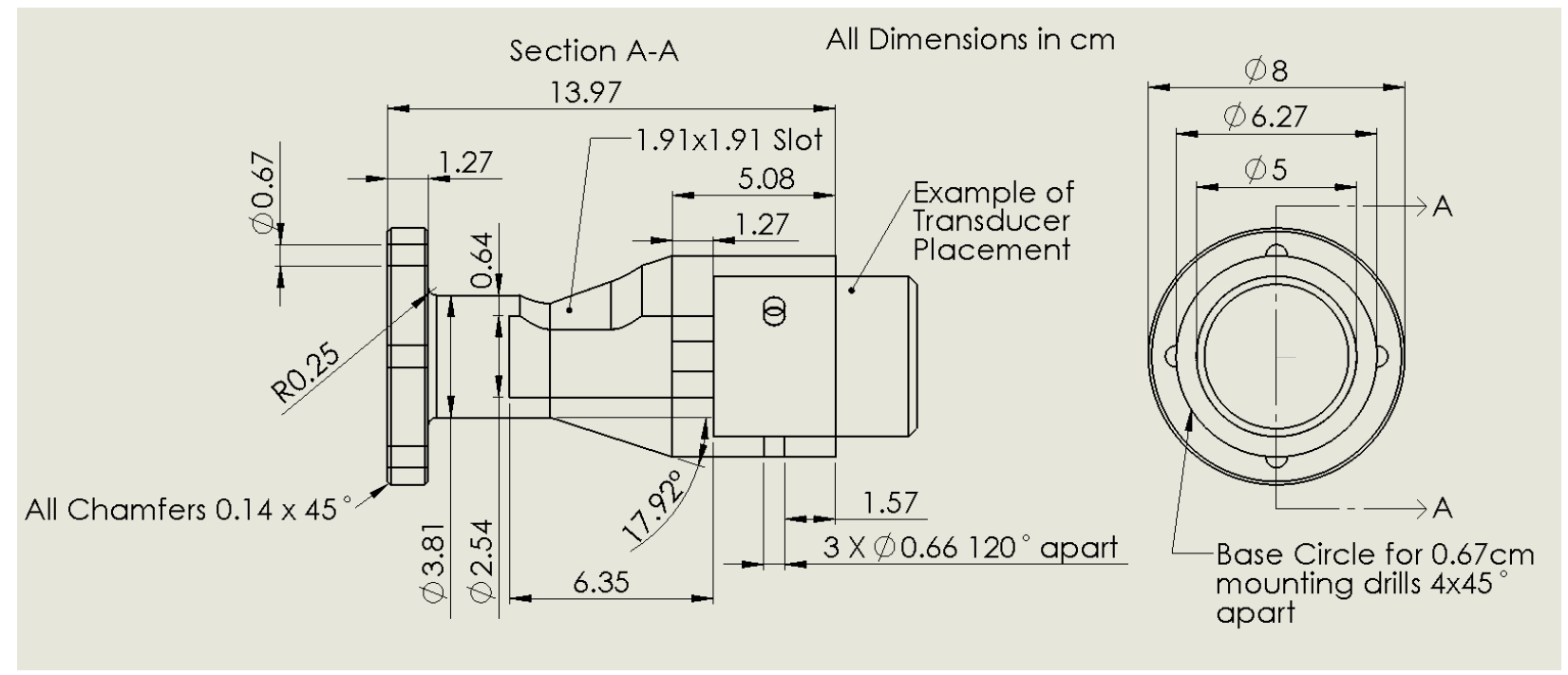

\section{A-7 Details of Robotic UPV Results}

Test 1

\begin{tabular}{|l|l|l|l|}
\hline \hline Parameter & Level 1 & Level 2 & Level 3 \\
\hline \hline & \multicolumn{3}{|c|}{ UPV (km/s) (min, max) } \\
\hline \hline Lateral Offset & $3.71,3.83$ & $3.76,3.88$ & $3.64,3.77$ \\
\hline Applied Force & $3.37,3.50$ & $3.77,3.89$ & $3.97,4.09$ \\
\hline Trans. Type & $3.37,3.50$ & $3.57,3.70$ & $4.18,4.30$ \\
\hline Beam Length & $4.12,4.24$ & $3.69,3.81$ & $3.30,3.43$ \\
\hline \hline
\end{tabular}

Test 2

\begin{tabular}{|l|l|l|l|l|}
\hline \hline Parameter & Level 1 & Level 2 & Level 3 & Level 4 \\
\hline \hline & \multicolumn{4}{|c|}{ UPV (km/s) (min, max) } \\
\hline \hline Beam Length & $2.60,4.56$ & $2.08,4.16$ & $\mathrm{n} / \mathrm{a}$ & $\mathrm{n} / \mathrm{a}$ \\
\hline Trans. Type & $2.60,3.53$ & $2.08,4.54$ & $3.63,4.56$ & $\mathrm{n} / \mathrm{a}$ \\
\hline Angular Offset & $2.39,4.56$ & $2.08,4.55$ & $2.09,4.51$ & $2.60,4.46$ \\
\hline \hline
\end{tabular}




\section{A-8 Robotic UPV Test 1 ANOVA F-Test Statistics}

For further information about the Statistical F-Test see [42]. The P-value is analogous to a parameter's significance level. P-values below 0.05 imply a parameter is above $95 \%$ significance. Thus the lesser the P-value, the greater the parameter's significance on the UPV magnitude set's mean.

\begin{tabular}{|c|c|c|}
\hline \hline Parameter & F-value & P-value \\
\hline \hline Lateral Offset & 2.22 & 0.1113 \\
\hline Trans. Applied Force & 66.28 & $9.0728 \mathrm{e}-24$ \\
\hline Trans. Type & 132.43 & $8.2941 \mathrm{e}-40$ \\
\hline \hline
\end{tabular}




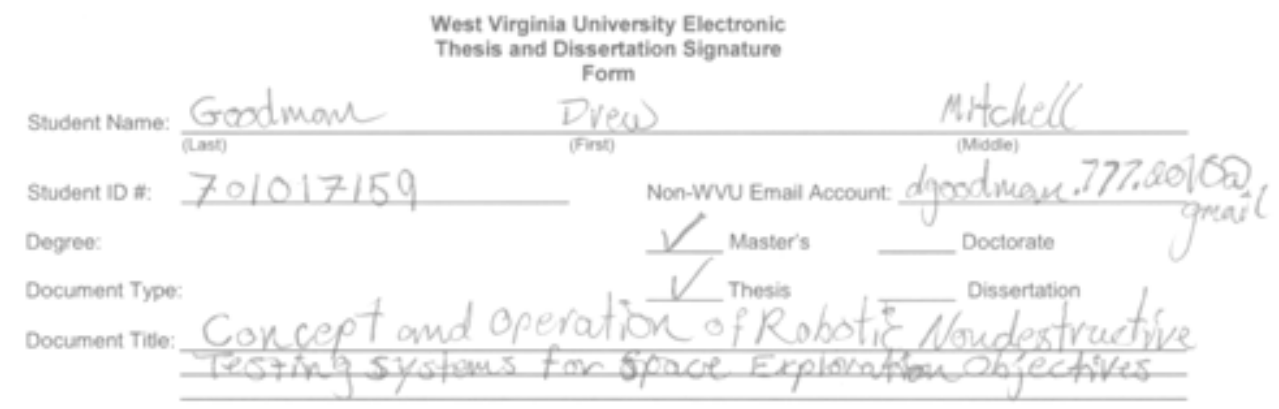

Student Agreement:

I hereby certify that, if appropriate, I have obtained and attached hereto a written permission statement from the owners of each third party copyrighted matter to be included in my thesis, dissertation, project report. or other research material. allowing distribution as specified upon depos?

I hereby grant to West Virginia University and its agents the non-exclusive license to archive and make accessible, under the conditions selected upon deposit, my above mentioned document in whole or in part in all forms of media, now or hereafler known. I retain ownership rights as specified in the WVU copyright policy to the copyright of the abovementioned document. I also retain the right to use in future works (such as articles or books) all or part of this abovementioned document.

Review and Acceptance:

The above mentioned document has been reviewed and accepted by the student's advisory committee. The undersigned agree to abide by the statements above, and agree that this Signature Form updates any and all previous Signature Forms submitted heretgfore.

Signed:

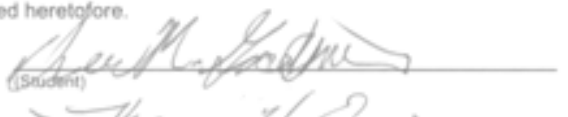

Commiltee.
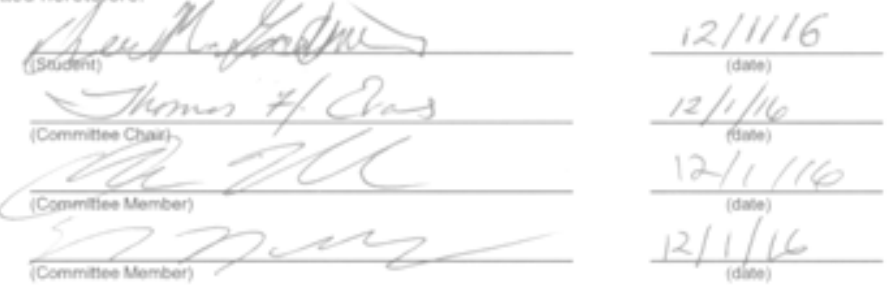

, 1

(Commities Member)

dake)

(Commene Member)

(dime)

Comminee Member)

(dase) 